\title{
Donor-acceptor rotaxanes with tetracationic cyclophane ring
}

\author{
Malgorzata Deska, Anna Nowik-Zajac, and Wanda Sliwa* \\ Jan Dlugosz University, Institute of Chemistry, Environmental Protection and Biotechnology, \\ 42-200 Czestochowa, Armii Krajowej 13/15 Street, Poland \\ E-mail: w.sliwa@ajd.czest.pl
}

\begin{abstract}
In the first part of the review the selected examples of title rotaxanes are shown, among them those containing thiophene and acridane units, as well as those of the dendrimeric structure. In the second part the rotaxanes with electrostatic or steric barriers, incorporated for increase of lifetime of their metastable state, are presented. The third part of the review deals with rotaxanes investigated in the aspect of their secondary structure, and in the fourth part rotaxanes containing a modified tetracationic cyclophane ring are described.
\end{abstract}

Keywords: Barriers, dumbbells, ground states, metastable states, threads

\section{Table of Contents}

1. Introduction

2. Selected Examples of Rotaxanes

2.1. Rotaxanes containing thiophene units in the thread

2.2. Rotaxanes containing acridane units in the thread

2.3. Other rotaxanes

2.4. Dendrimeric rotaxanes

3. Rotaxanes with a Barrier Increasing the Lifetime of their Metastable State

4. The Secondary Structures of Rotaxanes

5. Rotaxanes Containing a Modified Tetracationic Cyclophane Ring

6. Conclusions

7. Acknowledgements

References 


\section{Introduction}

Rotaxanes $^{1,2}$ are an interesting area of supramolecular systems, they belong to the class of mechanically interlocked molecules (MIMs) ${ }^{3,4}$ together with catenanes ${ }^{5,6}$ and daisy chains, ${ }^{7}$ and are promising for the design of molecular machines and devices, ${ }^{8,9}$ as well as of new materials with special properties. ${ }^{10}$ In view of the presence of pyridinium quaternary groups in their structure, rotaxanes may be divided into those incorporating pyridinium units in the thread ${ }^{11,12}$ and those with a tetracationic cyclophane ring. ${ }^{13,14}$

The title rotaxanes containing a tetracationic cyclophane ring are a large, rapidly developing class of the rotaxane family, and are important species useful in many fields such as construction of molecular switches and machines. One should point out the enormous contribution of the J.Fraser Stoddart School to this fascinating area of supramolecular chemistry. ${ }^{15,16}$

Two kinds of rotaxanes containing tetracationic cyclophane rings exist, namely the donoracceptor rotaxanes described in this paper, and a new kind, i.e. radical-radical rotaxanes ${ }^{13,14}$ which are not discussed here.

In this review, firstly selected examples of title rotaxanes are shown. Due to the possible use of rotaxanes in nonvolatile molecular memories, a long lifetime of their metastable state is required, therefore incorporation of electrostatic or steric barriers into rotaxanes is necessary. It is known also that the investigations concerning secondary structure of rotaxanes are important for a better understanding of secondary structure of biopolymers such as proteins or nucleic acids. Both these themes are included in the review. Since the number of reports concerning the title rotaxanes is growing rapidly, only selected works are discussed.

The present paper is a continuation of our former reviews on rotaxanes with threads containing pyridinium ${ }^{17}$ and viologen units ${ }^{18}$ as well as of our works dealing with interlocked structures of quaternary azaaromatics. ${ }^{19,20}$

\section{Selected Examples of Rotaxanes}

\subsection{Rotaxanes containing thiophene units in the thread}

Oligo- and poly-thiophene derivatives are widely used in design of optoelectronic devices due to possibility of their chemical modifications. So, three thiophene donor-acceptor [2]rotaxanes 1a-c, containing in the thread the thiophene, bithiophene and terthiophene units, respectively, and having the tetracationic cyclophane $\mathbf{W}^{4+}$ (wheel) as a ring, were synthesized. ${ }^{21}$

When acetonitrile solutions of threads $\mathbf{2 a - c}$ were treated with $\mathbf{W}^{4+} \cdot 4 \mathrm{PF}_{6}$ (a white powder), the color of solution changed as a result of CT (charge-transfer) interaction in formed pseudorotaxanes between the electron-rich thiophene units and the electron-deficient $\mathbf{W}^{4+}$. The reaction of TIPS triflate capping hydroxyl groups of pseudorotaxanes affords rotaxanes 1a-c as yellow, red and purple solids, respectively (TIPS denotes triisopropylsilyl). The above investigations are of interest for the design of interlocked systems. 
In a continuation of this study, two [2] rotaxanes 3a, b have been obtained. ${ }^{22}$ In both rotaxanes strong quenching of the terthiophene fluorescence occurs as a result of the interaction between the $\pi$-electron rich terthiophene and the $\pi$-electron-deficient bipyridinium units.

It was found that the thread of both rotaxanes may be electrochemically polymerized; the rotaxane 3a, however, is not polymerizable. This behavior is due to the presence of the ring $\mathbf{W}$ which suppresses the electrochemical polymerization of the terthiophene unit, since the electrostatic repulsive force and the steric effect of $\mathbf{W}$ hinder the dimerization of the terthiophene radical cations.

Polyrotaxanes are often built from flexible molecular backbones, and this is disadvantageous for the construction of molecular machines, since the mechanical motion is dissipated by conformational changes of these flexible threads. Therefore oligothiophenes may be considered as very suitable components for the design of molecular machines due to their rigidity and polymerizability.

In this respect the rotaxane $\mathbf{4}$ was electrochemically polymerized using tetrabutylammonium perchlorate (TBA. $\mathrm{ClO}_{4}$ ) as the supporting electrolyte. ${ }^{23}$ It should be pointed out that the obtained polymer 5 consists of well-defined repeating units and is promising for construction of molecular machines.

Due to the presence of electrochemically active, long and multidentate binding sites in polythiophene, the preparation of polymer $\mathbf{5}$ is of interest for the design of an electrochemically controllable polyrotaxane. Polymer 5 may be considered as a new type of insulated molecular wire with a donor-acceptor interaction between the conducting polymer and the macrocycle $\mathbf{W}$. (Scheme 1). 

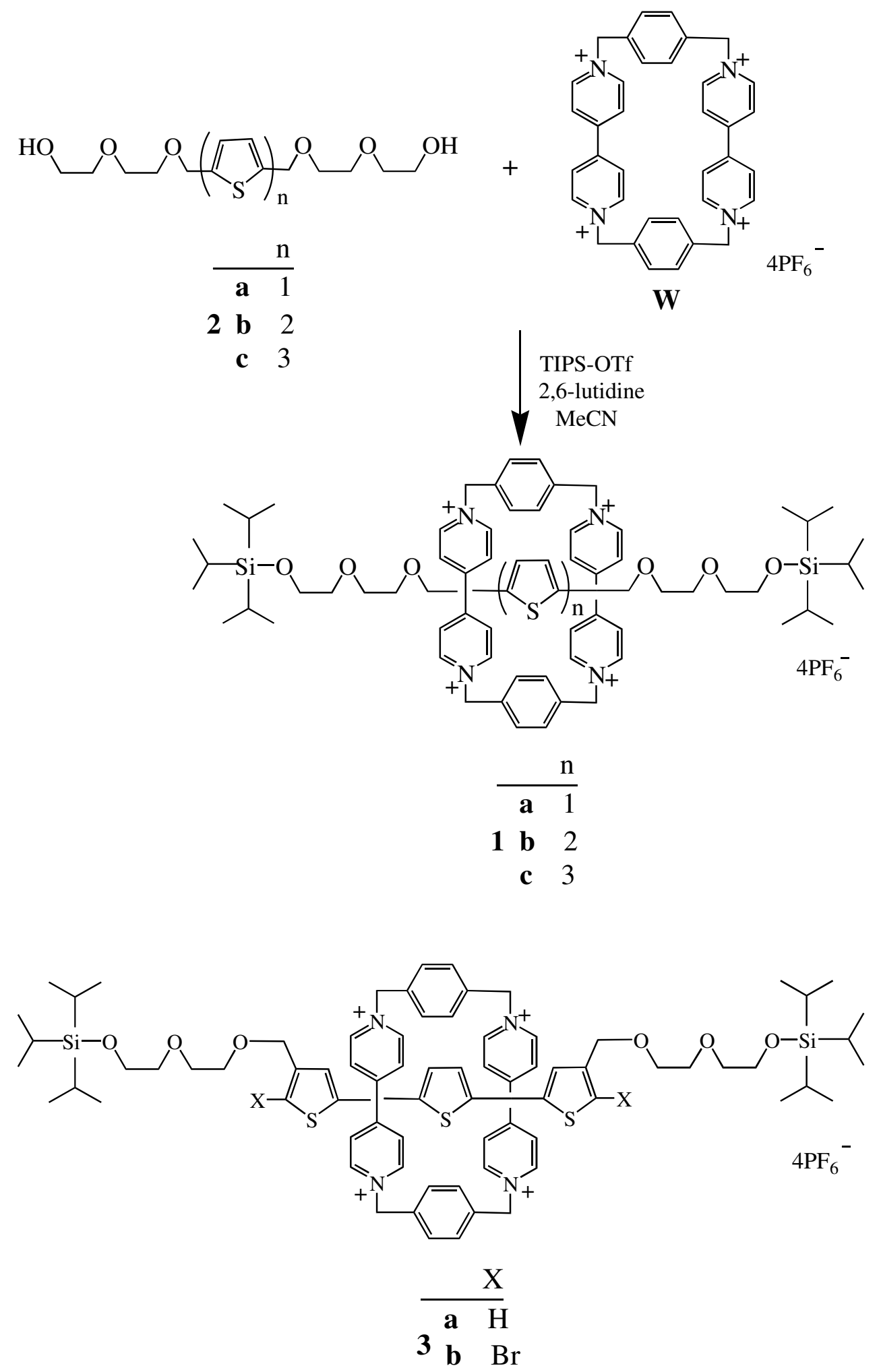


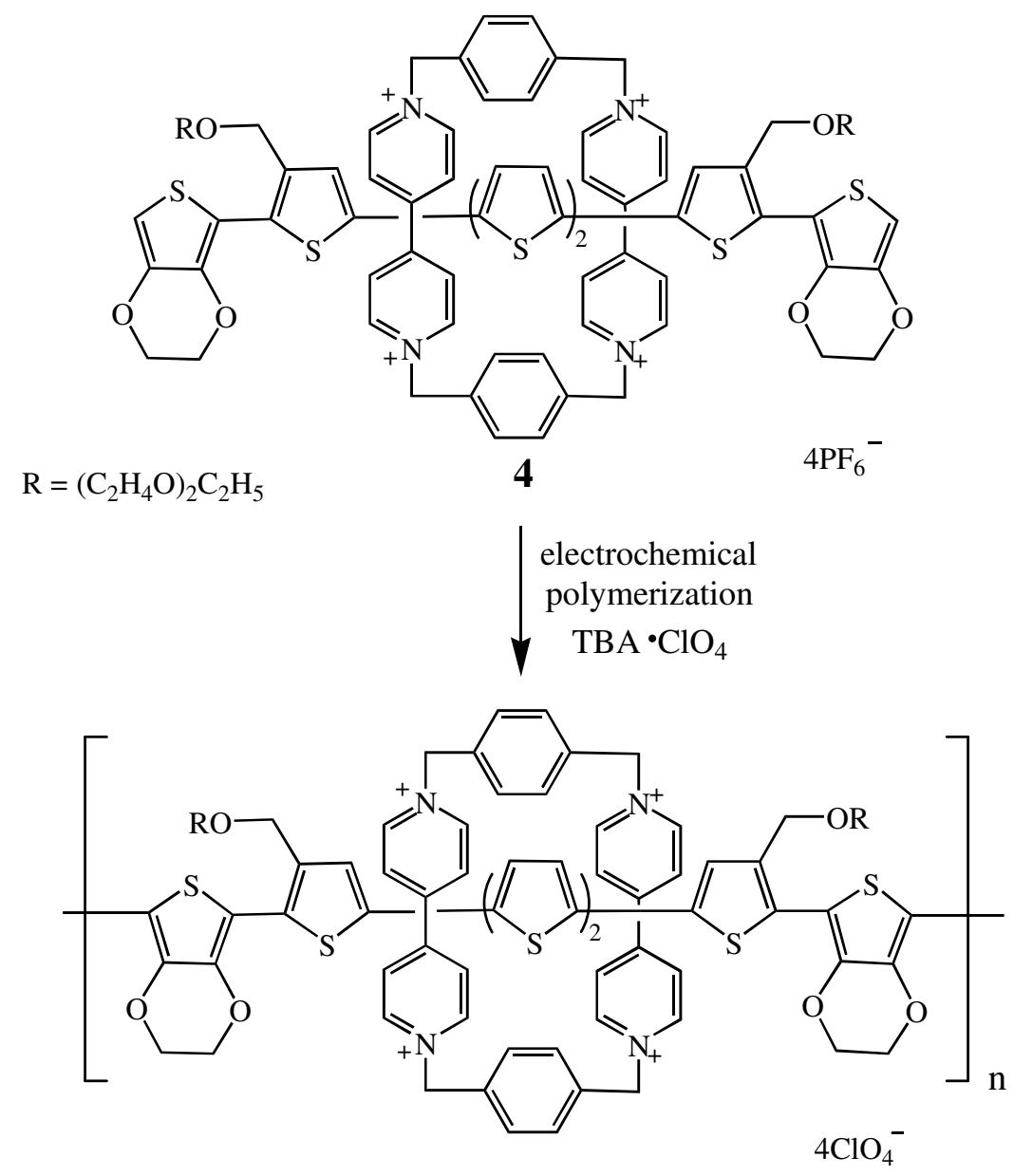

5

\section{Scheme 1}

In view of the properties of thiophene-based rotaxanes containing the ring $\mathbf{W}$, which are promising for the preparation of electromechanical systems, ${ }^{24}$ rotaxanes 6 and 7 , bearing an electrochemically reactive thiophene group at one end, have been investigated. ${ }^{25}$

For the synthesis of rotaxane $\mathbf{6}$, first the 3-substituted thiophene $\mathbf{8}$ was submitted to lithiation with $n$-BuLi, followed by the oxidative coupling with $\mathrm{CuCl}_{2}$ affording bithiophene 9 which upon stannylation gave monostannylated bithiophene 10. The palladium catalyzed Stille coupling of 10 with the half-dumbbell 11 yielded dumbbell 13 which upon clipping with 12, followed by treatment with $p$-dibromoxylene afforded rotaxane $\mathbf{6}$ as a red solid.

For the synthesis of rotaxane 7, similarly to the above, EDOT (i.e. 3,4-ethylenedioxythiophene) was converted into BEDOT (i.e. bis(3,4-ethylenedioxy)thiophene) which upon stannylation gave the monostannylated compound 14. The palladium-catalyzed Stille coupling of 14 with 11 afforded dumbbell 15 which by clipping with 12, and subsequent treatment with $p$ (dibromomethyl)xylene, yielded rotaxane $\mathbf{7}$ as a green solid. The colors of the rotaxanes $\mathbf{6}$ and $\mathbf{7}$ result from their donor-acceptor CT interactions. (Scheme 2). 


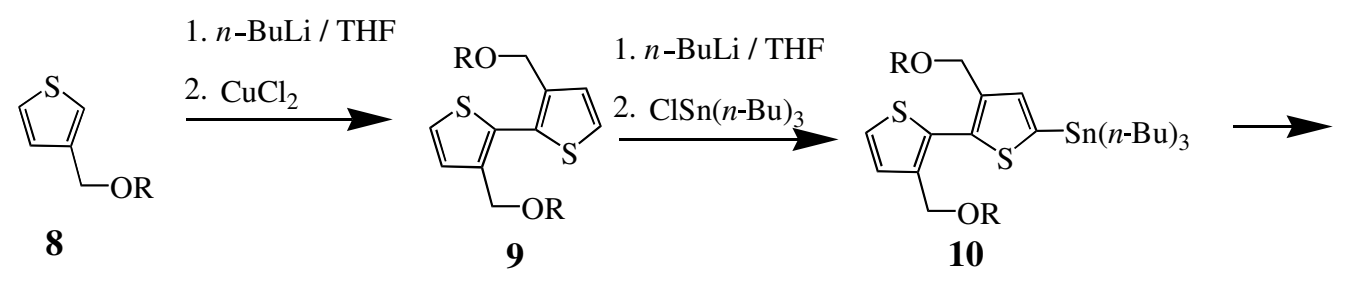

$\mathrm{R}=\left(\mathrm{C}_{2} \mathrm{H}_{4} \mathrm{O}\right)_{2} \mathrm{C}_{2} \mathrm{H}_{5}$

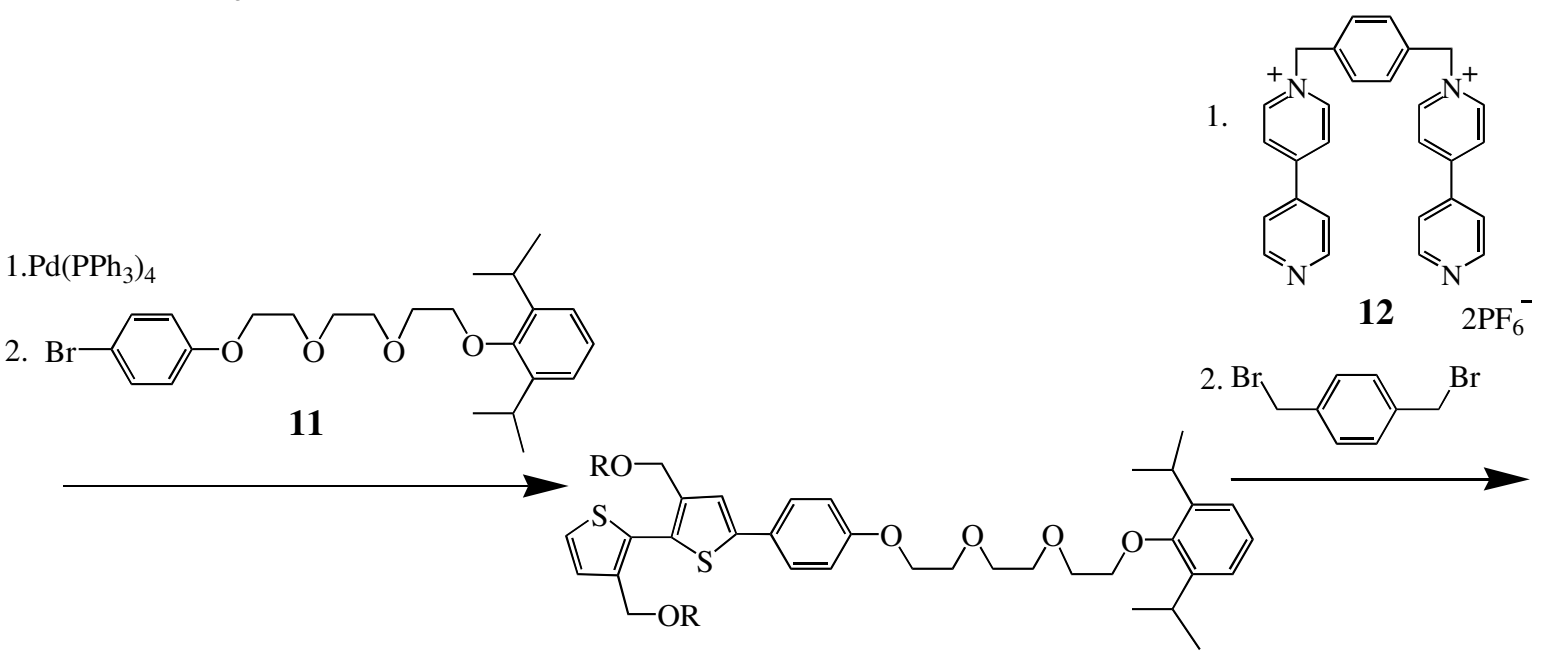

dumbbell 13

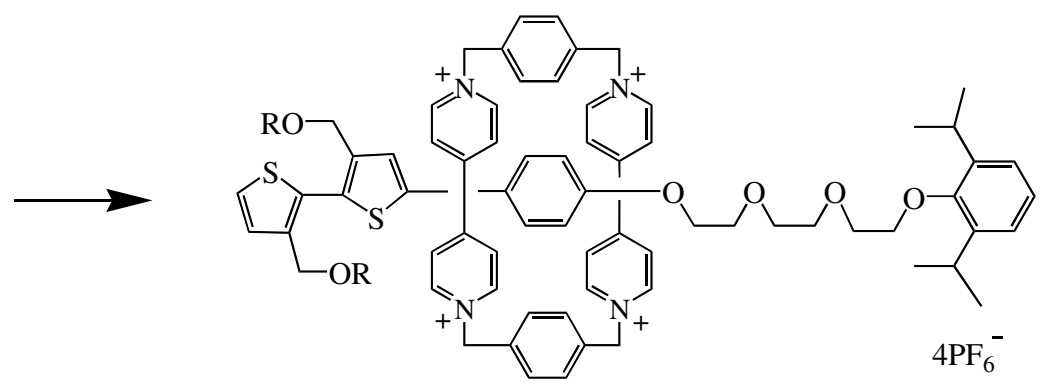

6 


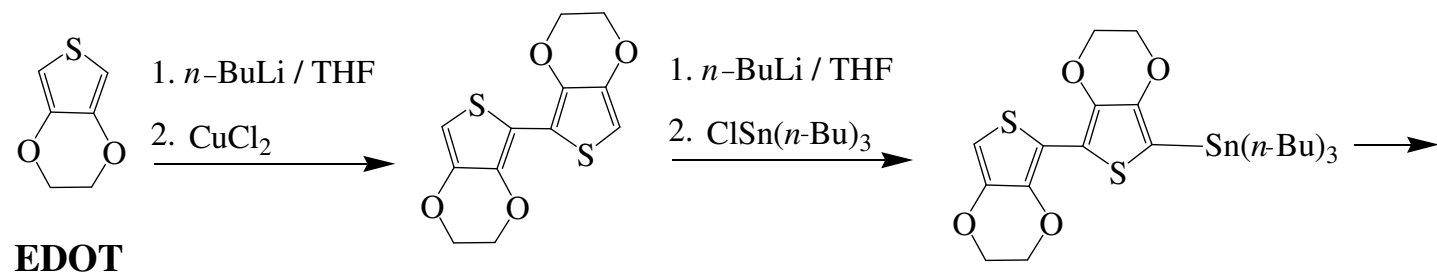

BEDOT

14
1.<smiles></smiles>

12

2 .

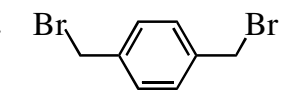

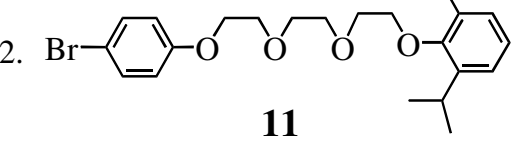

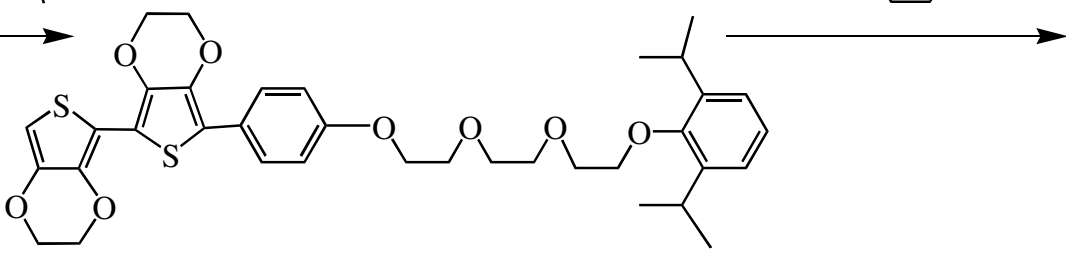

dumbbell 15
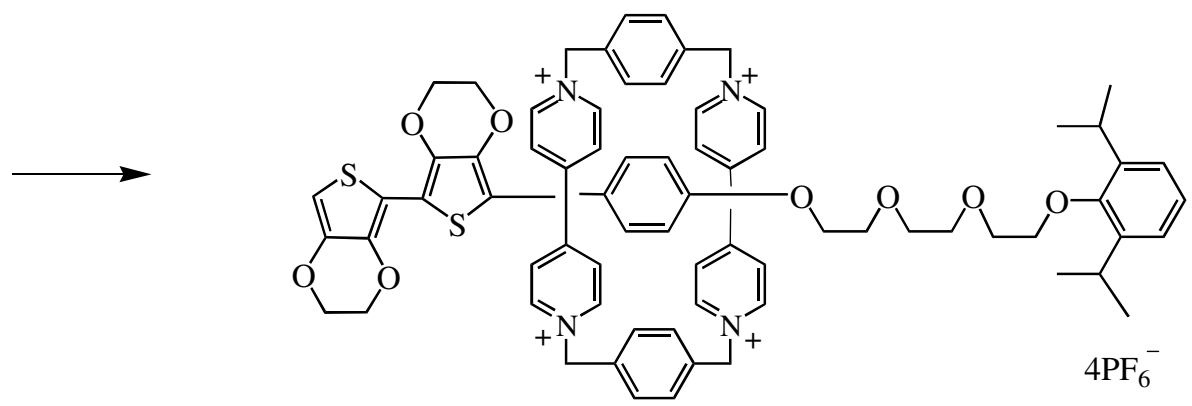

7

\section{Scheme 2}

\subsection{Rotaxanes containing acridane units in the thread}

In investigations of one-and two-station acridane rotaxanes, first the synthesis of one-station acridane rotaxanes $\mathbf{1 6 a - c}$ was performed. ${ }^{26}$ The process begins with the treatment of acridinium salts 17a-c with methanol or ethanol (for 17a ethanol was used) in the presence of $\mathrm{K}_{2} \mathrm{CO}_{3}$.

The obtained acridane half-dumbbells 18a-c reacted with $\mathbf{W}$ and adamantyl chloride to form the unisolated intermediate acridane rotaxanes $19 a-c$, which on treatment with $\mathrm{NH}_{4} \mathrm{PF}_{6}$ gave the 
one-station acridinium rotaxanes 20a-c. Upon addition of a small amount of methanol in acetonitrile in the presence of weak bases (e.g. $\mathrm{NaHCO}_{3}$ or ethyldiisopropylamine) they afford one-station acridane rotaxanes 16a-c. (Scheme 3 )
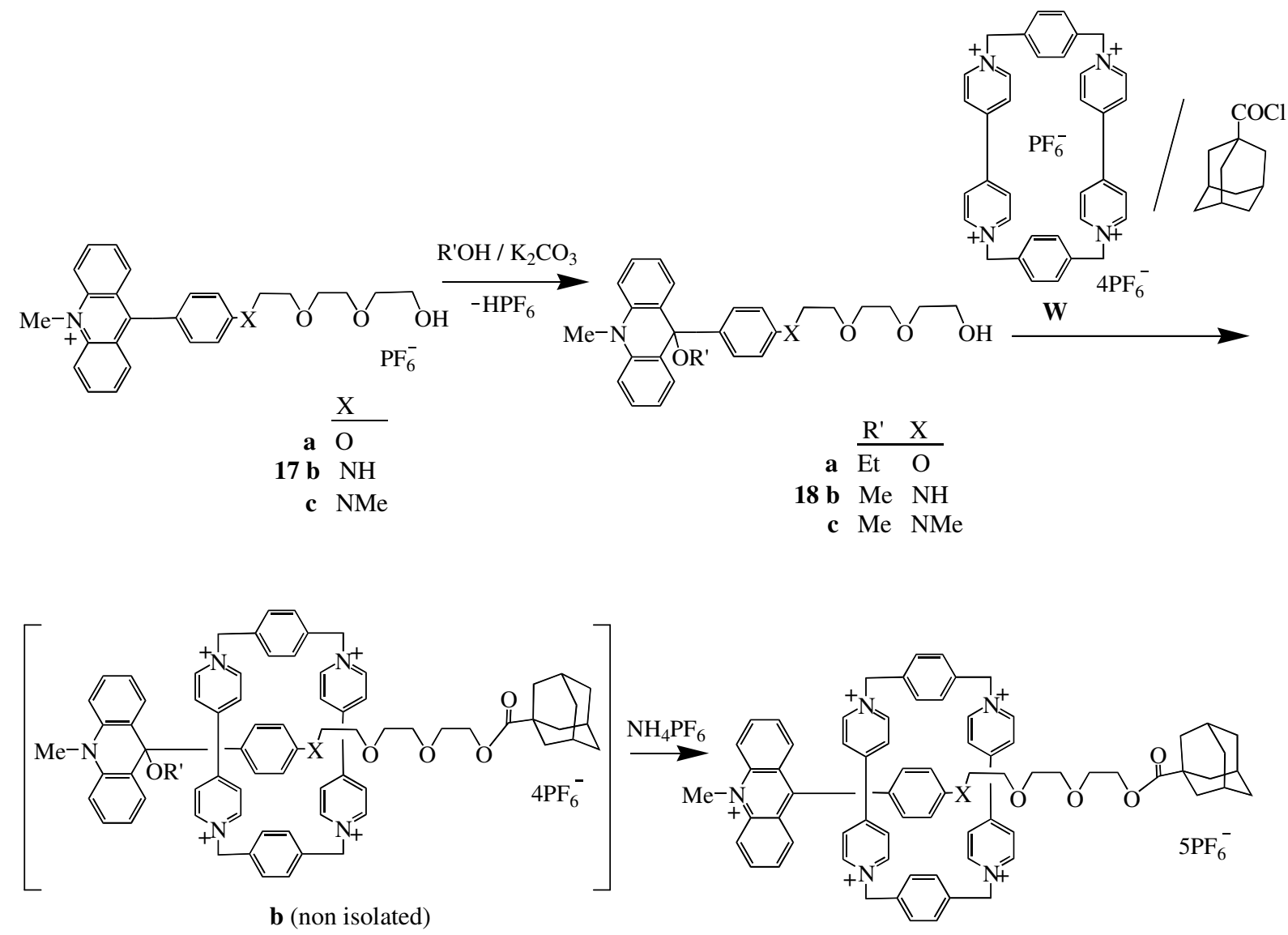

19a-c

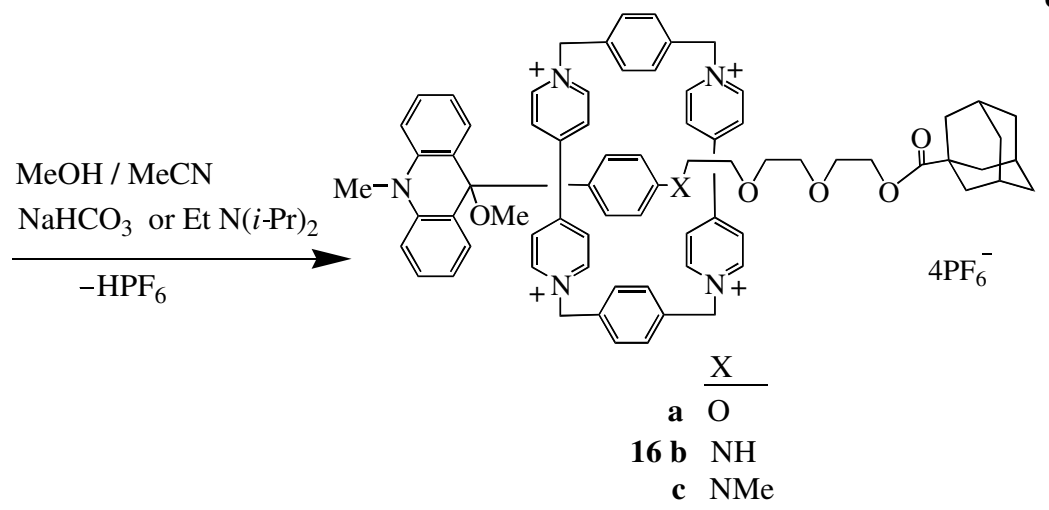

\section{Scheme 3}


In a study of two-station acridane rotaxanes, the shuttle switching of rotaxane 21 was investigated. The rotaxane $\mathbf{2 1}$ (obtained from $\mathbf{2 2}$ by treatment with methanol) undergoes both photoswitching and acid-base switching. In photoswitching of $\mathbf{2 1}$ irradiation affords the acridinium rotaxane 22. This transformation is connected with shuttling of the ring $\mathbf{W}$ from the station A to the station B since the positively charged acridinium ion repels the positively charged ring $\mathbf{W}^{4+}$; the thermal back reaction recovers 21 . In acid-base switching of rotaxane 21 acidification with TFA also yields acridinium rotaxane 22; this process is accompanied by shuttling of the ring $\mathbf{W}$ from station A to station $\mathrm{B}$; treatment with methanol in the presence of weak bases $\left(\mathrm{NaHCO}_{3}\right.$ or EtNi-Pr$)$ reforms 21 (TFA denotes trifluoroacetic acid). (Scheme 4).
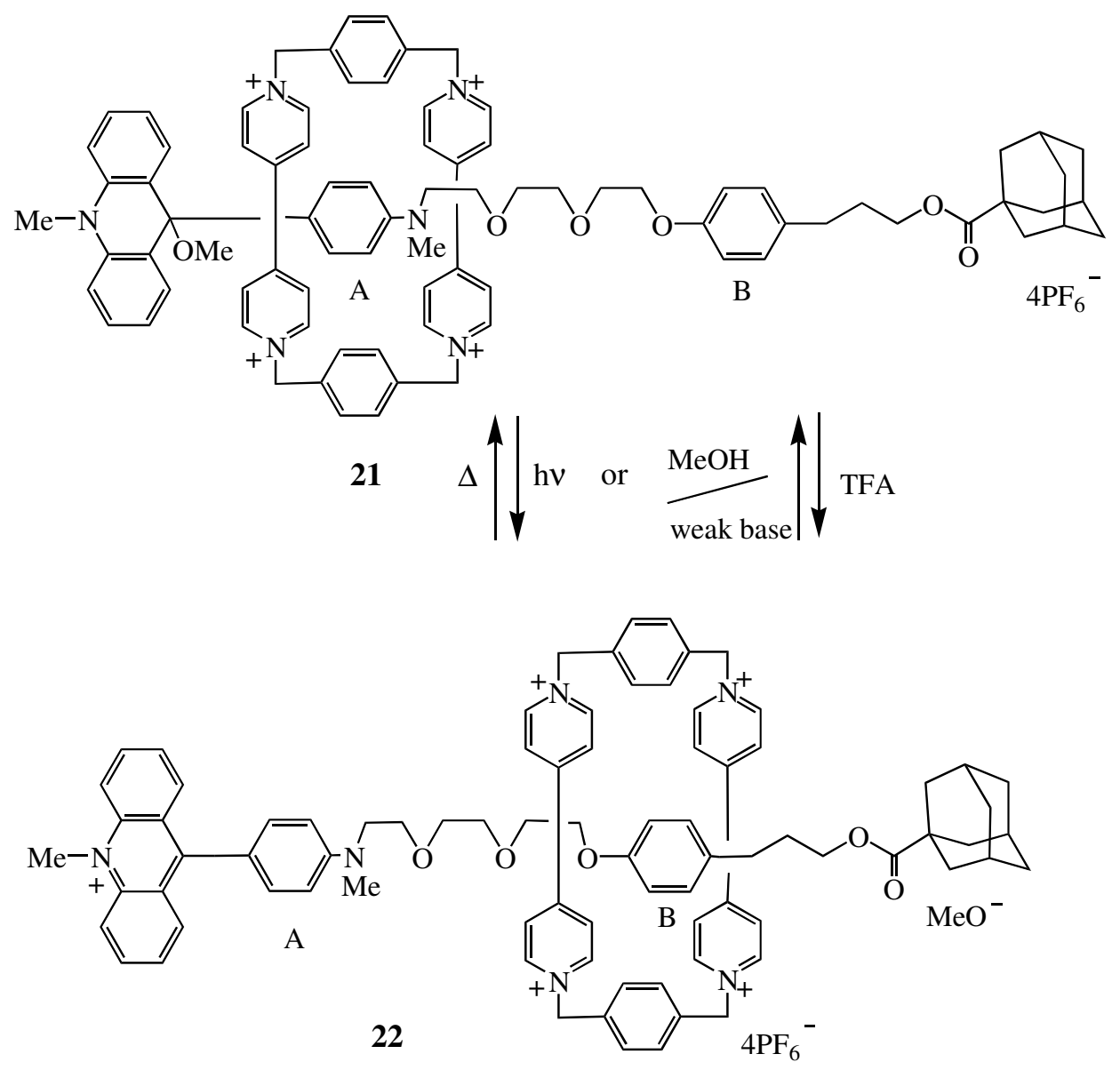

\section{Scheme 4}

Rotaxanes having two acridinium/acridane recognition stations at the ends of the thread, and containing the ring $\mathbf{W}^{4+}$ have been synthesized; they differ from each other by kind and number of stations incorporated in the thread. ${ }^{27}$ 
The synthesis of the above rotaxanes involves the connection of the left half-dumbbell containing the acridane unit with the right half-dumbbell containing the acridinium unit; the process is performed in the presence of the ring $\mathbf{W}^{4+}$. The click reaction and the esterification were employed to connect left and right half-dumbbells. (The click or $\mathrm{Cu}$ AAC reaction is $\mathrm{Cu}(\mathrm{I})$ catalyzed Huisgen 1,3-dipolar cycloaddition). The treatment of obtained acridinium rotaxanes with methanol in acetonitrile in the presence of $\mathrm{NaHCO}_{3}$ afforded the corresponding acridane rotaxanes. Below four examples are given; in the first three examples (a-c) click reactions, and in the fourth example (d) esterification, were used.

a) The click reaction of $\mathbf{2 3}$ with $\mathbf{2 4}$ affords the three-station acridinium rotaxane $\mathbf{2 5}$, converted by $\mathrm{MeOH} / \mathrm{NaHCO}_{3}$ into acridane rotaxane 26. (Scheme 5) 

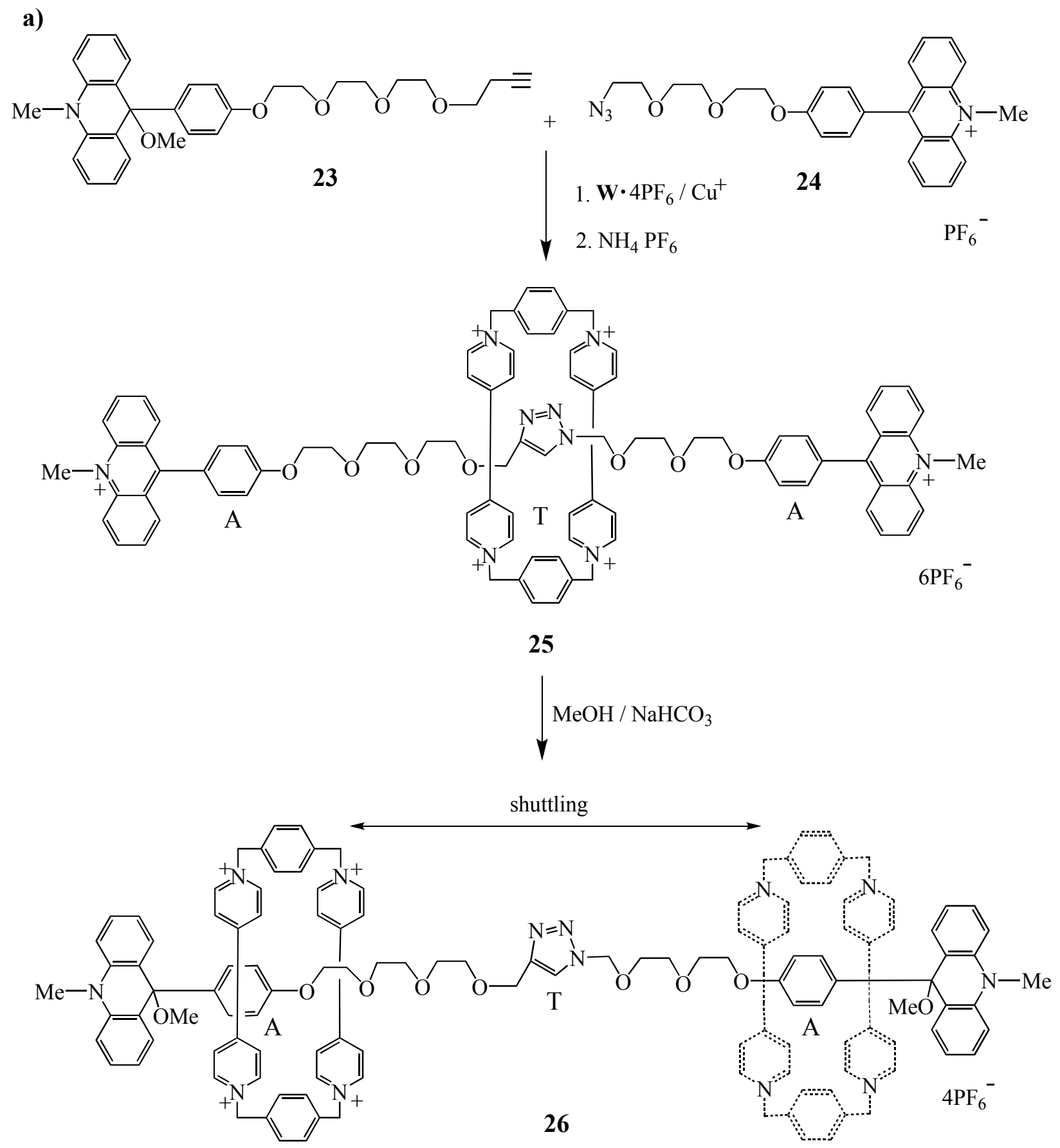

\section{Scheme 5}

b) The click reaction of $\mathbf{2 7}$ with $\mathbf{2 8}$ affords the three-station acridinium rotaxane $\mathbf{2 9}$, converted by $\mathrm{MeOH} / \mathrm{NaHCO}_{3}$ into acridane rotaxane 30. (Scheme 6) 


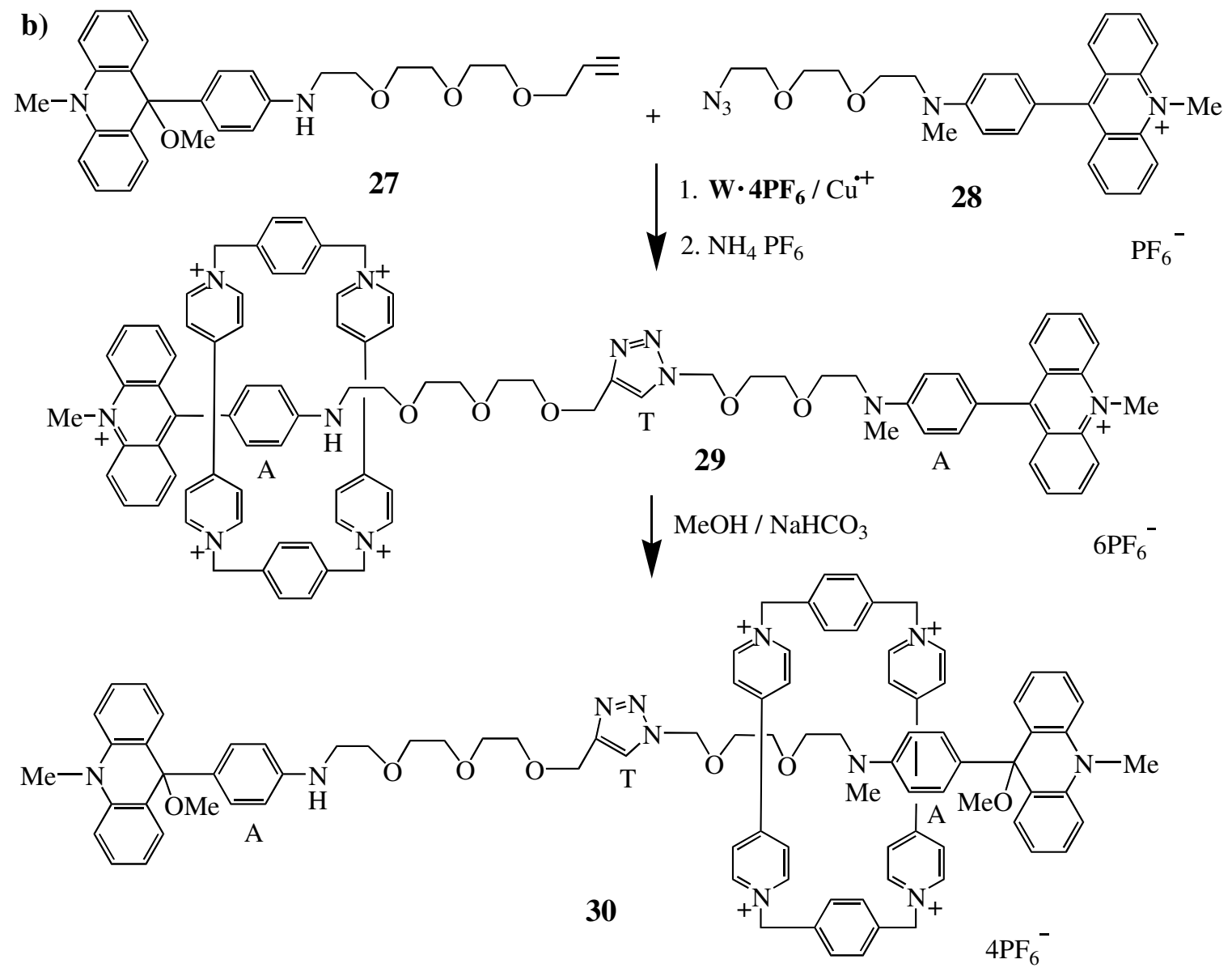

\section{Scheme 6}

c) The click reaction of $\mathbf{3 1}$ with $\mathbf{2 4}$ yields the four-station acridinium rotaxane $\mathbf{3 2}$, converted by $\mathrm{MeOH} / \mathrm{NaHCO}_{3}$ into the acridane rotaxane 33. (Scheme 7)

d) The esterification of the alcohol $\mathbf{3 4}$ with the acid $\mathbf{3 5}$ affords both the four-station acridinium [3] rotaxane 36 and the four-station acridinium [2]rotaxane 37 ; the acridinium rotaxane 37 was converted by $\mathrm{MeOH} / \mathrm{NaHCO}_{3}$ into the acridane rotaxane 38. (Scheme 8)

Investigation of acridinium rotaxanes has shown that:

a) in $\mathbf{2 5}$ the triazole station $\mathrm{T}$ competes with the stations $\mathrm{A}$ to accommodate $\mathbf{W}^{\mathbf{4 +}}$, which resides mainly on the triazole station. (Scheme 5)

b) in $\mathbf{2 9}$ the ring $\mathbf{W}^{\mathbf{4 +}}$ resides mainly at aminophenyl station A (the left station A). (Scheme 6)

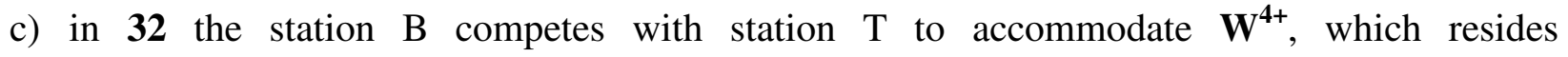
predominantly on the station B. (Scheme 7)

d) in $\mathbf{3 6}$ the ring $\mathbf{W}^{\mathbf{4 +}}$ shuttles between stations B and C. (Scheme 8) 

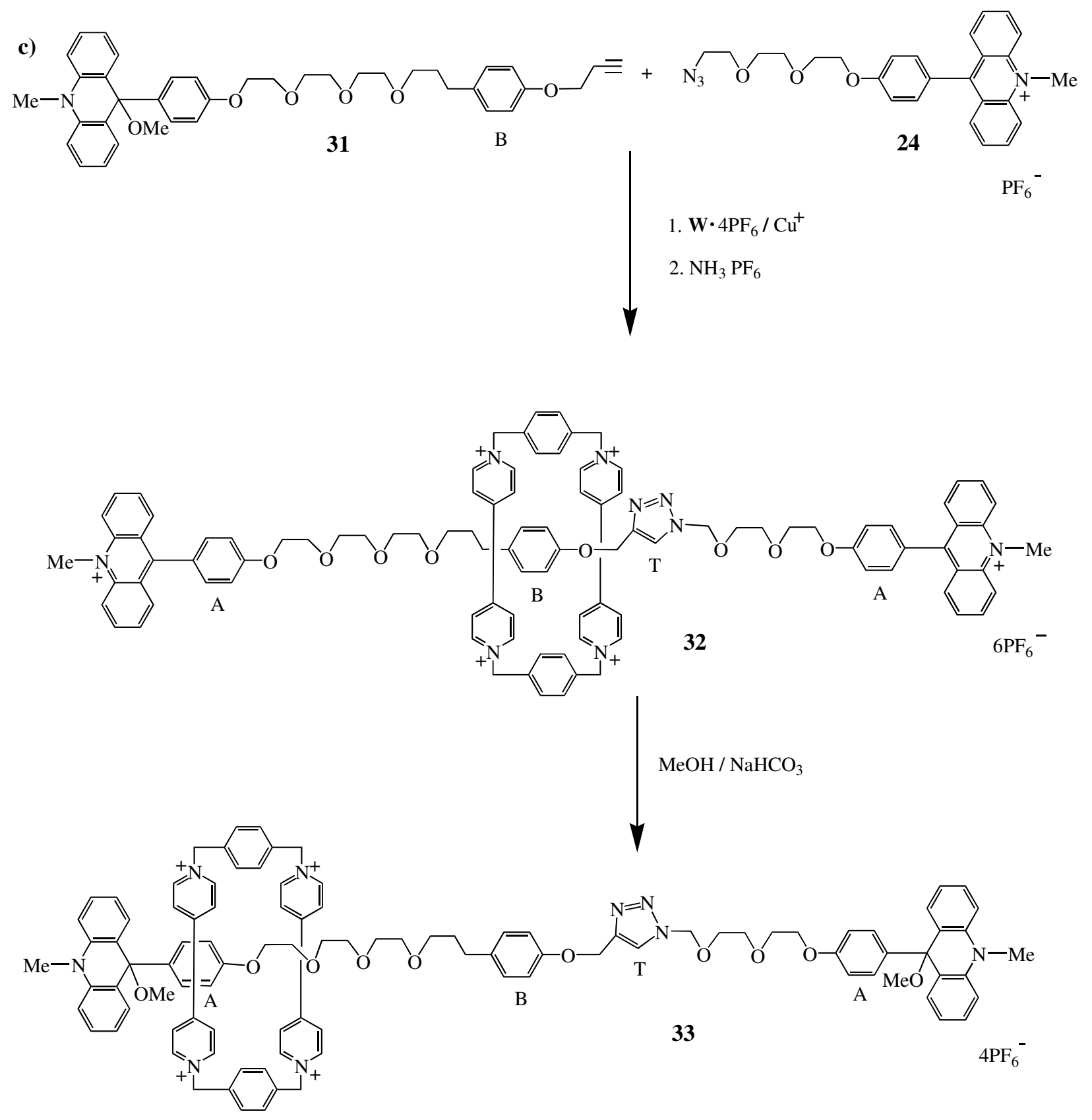

\section{Scheme 7}

Investigation of acridane rotaxanes has shown that:

a) in $\mathbf{2 6}$ and $\mathbf{3 8}$ the shuttling of $\mathbf{W}^{\mathbf{4 +}}$ between two stations A occurs. (Schemes 5, 8)

b) in 30 the ring $\mathbf{W}^{4+}$ resides at the $N$-methylaminophenyl station A (the right station A). One should point out that the both acridane stations $A$ in $\mathbf{3 0}$ are not exactly identical. (Scheme 6)

c) in $\mathbf{3 3}$ the ring $\mathbf{W}^{\mathbf{4}}$ resides at the left station $\mathrm{A}$, no shuttling was detected. (Scheme 7) 
d)

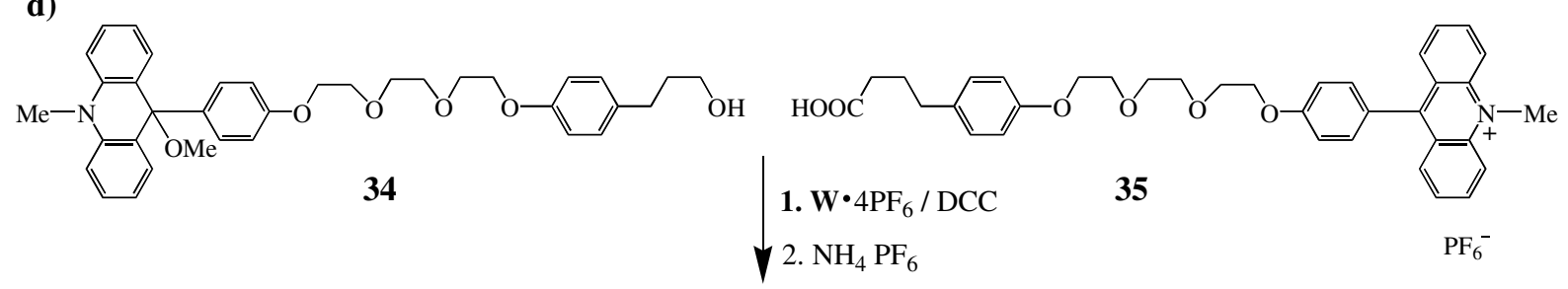

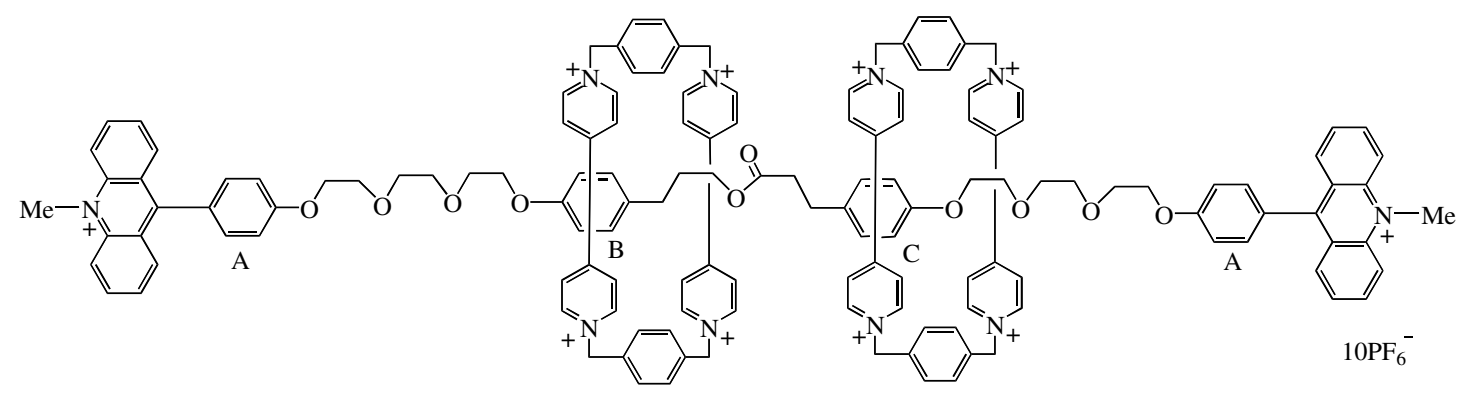

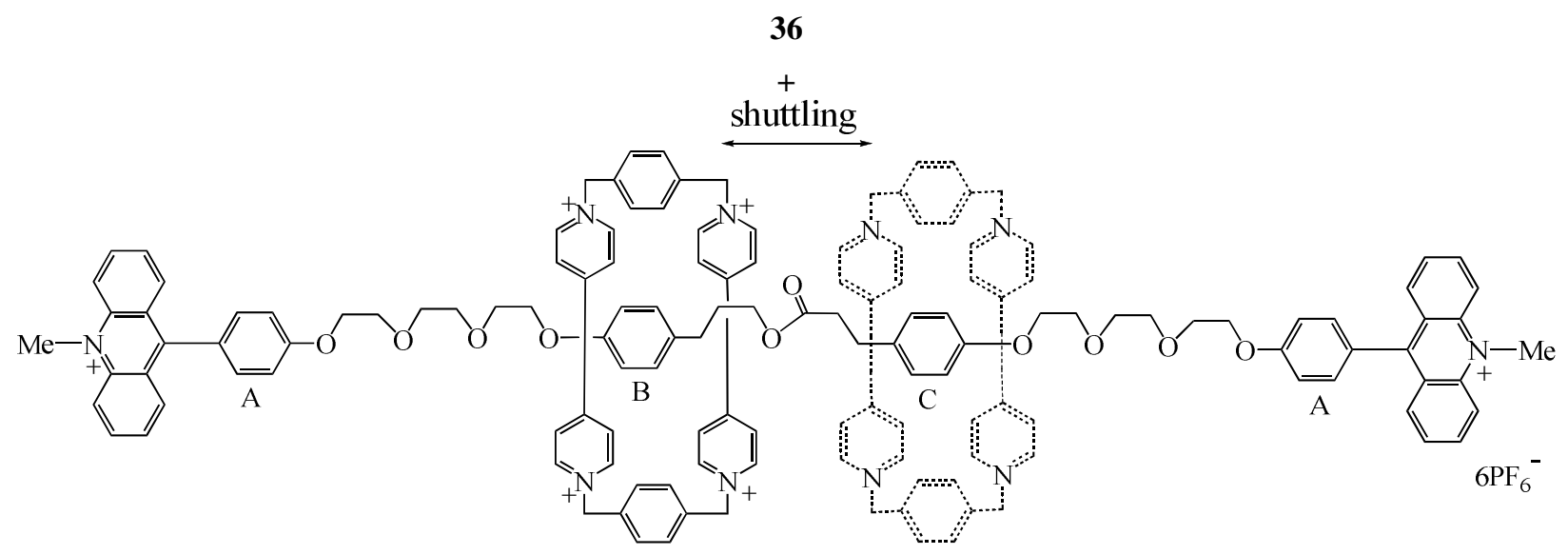

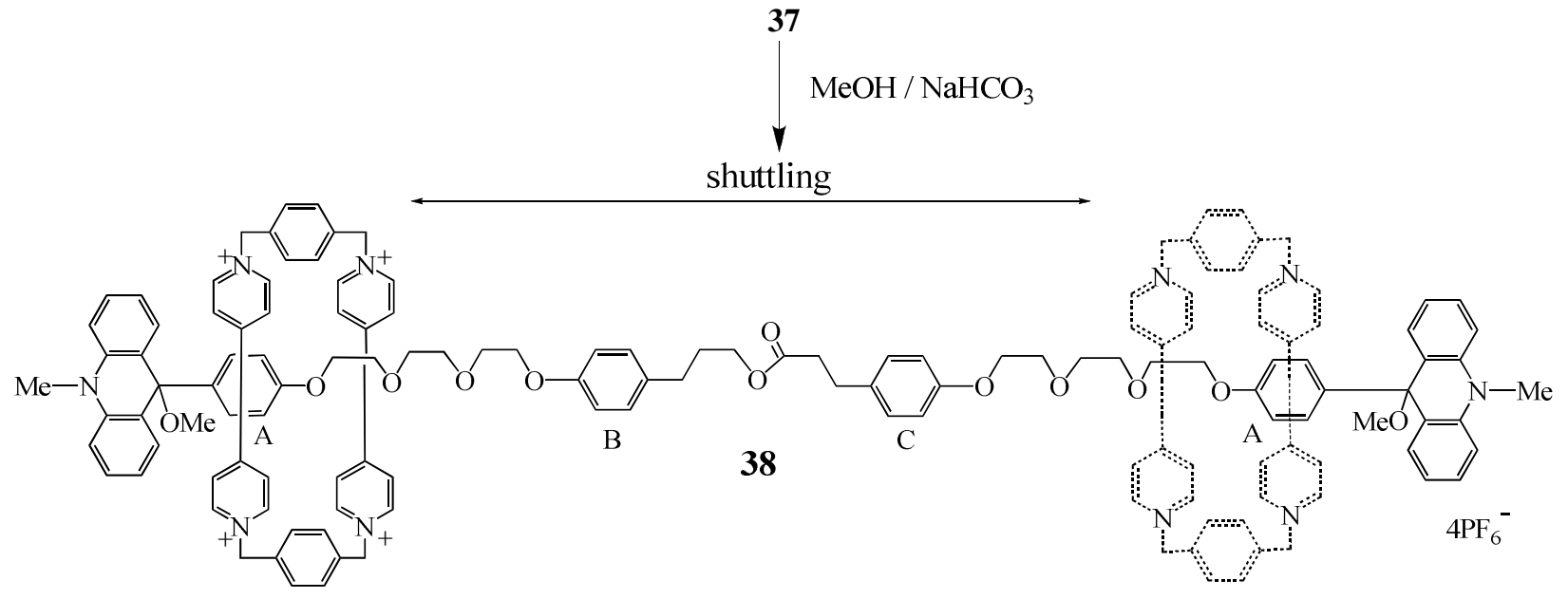

Scheme 8 
It was observed that, in synthesized rotaxanes with acridane units at both ends of the thread, the ring $\mathbf{W}^{4+}$ shuttles from one acridane unit to the other one along the whole length of the thread. This large amplitude movement between the acridane units (about $2.5 \mathrm{~nm}$ for $\mathbf{2 6}$ and $3.5 \mathrm{~nm}$ for 38, assuming an extended linear structure of the thread) is stopped either by light (photoswitching) or by addition of protons (acid-base switching). The behavior of acridane rotaxane $\mathbf{2 6}$ is described below for these two kinds of switching.

In the photoswitching of $\mathbf{2 6}$ the right acridane unit is converted into acridinium, while the left acridane unit is not. After excitation by light $(>300 \mathrm{~nm})$, the right acridane unit upon release of methoxide ion forms the acridinium ion. The ring $\mathbf{W}$, which was at the left acridane unit, remains there, since it has greater affinity to this uncharged acridane unit than to the newly formed acridinium, or to the station $\mathrm{T}$ in the middle of the thread, therefore rotaxane 39 is formed, and no shuttling occurs. (Scheme 9)

Photoswitching of $\mathbf{2 6}$ :
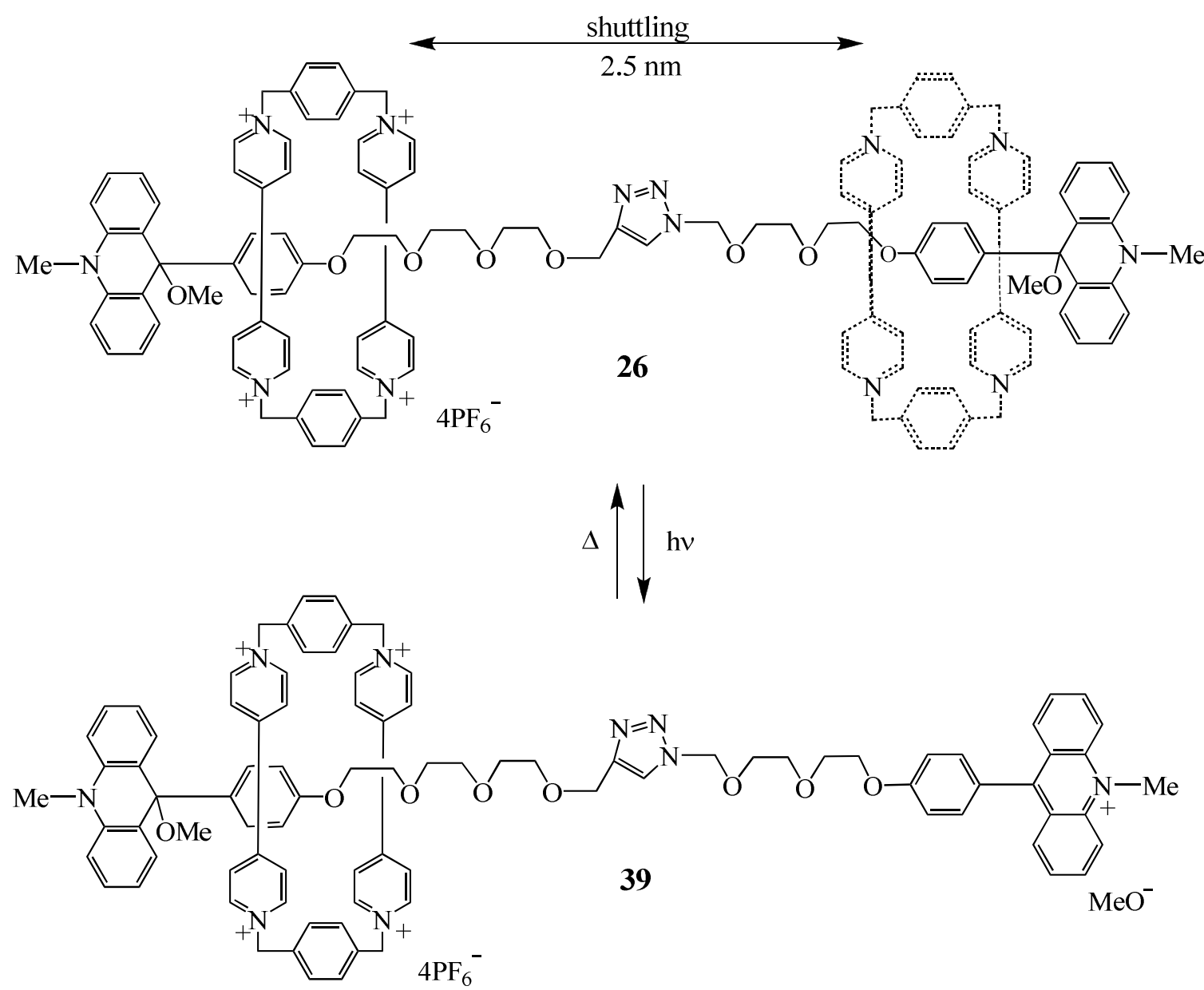

\section{Scheme 9}


On the other hand, in the acid-base switching of $\mathbf{2 6}$, both acridane units are involved. The addition of the acid converts both acridanes into acridinium units, therefore the ring $\mathbf{W}$ resides on the station $\mathrm{T}$ in the middle of the thread, the rotaxane $\mathbf{2 5}$ is formed and no shuttling occurs. (see Scheme 10)

\section{Acid-base switching of $\mathbf{2 6}$}
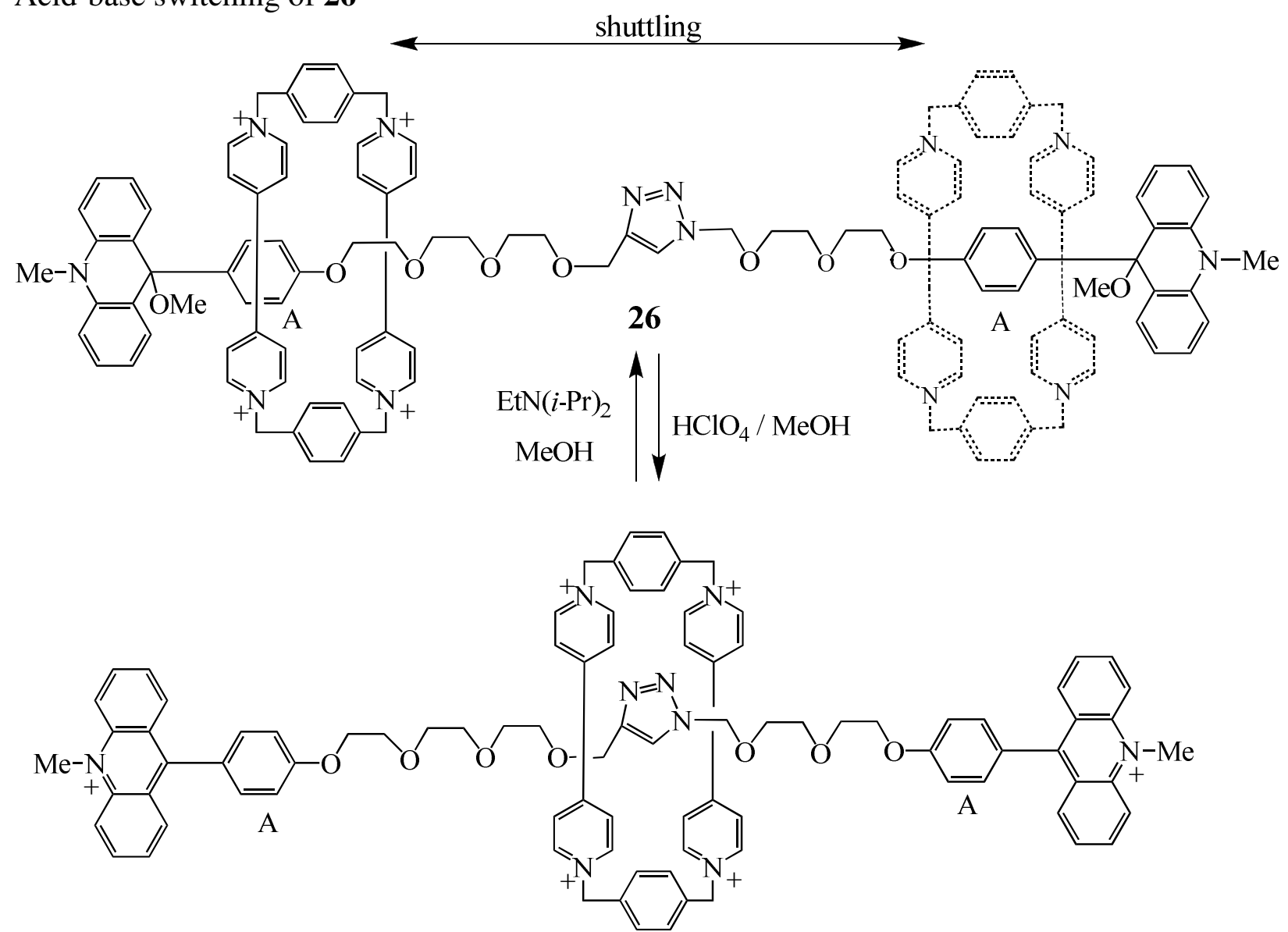

25

\section{Scheme 10}

In the acid-base switching of $\mathbf{3 8}$ also both acridane units are involved, similar to the case with 26. The addition of acid converts both acridane units into acridinium units, therefore in the formed rotaxane $\mathbf{3 7}$ the shuttling occurs at a smaller amplitude than in rotaxane $\mathbf{3 8}$. (Scheme 11) 
Acid-base switching of $\mathbf{3 8}$
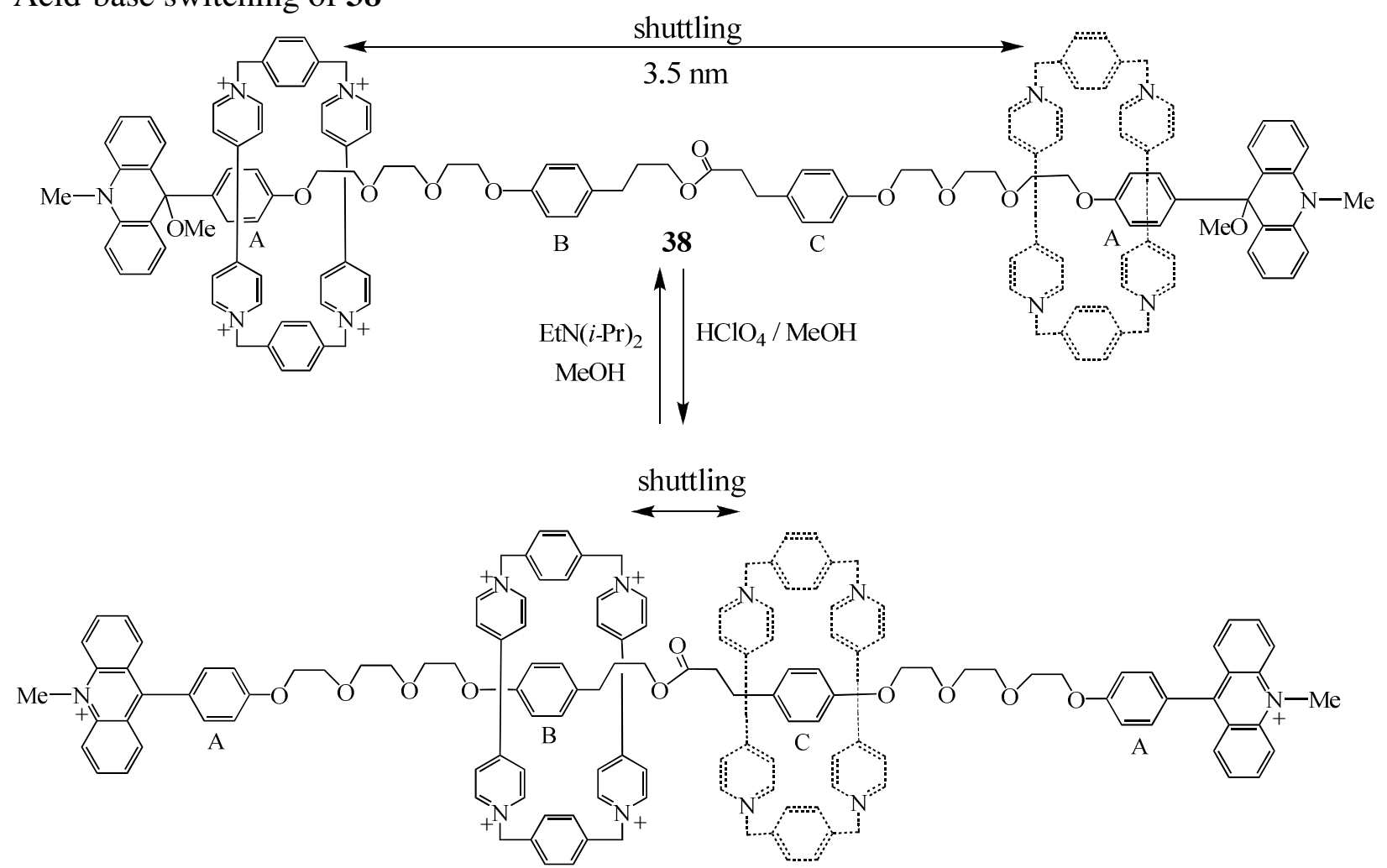

37

\section{Scheme 11}

It was established that both kinds of switching are reversible, photoswitching by a thermal process, and acid-base switching by reaction with ethyldiisopropylamine; both kinds of switching can be repeated at least ten times. The above results show novel principles for controlling the motion of rotaxanes. These findings are promising for development of molecular machines.

\subsection{Other rotaxanes}

It is known that for use of rotaxanes in molecular devices the work should be performed with rigid systems. For this purpose the rigid degenerate rotaxane $\mathbf{4 0}$ was investigated; it consists of the dumbbell incorporating two identical naphthalene based stations NP and the ring $\mathbf{W}$ shuttling between them. ${ }^{28}$

The synthesis of $\mathbf{4 0}$ involves the threading approach and $\mathrm{Cu}^{2+}$-mediated Eglinton coupling of two half-dumbbells 41 via their terminal alkyne groups. (Scheme 12). The crystallographic analysis of 40 shows that its molecules are situated in parallel $\pi-\pi$ stacks of alternating naphthalene systems and $\mathbf{W}$ units, forming an interdigitated superstructure; these results are promising for the design of molecular devices. 

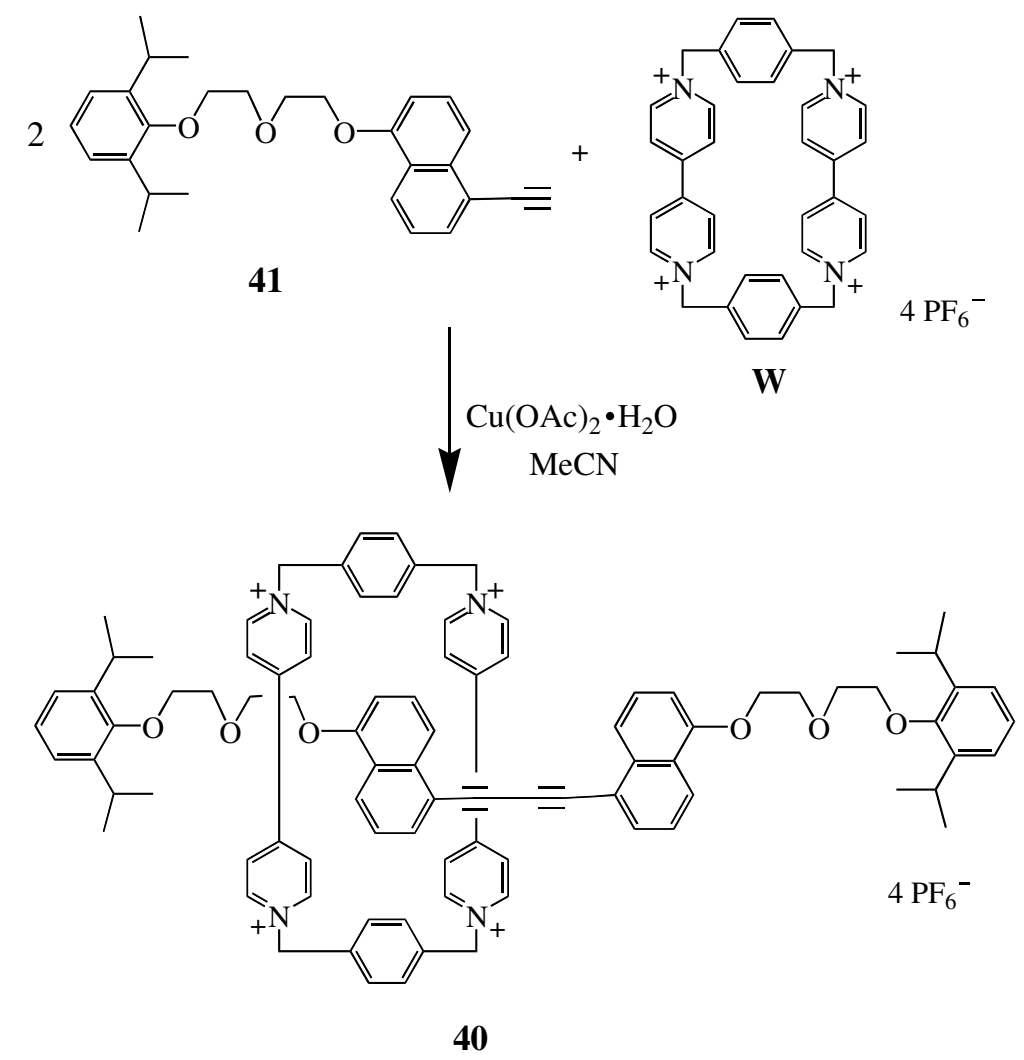

\section{Scheme 12}

The introduction of the rigidity into the dumbbell molecule of [2]rotaxanes is advantageous in the construction of switches and machines. For investigation of the shuttling in [2] rotaxane with an extended rigid linker between two naphthalene NP units in the thread, a $p$-phenylene unit has been introduced between two ethynyl groups in rotaxane $\mathbf{4 0}$ to give [2] rotaxane $\mathbf{4 2} .^{29}$ This rotaxane was synthesized from the dumbbell $\mathbf{4 3}$, compound $\mathbf{1 2}$ and $p$-dibromoxylene using the template-directed protocol of clipping under high-pressure conditions. (Scheme 13)

The ${ }^{1} \mathrm{H}$ NMR spectroscopy results of rotaxanes $\mathbf{4 0}$ and $\mathbf{4 2}$ have shown the existence of a thermodynamic balance between the enthalpic $(\Delta H)$ and entropic $(T \Delta S)$ components to the free energy; at low temperatures enthalpy takes over, while at higher temperatures, entropy prevails. Therefore one can say that both rotaxanes $\mathbf{4 0}$ and $\mathbf{4 2}$ are examples of a molecular thermal switch where the ring $\mathbf{W}$ shuttles constantly from one station to the other. At low temperature, $\mathbf{W}$ resides for a longer time on the NP units, but upon the temperature increase, $\mathbf{W}$ is localized for a shorter and shorter time on the NP units, instead it is moving along the whole length of the dumbbell.

In order to investigate the nature of the weak forces which govern the extended and highly ordered $\pi-\pi$ stacking in $\mathbf{4 0}$ and $\mathbf{4 2}$, their molecular structures were calculated using the DREIDING force field. It was found that the shuttling energy barriers in $\mathbf{4 0}$ and $\mathbf{4 2}$ are very 
similar. This fact shows that the different length of the spacers between two NP units in both rotaxanes 40 and $\mathbf{4 2}$ (the length of the spacer in $\mathbf{4 0}$ is lower than in $\mathbf{4 2}$ ) has little effect on the energy barrier for the movement between the two NP stations.

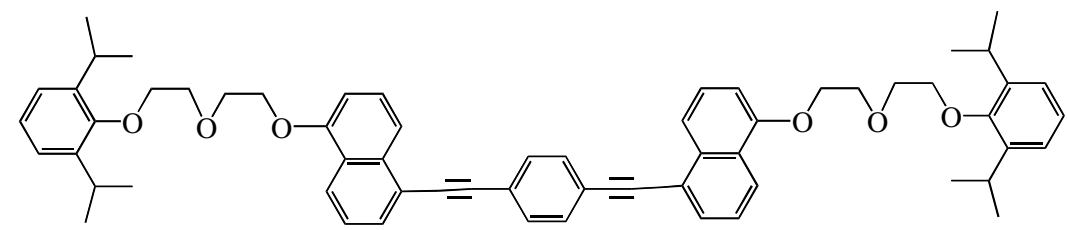

43

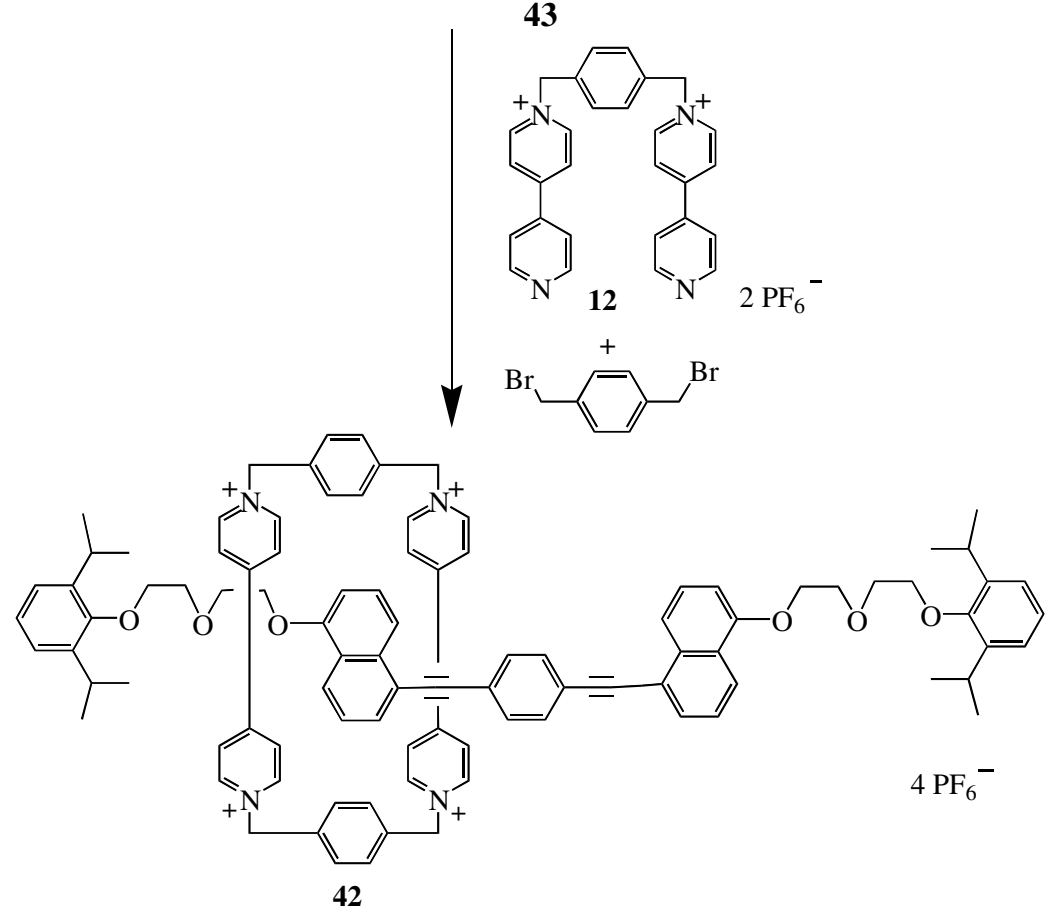

\section{Scheme 13}

It is known that cholesterol is an effective constituent of organogels and liquid crystals. With this in view the synthesis of the bistable (i.e. containing two different stations) [2] rotaxane 44 stoppered by cholesterol units was performed. ${ }^{30}$ The switching properties, gelation behavior and self-organization of $\mathbf{4 4}$ have been investigated, and compared with those of its dumbbell $\mathbf{4 5}$ (i.e. 44 without the ring). It was established that the shuttling of the ring $\mathbf{W}$ between TTF and DNP units is based on the redox properties of TTF and is fully reversible (TTF denotes tetrathiafulvalene, and DNP denotes 1,5-dihydroxynaphthalene). 


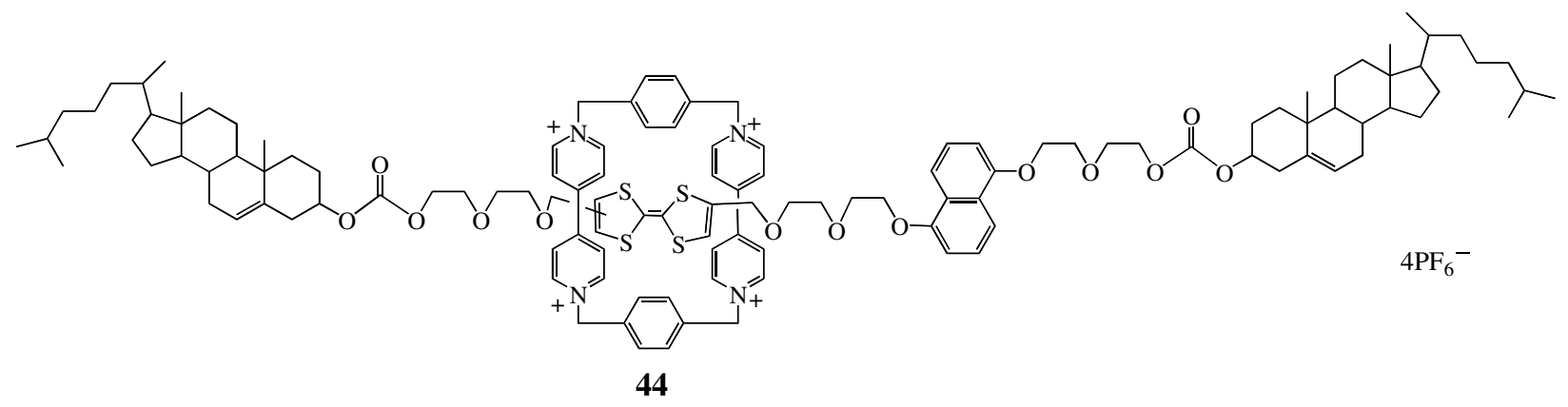

As expected, rotaxane $\mathbf{4 4}$ and its dumbbell $\mathbf{4 5}$ form organogels; their gelation behavior was studied in a number of solvents. For both 44 and 45 the mixed solvent system $\mathrm{CH}_{2} \mathrm{Cl}_{2} / \mathrm{MeOH}$ (3:2) proved to be appropriate. Organogels are formed by 44 and 45 in this solvent system, and are liquefied by addition of an oxidizing agent. The AFM (atomic force microscopy) observations indicate that $\mathbf{4 4}$ and $\mathbf{4 5}$ self-organize forming linear superstructures of a helical character. It is noteworthy that the cholesterol stoppers play an important role in this selforganization. The above results show that the self-organization may be induced by use of mechanically interlocked species.

A computational study of rotaxane $\mathbf{4 6}$ as a representative example of bistable [2] rotaxanes was performed. ${ }^{31}$ In the rotaxane 46 the ring $\mathbf{W}^{\mathbf{4 +}}$ is shuttling between the electron-donating groups TTF and DNP. For investigations, the rotaxane 46 has been incorporated into a twodimensional crossbar circuit. This system can function as a molecular switch, since the two coconformations have different conductivities. Namely, the ground state co-conformation (GSCC), when the ring resides at the TTF station, shows low conductance (off-state), while the metastable co-conformation (MSCC), when the ring is at the DNP station, shows high conductance (onstate). ${ }^{32}$ This behavior has been observed experimentally in many rotaxanes of this type.

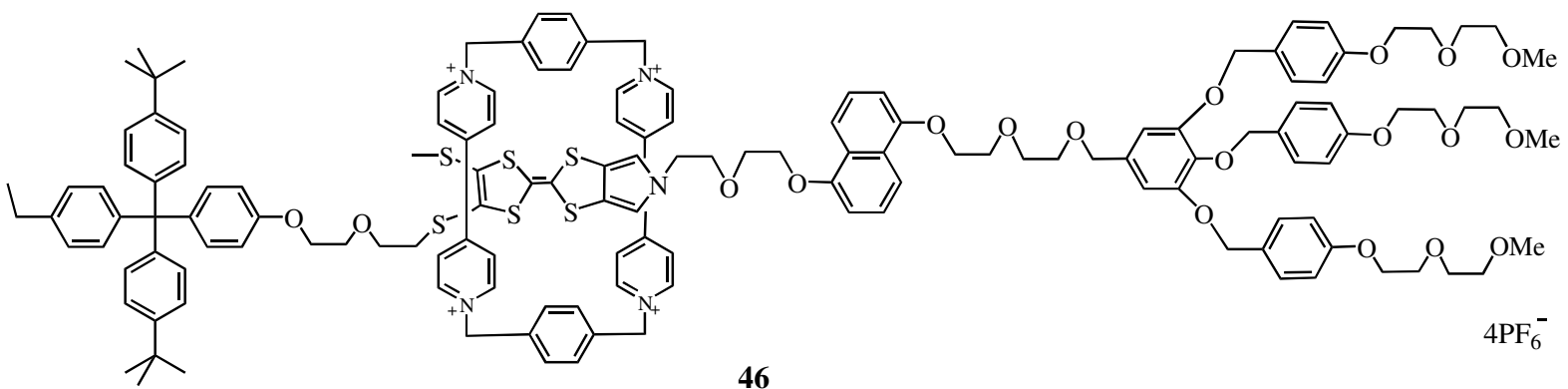

The GSCC and MSCC states are controlled by oxidation, occurring predominantly at the TTF unit. Oxidation results in the electrostatic repulsion of $\mathbf{W}^{4+}$ from $\mathrm{TTF}^{2+}$, therefore the ring shuttles to DNP station. Upon reduction, the ring remains at the DNP station; in this MSCC state the rotaxane $\mathbf{4 6}$ is highly conductive. After a period of time the system returns to GSCC. The 
relaxation time depends on the shuttling barrier which must be overcome. Due to these facts, the site preference and the shuttling barrier are of a great importance for design of a functional and nonvolatile memory.

To investigate the binding site preference and the energy profiles for shuttling of the ring in 46, the AM1-FS1 and DFT methods were used; ${ }^{33,34}$ they allowed prediction of the binding site preference and co-conformational relative stabilities, as well as the value of isomerization barrier between the different co-conformational states. One should point out that these properties are crucial for the working of rotaxane-based molecular electronic devices. Moreover, the reorganization energy associated with the oxidation/reduction process was determined, and in the study the presence of $\mathrm{PF}_{6}^{-}$counterions was taken into account.

The above investigations allow an understanding of the observed conductivity difference between the two conformational states, which is an important property for work of memory elements and is valuable for the development of molecular electronic devices.

Polymeric micelles ${ }^{35-37}$ are a topic of wide investigation due to their unusual aggregation morphologies and possibility of use in nanocarriers or nanoreactors. Such micellar systems are often prepared from amphiphilic block copolymers upon contact with aqueous environments.

For the study of micellization, the amphiphilic, linear poly $(N$-isopropylacrylamide $)$ (PNIPAM) derivative 47 functionalized by TTF was used in aqueous solution. ${ }^{38,39}$ The temperature-induced micellization was monitored by fluorescence spectroscopy, dynamic light scattering (DLS) and differential scanning calorimetry.

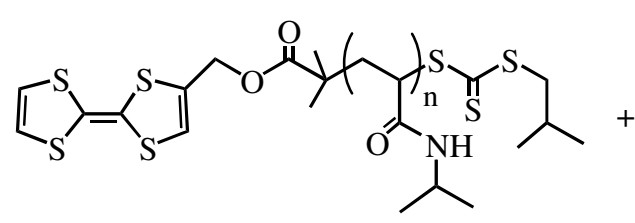

47

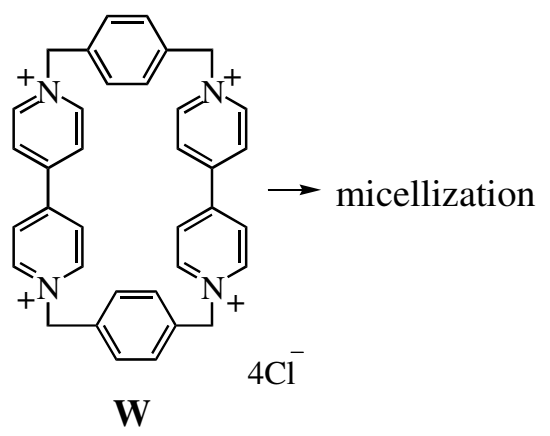

$\mathbf{W}$

The amphiphilic polymers of the type 47 can self-assemble in water to give multistimuli responsive polymeric micelles. It is known that the hydrophobic TTF unit can form a tunable pseudorotaxane assembly with the electron-deficient $\mathbf{W}^{4+}$, this property may be used to control the micellization process of the polymer 47.

The critical micelle concentration $(\mathrm{CMC})$ of polymer 47 in water was observed using fluorescent dye solubilization method; Nile Red served as the fluorescence probe. The influence of temperature on the micellization of $\mathbf{4 7}$ was studied by performing variable-temperature fluorescence experiments. The results showed that $\mathbf{4 7}$, upon temperature increase, underwent in 
water two successive phase transitions corresponding to the unimer-to-micelle and the lower critical solution temperature (LCST) transitions, respectively. Then an investigation was made to see whether the unimer-to-micelle transition process of 47 could be controlled by its complexation with $\mathbf{W}$ affording the $\mathbf{4 7} \cdot \mathbf{W}$ complex. To this end, the influence of the formation of 47-W on the fluorescence intensity of Nile Red and on the hydrodynamic diameter of 47 at different temperatures was studied.

It was found that the formation of the complex $\mathbf{4 7} \cdot \mathbf{W}$ strongly altered the amphiphilicity of 47 toward higher hydrophobicity, in this way controlling the unimer-to-micelle transition process. The fact that the formation of $\mathbf{4 7} \cdot \mathbf{W}$ induced a shift of the LCST toward a lower temperature confirmed this behavior. The obtained results, compatible with those of previous experiments, ${ }^{40}$ are due to the formation of $\mathbf{4 7} \cdot \mathbf{W}$ having a pseudorotaxane-like architecture. The above experiments are promising for design of switchable self-assemblies useful in drug delivery and in preparation of advanced materials.

In order to incorporate bistable rotaxanes into integrated nanosystems, their conjugation with metal nanoparticles (MNPs), showing a variety of mechanical, electronic, optical and catalytic properties, was investigated. ${ }^{41}$

The conventional preparation of functionalized MNPs involves the use of thiolate ligands in a reducing environment. However such conditions are not suitable for functionalization of MNPs by rotaxanes. Therefore another preparation of MNPs containing $\mathrm{Au}, \mathrm{Pd}$ or $\mathrm{Pt}$ cores functionalized by rotaxanes was employed. This method involves the reaction of weakly protected MNPs, i.e. MNP precursors (further referred to as precursors) with dithiolanes bearing redox-active MIM (mechanically interlocked molecule) component; in the described example it is TTF. The precursors are stabilized with low-affinity ligands, such as tetraoctylammonium bromide (TOAB).

The process begins with the preparation of precursors; they were obtained by reduction of toluene solutions of tetraoctylammonium tetrachloroaurate $\left[\mathrm{AuCl}_{4}\right]^{-}$, tetrachloroplatinate $\left[\mathrm{PtCl}_{4}\right]^{2-}$ and tetrachloropalladate $\left[\mathrm{PdCl}_{4}\right]^{2-}$, respectively, with aqueous solutions of $\mathrm{NaBH}_{4}$. The obtained precursors upon mixing, as toluene solutions, with dithiolane ligands 48 and 49 dissolved in acetonitrile undergo rapid ligand-exchange reactions. In this way the MNPs covered with mixed self-assembled monolayers (mSAMs), namely 50, comprising inert ligands 48 and functional ligands 49 have been prepared.

The above process, i.e. the introduction of ligands on the MNPs surface is very important for solubility of MNPs. The TOAB-protected MNPs, prior to ligand exchange are soluble only in strongly apolar solvents, such as hexane or toluene. However, after functionalization with ligands 48 and 49 they are readily soluble in more polar solvents, such as methanol, acetonitrile or DMF.

The changes in the surface and $\zeta$ potentials of $\mathbf{5 0}$ as a function of the redox potential were investigated, using as an example 50 with AuNPs (for PtNPs and PdNPs the results are similar as for AuNPs). The oxidation of $\mathbf{5 0}$ with $\mathrm{Fe}\left(\mathrm{ClO}_{4}\right)_{3}$ involved the oxidation TTF to $\mathrm{TTF}^{2+}$. Upon 
addition of ascorbic acid, the $\mathrm{TTF}^{2+}$ was reduced back to neutral state (TTF), and the $\zeta$ potential decreased almost to zero. The MNPs may undergo several such oxidation/reduction cycles. The treatment of $\mathbf{5 0}$ with $\mathbf{W} \cdot 4 \mathrm{PF}_{6}$ gives rise to pseudorotaxane 51. Addition of $\mathrm{Fe}\left(\mathrm{ClO}_{4}\right)_{3}$ leads to dissociation of the pseudorotaxane $\mathbf{5 1}$ resulting from the electrostatic repulsion between $\mathrm{TTF}^{2+}$ and $\mathbf{W}^{\mathbf{4 +}}$.

The above method for attaching functional groups to the surface of metal nanoparticles allowed preparation of $\mathrm{Au}, \mathrm{Pt}$ and $\mathrm{Pd}$ nanoparticles functionalized with thread-like $\pi$-electron rich recognition sites. The redox switching of these groups and threading-dethreading of the macrocycle $\mathbf{W}$ of pseudorotaxane $\mathbf{5 1}$ were verified by $\zeta$ potential measurements and by cyclic voltammetry. The observation that the redox potentials of the described switches can be tuned by the composition of mSAMs is promising for design of novel nanomaterials. (Scheme 14).

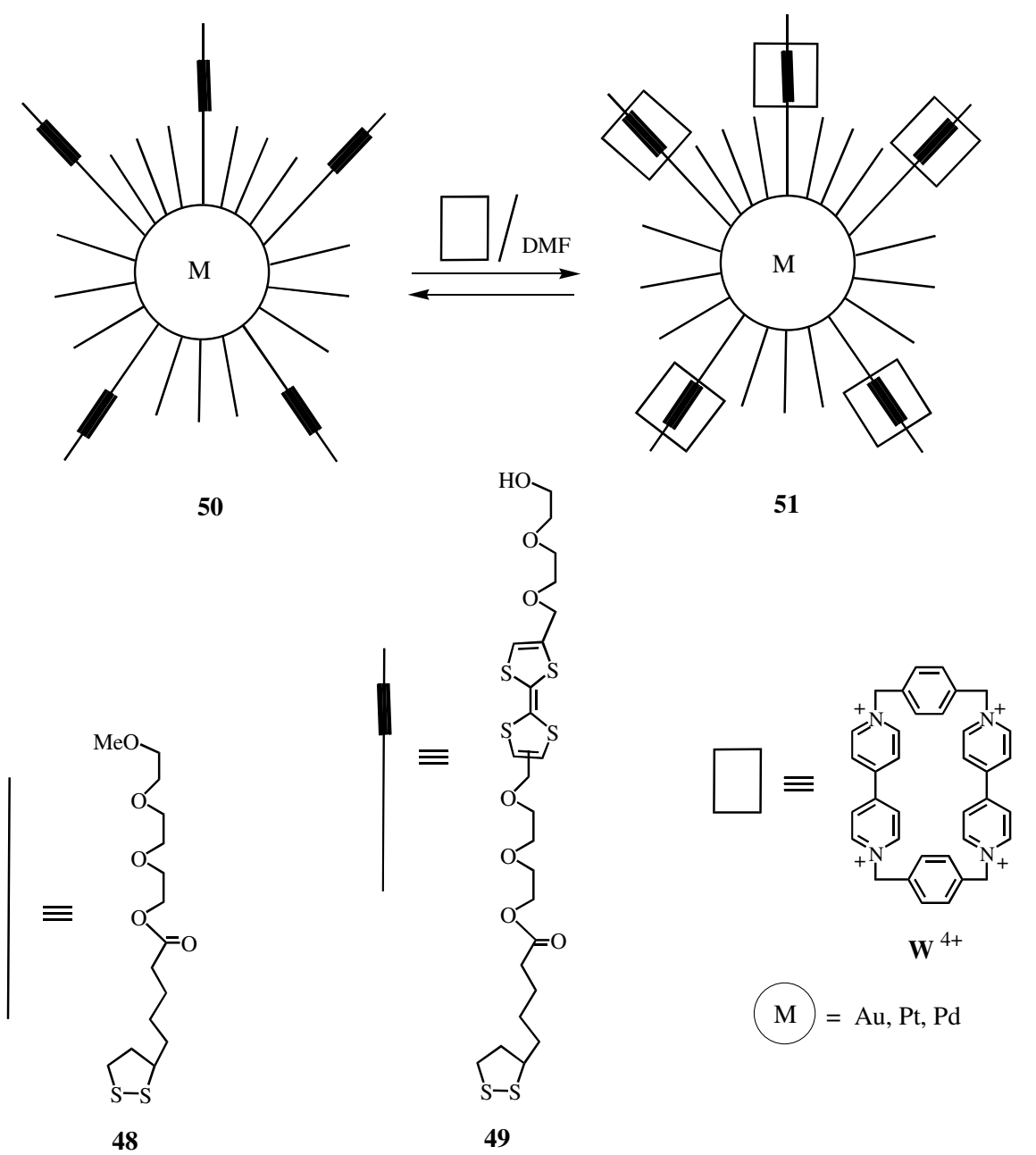

\section{Scheme 14}

\subsection{Dendrimeric rotaxanes}

In the study of liquid crystals (LC), the electrochemically switchable, bistable [2] rotaxane $\mathbf{5 2}$ has been aligned within LC phases. The synthesis of $\mathbf{5 2}$ was performed readily with the use of click 
chemistry. The bistable [2]rotaxane precursor $\mathbf{5 3}$ was mixed with $\mathbf{W}^{\mathbf{4 +}}$ in DMF at room temperature. The initially formed pseudorotaxane 53. W was treated in situ with two molecules of the half-dumbbell dendritic mesogen 54, catalytic amount of $\mathrm{CuSO}_{4} \cdot 5 \mathrm{H}_{2} \mathrm{O}$ and ascorbic acid as a reductant to give rotaxane $\mathbf{5 2}$. Rotaxane $\mathbf{5 2}$ bears two dendritic mesogenic stoppers $\mathbf{5 4}$ and exhibits a smectic phase over a wide temperature range, from room temperature to $150{ }^{\circ} \mathrm{C} .{ }^{42}$

In rotaxane 52 the ring $\mathbf{W}$ resides in the ground state at the TTF station as it is more electron rich than the DNP station. The reversible oxidation of TTF, first to the radical cation $\mathrm{TTF}^{\circ+}$ and then to dication $\mathrm{TTF}^{2+}$ causes the Coulombic repulsion between $\mathrm{TTF}^{2+}$ and ring $\mathbf{W}^{4+}$, resulting in its movement to the DNP station. The reduction of the positive charges of $\mathrm{TTF}^{\circ+} / \mathrm{TTF}^{2+}$ units recovers the starting state when $\mathbf{W}$ encircles the TTF station. It was established that the switching process is universal, it occurs in the solution phase, in polymer matrices and in SAMs. (Scheme 15). 


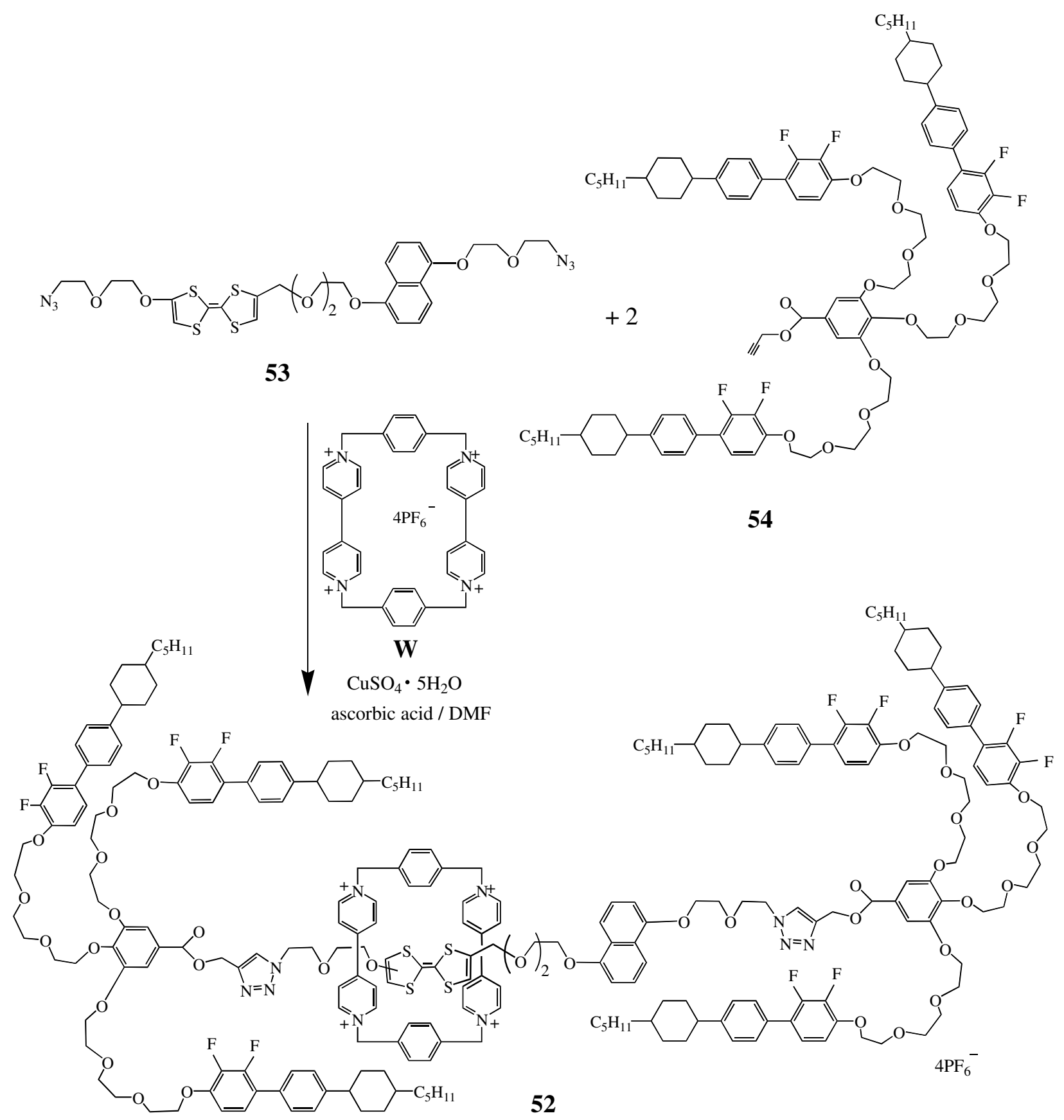

\section{Scheme 15}

An example of use of sequential click reactions is the synthesis of the tripodal [4] rotaxane $\mathbf{5 5}$ which was obtained by one-pot procedure employing multiple click reactions and stepwise stoppering of formed pseudorotaxanes. ${ }^{43}$ The sequential reactions were controlled by silylprotection and $\mathrm{Ag}(\mathrm{I})$ catalyzed deprotection of a terminal alkyne. 


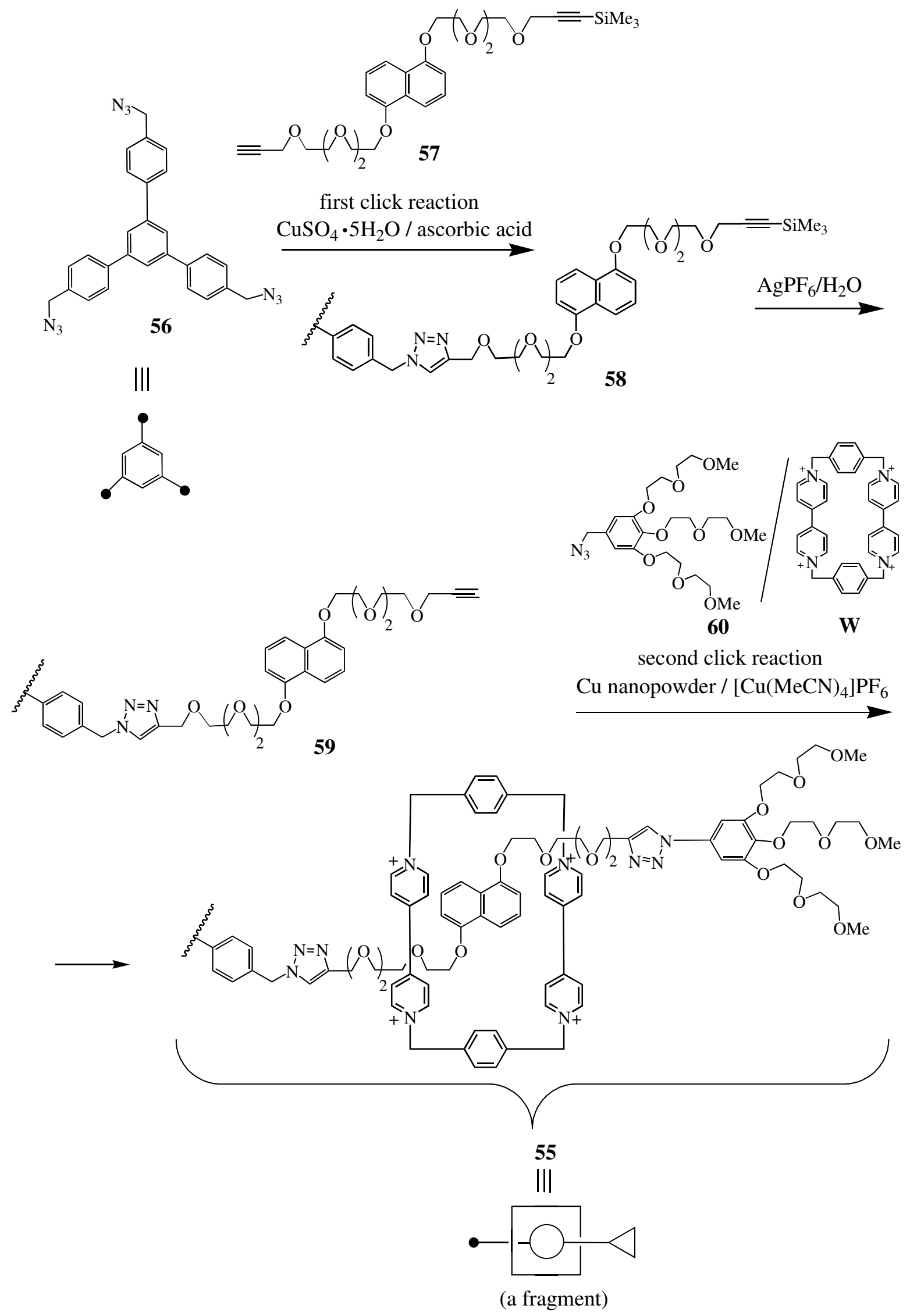




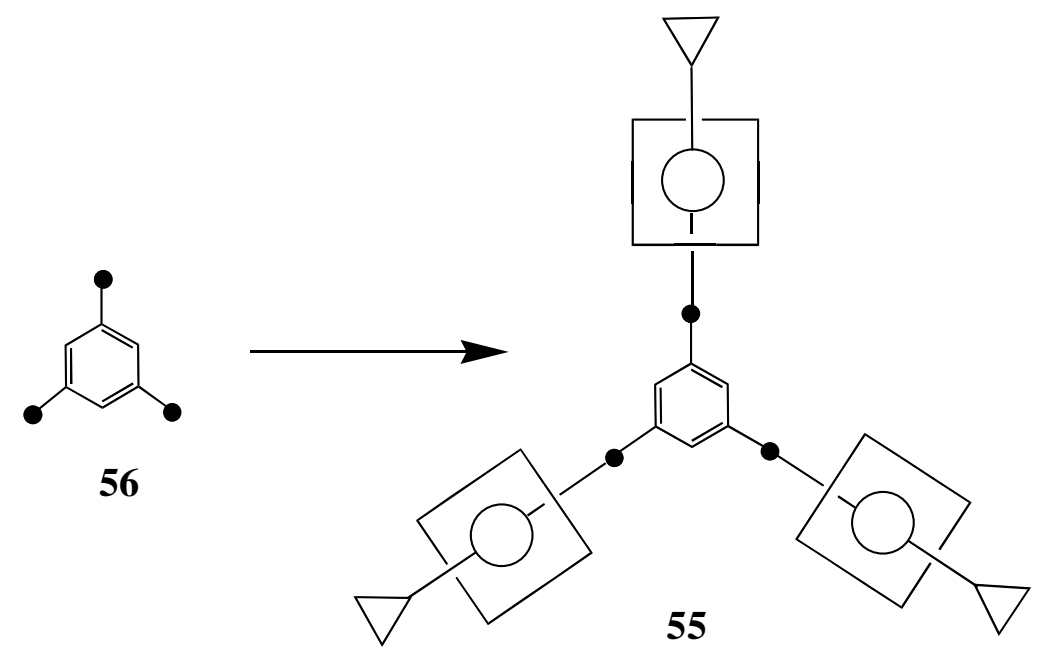

\section{Scheme 16}

The treatment of trifunctional azide $\mathbf{5 6}$ with DNP derivative 57 proceeded via stepwise click reactions affording TMS-protected intermediate 58. The $\mathrm{Ag}(\mathrm{I})$-catalyzed stepwise desilylations of 58, performed by $\mathrm{AgPF}_{6}$ yielded the tris-alkyne 59, which upon treatment with azide 60 serving as a stopper, in the presence of the ring $\mathbf{W}^{4+}$ underwent the second $\mathrm{Cu}$ nanopowder $/\left[\mathrm{Cu}(\mathrm{MeCN})_{4}\right] \mathrm{PF}_{6}$-promoted click reaction to give [4]rotaxane 55. It should be pointed out that [4]rotaxane $\mathbf{5 5}$ was prepared readily and efficiently, and the above procedure involving sequential click reactions is promising for the design of molecular machines. (Scheme 16).

\section{Rotaxanes with a Barrier Increasing the Lifetime of their Metastable State}

Molecular switches and devices based on rotaxanes are today a widely investigated topic. In the search for electronic devices, ${ }^{44-46}$ the bistable [2] rotaxanes ${ }^{47}$ containing TTF and DNP units as electron rich recognition sites in their threads ${ }^{48}$ and tetracationic cyclophane $\mathbf{W}$ as an electron deficient ring ${ }^{49}$ have been investigated. The rotaxanes are localized inside molecular switch tunnel junction (MSTJ) devices in extended cross-bar networks.

However, a drawback of these MSTJ devices is their short lifetime resulting from quick relaxation from the metastable state co-conformation (MSCC) to the ground state coconformation (GSCC), while for the ability of these MSTJ devices to store information as nonvolatile memory, it is necessary to generate a long-lived MSCC of the [2]rotaxanes.

It was observed that in bistable [2] rotaxanes containing both TTF and DNP stations in the thread, with $\mathbf{W}$ encircling the TTF unit in the ground state, the barriers for their relaxation from metastable to ground states may be raised electrostatically ${ }^{50}$ or sterically ${ }^{51}$ by introducing a 
"speed bump" between two recognition sites. Below the electrostatic barriers in rotaxanes and pseudorotaxanes will be described. As electrostatic barriers the BIPY ${ }^{2+}$ units were used; they create an electrostatic repulsion with $\mathbf{W}^{50}$ (BIPY ${ }^{2+}$ denotes 4,4'-bipyridinium).

The degenerate rotaxane $\mathbf{6 1}$ was synthesized from azide 62, alkyne $\mathbf{6 3}$ and $\mathbf{W}$ by click reaction, followed by ion exchange $\mathrm{PF}_{6}{ }^{-} \rightarrow \mathrm{Cl}^{-} .{ }^{52}$ The dynamic ${ }^{1} \mathrm{H}$ NMR spectroscopy was used to probe the rate of shuttling of $\mathbf{W}$ between two DNP units in the [2]rotaxane $\mathbf{6 1}$ in aqueous medium. It was established that BIPY ${ }^{2+}$ unit acts as a efficient electrostatic "speed bump" for the shuttling of $\mathbf{W}$, since the presence of $\mathrm{BIPY}^{2+}$ causes the self-folding of the dumbbell.

Based on this observation, the threads $64 \cdot 4 \mathrm{Cl}$ and $65 \cdot 2 \mathrm{Cl}$ for the synthesis of two pseudorotaxanes were investigated:

a) the thread $\mathbf{6 4} \cdot 4 \mathrm{Cl}$ containing central DNP unit and two terminal $\mathrm{BIPY}^{2+}$ units

b) the thread $65 \cdot 2 \mathrm{Cl}$ containing $\mathrm{BIPY}^{2+}$ unit and two terminal DNP units

c) moreover, the model thread 66 was considered.

In the threads 64 and 65 the long and flexible oligoethylene glycol chains enable the intramolecular donor-acceptor interactions between electron-rich DNP and electron-deficient $\mathrm{BIPY}^{2+}$, which result in the spontaneous self-folding of these threads in aqueous solution.

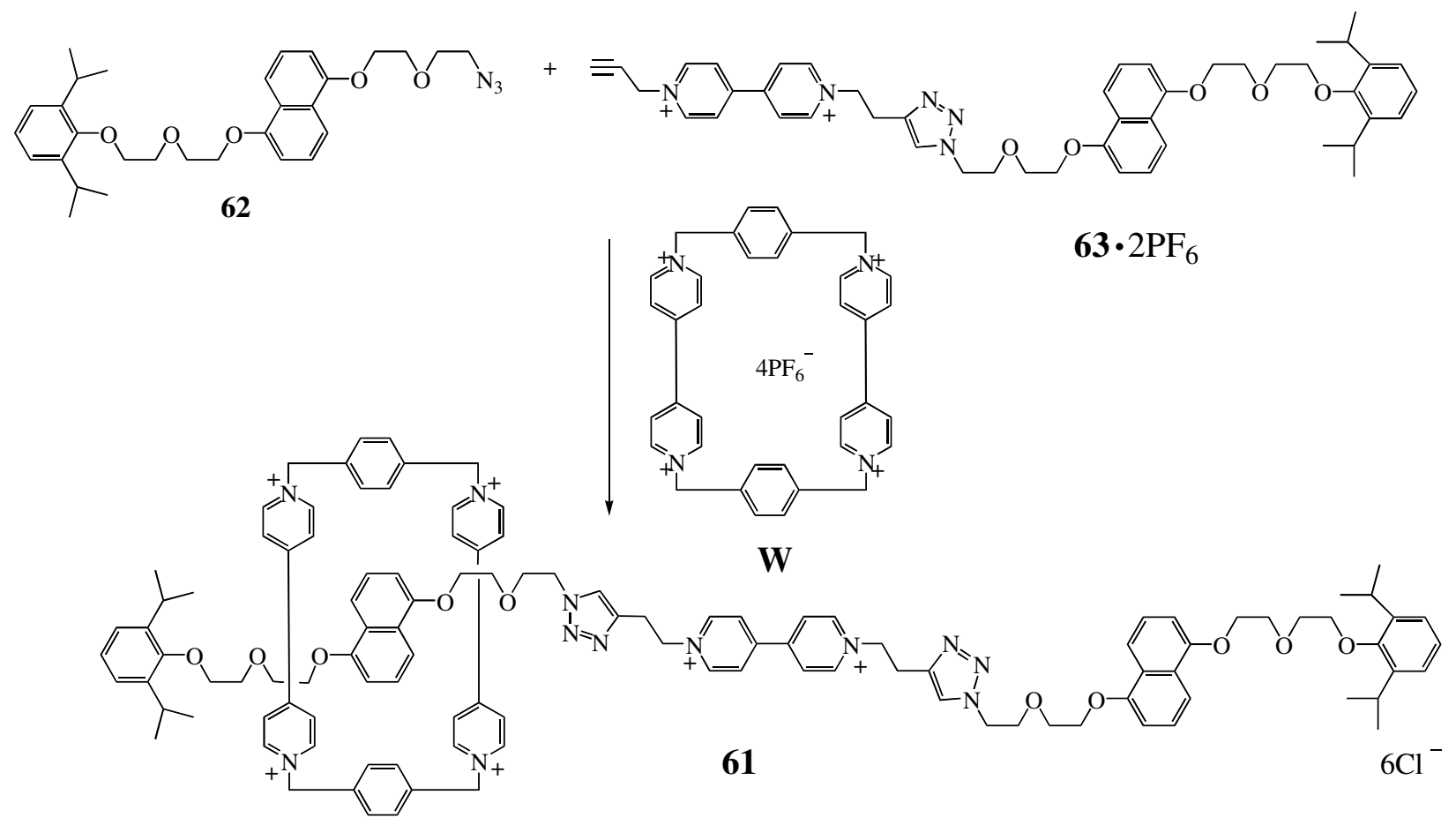




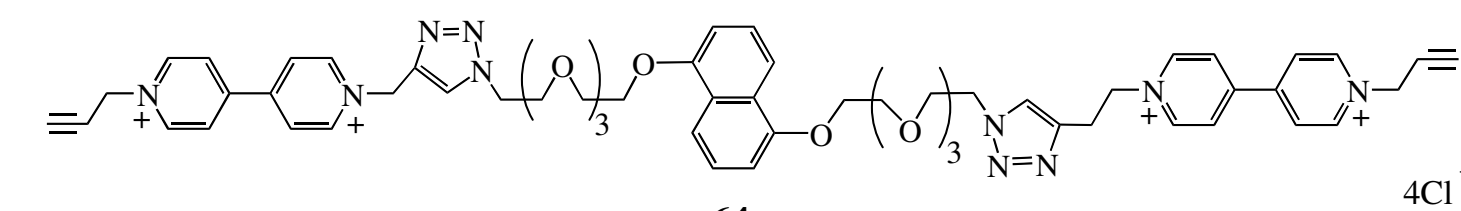

64

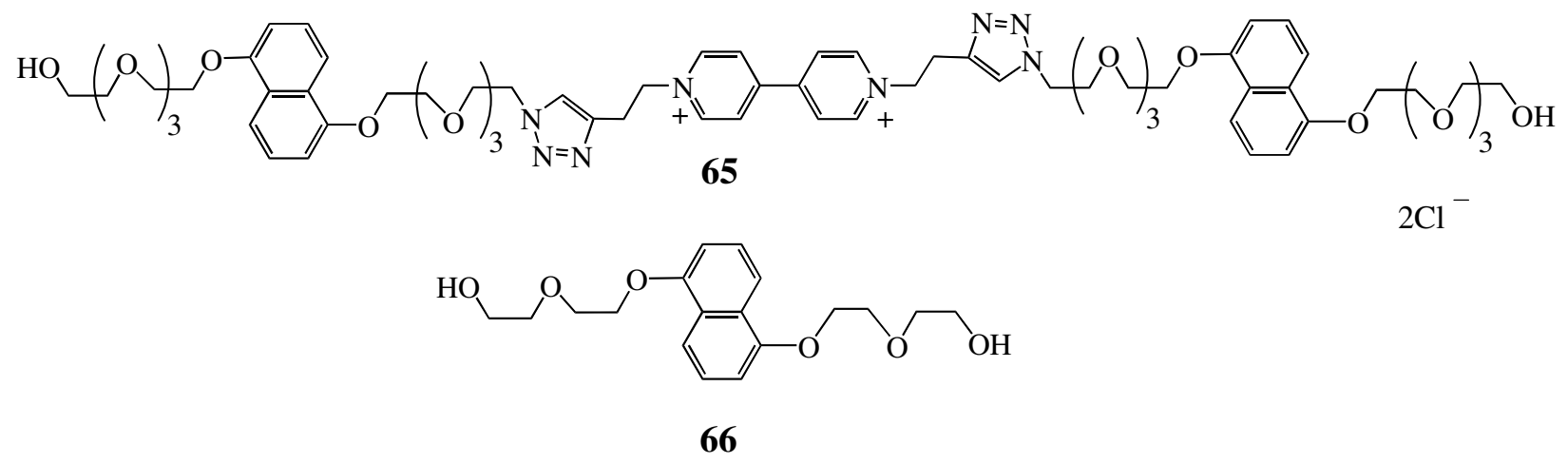

\section{Scheme 17}

a) For $64^{4+}$ the formation of [2]pseudorotaxane $\mathbf{6 4} \cdot \mathbf{W}$ is very slow; the equilibrium is attained after more than one week. The formation of the [2]pseudorotaxane $64 \cdot \mathbf{W}$ proceeds very slowly due to the strong electrostatic repulsion between the BIPY ${ }^{2+}$ termini and the ring $\mathbf{W}^{4+}$ and due to the self-folded structure of $64^{4+}$.

b) For $\mathbf{6 5}^{2+}$, containing two terminal DNP units, two pseudorotaxanes were formed, namely [2] pseudorotaxane $65 \cdot \mathbf{W}$ and [3] pseudorotaxane $\mathbf{6 5} \cdot \mathbf{W}_{\mathbf{2}}$. In contrast to 64 , the formation of pseudorotaxanes $\mathbf{6 5} \cdot \mathbf{W}$ and $\mathbf{6 5} \cdot \mathbf{W}_{\mathbf{2}}$ proceeds much faster, only in few seconds.

For the thread 65, the threading of the first molecule $\mathbf{W}$ results in the formation of the [2]pseudorotaxane $\mathbf{6 5} \cdot \mathbf{W}$. The binding of the second molecule $\mathbf{W}$ is more difficult than the binding of the first $\mathbf{W}$ due to increased intramolecular interactions between central BIPY ${ }^{2+}$ and the remaining DNP unit; the self-folding of this unoccupied DNP unit with the central BIPY $^{2+}$ was observed.

c) For the model thread 66, i.e. in the absence of electrostatic and steric hindrances, the formation of the [2]pseudorotaxane $\mathbf{6 6} \cdot \mathbf{W}$ proceeds rapidly.

The above study of two threads 64 and $\mathbf{6 5}$ has shown that the incorporation of BIPY ${ }^{2+}$ units into [2] pseudorotaxanes $\mathbf{6 4} \cdot \mathbf{W}$ and $\mathbf{6 5} \cdot \mathbf{W}$ acts as an electrostatic barrier for shuttling of $\mathbf{W}$. It was established that the binding of $W$ with threads 64 and 65 in aqueous solution is governed by a combination of electrostatics and self-folding of the threads. One should point out that the use of electrostatic barriers in water is promising for the increase of the lifetime of the metastable state in donor-acceptor bistable rotaxanes, this property being of a great importance for their possible applications in molecular electronic devices. (Scheme 17). 
Degenerate [2] rotaxanes generally show equilibrium dynamics with low free energies of activation $\left(\Delta \mathrm{G}^{\ddagger}\right)$ for the shuttling process. This $\Delta \mathrm{G}^{\neq}$value can be strongly increased by inserting electrostatic or steric barriers into the chains linking the two identical binding sites.

It was investigated how light as well as the thermal energy may be used to raise and lower at will the free energy barrier, and in this way to create a STOP and GO sequence during the shuttling process. For construction of a light-gated STOP-GO molecular shuttle the degenerate rotaxanes 67 and 68, containing the azobenzene unit 69 or 70 have been investigated. ${ }^{51}$ In order to decrease binding of azobenzene unit with the ring W sterically (in 69) or electronically (in 70), in 69 the four methyl groups, and in $\mathbf{7 0}$ the four fluorine atoms were introduced into azobenzene unit, respectively.

For the synthesis of rotaxanes 67 and 68 the dialkyne azobenzene derivatives 69 and 70 were submitted to click reaction with two azide half-dumbbell $\mathbf{7 1}$ molecules containing DNP units and 2,6-diisopropylphenyl stoppers; this reaction afforded degenerate [2]rotaxanes trans-68 and trans-69, respectively. (Scheme 18)

The photoisomerization of [2]rotaxanes trans-67 and trans-68 has been performed: the irradiation of trans-67 and trans-68 with UV light afforded cis-isomers, which could be isomerized back to trans-67 and trans $\mathbf{- 6 8}$ by irradiation with visible light.

In the case of trans-67, the ${ }^{1} \mathrm{H}$ NMR results at $238-350 \mathrm{~K}$ have shown that the ring $\mathbf{W}$ resides exclusively on one of the two degenerate DNP units, i.e. shuttling does not occur even at $350 \mathrm{~K}$.

However, in the case of trans-68 upon irradiation with UV light, in ${ }^{1} \mathrm{H}$ NMR spectrum recorded at $309 \mathrm{~K}$ the strong changes were observed. In the formed cis-68 the ring $\mathbf{W}$ resides only on one of the two DNP units, (i.e. the azobenzene gate in its cis configuration sterically stops the shuttling of the ring $\mathbf{W}$ ) but irradiation of cis-68 with visible light restores trans-68 with shuttling of $\mathbf{W}$ at $309 \mathrm{~K}$. By alternating UV and Vis light to gate $\mathbf{6 8}$ between its trans and cis isomers, the shuttling of $\mathbf{W}$ shows a STOP-GO-STOP-GO sequence; it means that a light-gated STOP-GO molecular shuttle was built. (Scheme 19)

It is worth noting that the isomerization of cis-68 back to trans $\mathbf{6 8}$ may be also achieved by heating cis-68 at $350 \mathrm{~K}$. One should point out that an alternating process of UV light and heat can also be repeated, as was confirmed by the sequence trans-68 $\stackrel{U V}{\longrightarrow}$ cis $\stackrel{\Delta}{\longrightarrow}$ trans $\stackrel{U V}{\longrightarrow}$ cis $\stackrel{\Delta}{\longrightarrow}$ trans observed in ${ }^{1} \mathrm{H}$ NMR spectrum. 

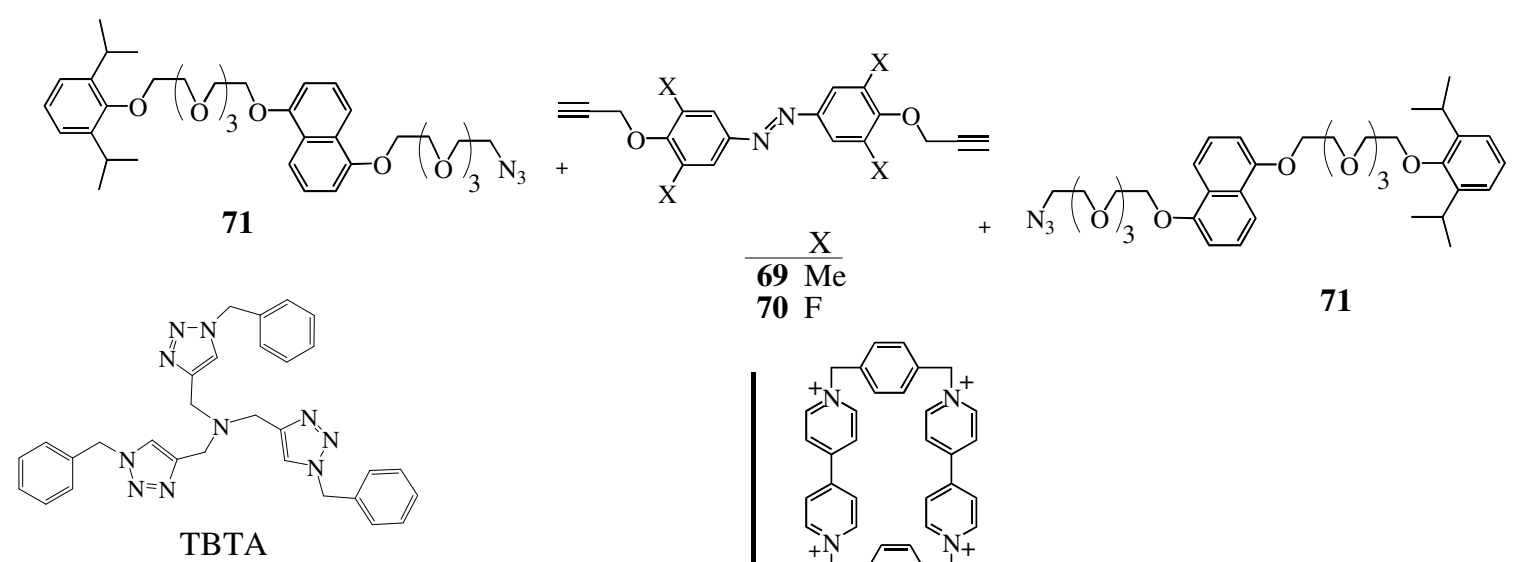

$70 \mathrm{~F}$

71
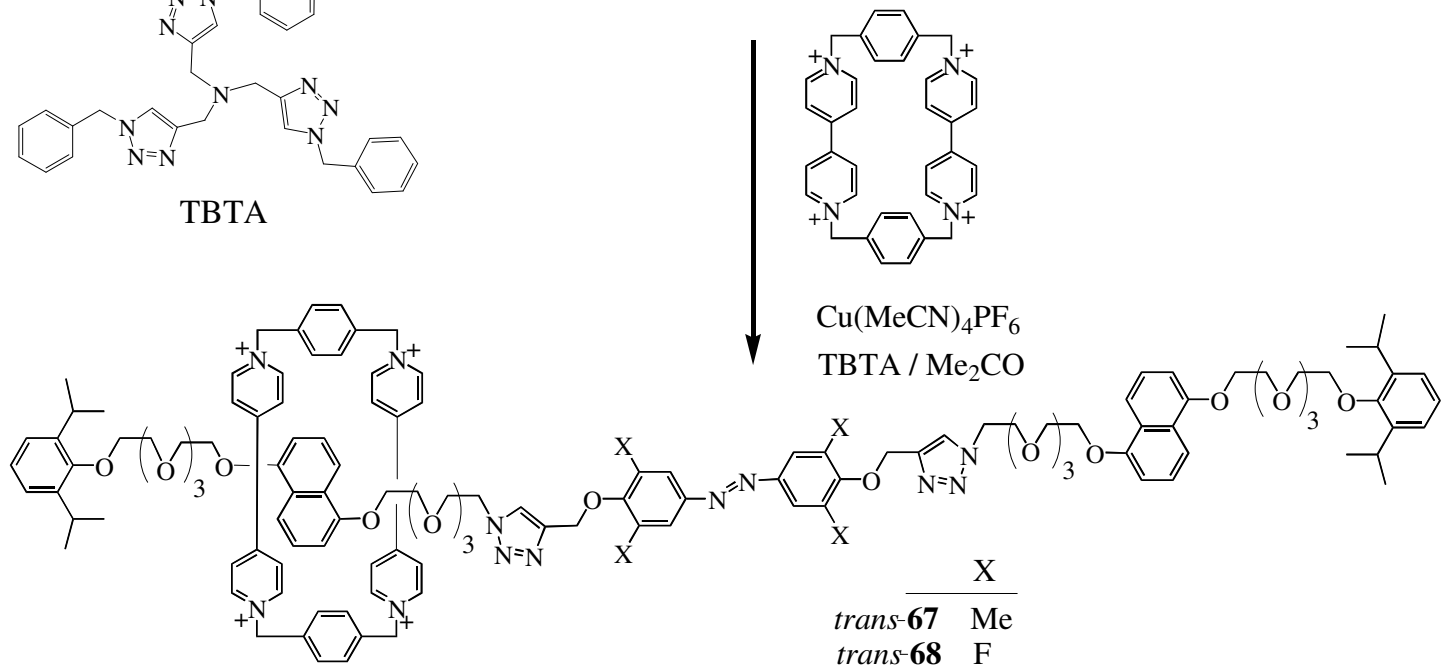

\section{Scheme 18}

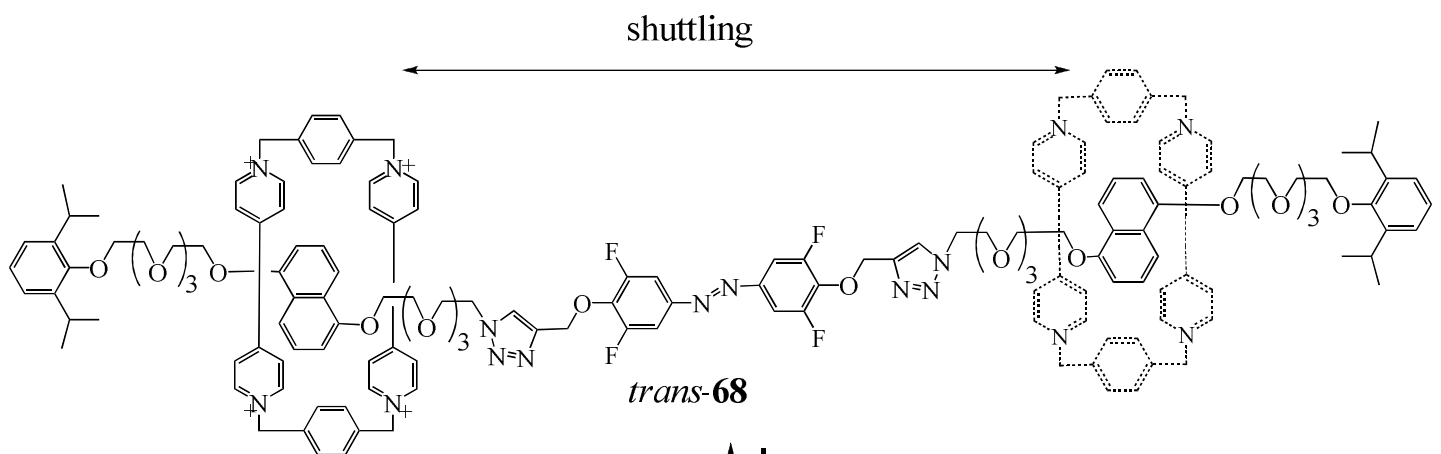

Vis $/ \triangle \uparrow$
(GO) $\downarrow \begin{aligned} & \text { UV } \\ & \text { (STOP) }\end{aligned}$

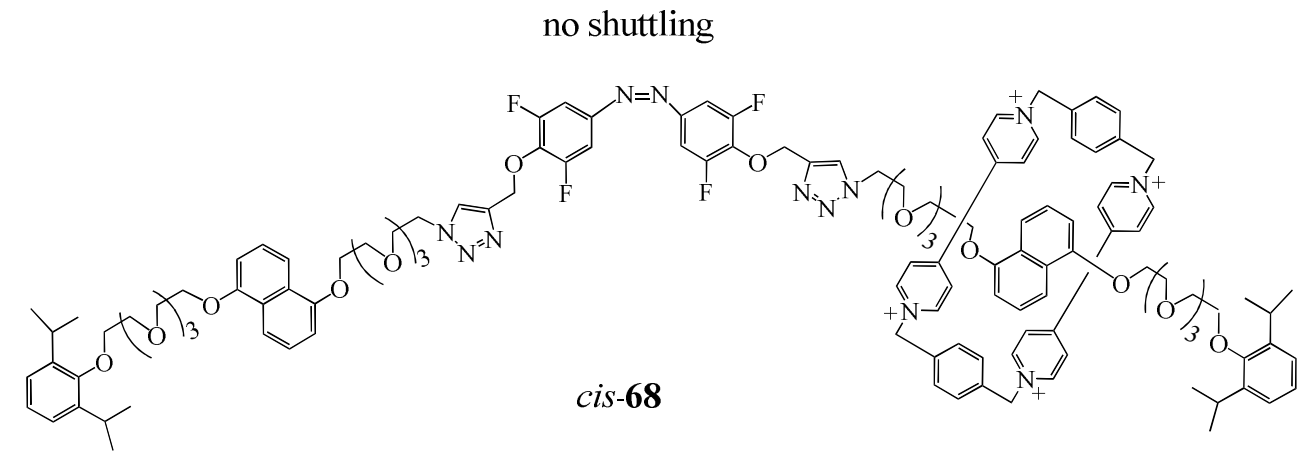

\section{Scheme 19}


It is known that deformable foldamer spacers may serve as steric barriers for generation of long-lived MSCC of rotaxanes; they provide an additional stability to MSCC. One should emphasize a great importance of long-lived MSCC of rotaxanes in the design of nonvolatile molecular memories, therefore the development of novel strategies for the control of the interconversion between GSCC and MSCC is necessary. It has been reported that hydrogenbonding-mediated arylamide foldamers can be used for an effective tuning of this interconversion. ${ }^{53,54}$

Foldamers are synthetic oligomers with folded structures stabilized by intramolecular noncovalent forces. ${ }^{55-58}$ The apparent sizes of folded states are larger than those of extended states. If the apparent diameter of the extended state of a foldamer is smaller than the internal diameter of the ring, the ring would slip over the extended state. The folding and unfolding processes are reversible.

The lengths of foldamers can readily be modified by simply changing the number of their repeating units, and therefore foldamer segments may serve as spacers for regulation of the behavior of rotaxanes and pseudorotaxanes. The changes in the foldamer size occurring on folding and unfolding serve to modulate the mechanical movement of $\mathbf{W}^{4+}$ along the thread. By varying the number of the repeating units of the foldamer, in pseudo[2]rotaxanes the kinetics of the solvent-dependent slippage/deslippage, and in [2] rotaxanes the switching of $\mathbf{W}^{4+}$ between TTF and DNP can be tuned in solvents of different polarity.

For the study the 3-amino-2-methoxybenzoic acid-derived foldamers were chosen, since they survive a range of solvents, and their five repeating units form one turn. ${ }^{59-61}$ The presence of a large Fréchet-type G-3 dendron (see Scheme 20) ensures for foldamers solubility in polar and less polar solvents.

In the experiments rotaxanes $\mathbf{7 2 a}, \mathbf{b}$ and rotaxanes $\mathbf{7 3 a}, \mathbf{b}$ were synthesized. ${ }^{62,63}$ In rotaxanes 73a,b the foldamer-tuned switching of $\mathbf{W}$ between TTF and DNP stations was investigated. The TTF unit is more electron-rich than DNP, therefore the equilibrium is shifted toward $\mathbf{W}$ encircling the TTF station to form GSCC, and not toward $\mathbf{W}$ encircling DNP station to form the less stable MSCC. Oxidation of TTF unit to $\mathrm{TTF}^{+}$or $\mathrm{TTF}^{2+}$ results in the repelling of $\mathbf{W}^{4+}$ from $\mathrm{TTF}^{\circ+}$ or $\mathrm{TTF}^{2+}$ over the foldamer segment to encircle the DNP unit, and to form the MSCC. The subsequent reduction of $\mathrm{TTF}^{\circ+}$ or $\mathrm{TTF}^{2+}$ to TTF results in the return of $\mathbf{W}$ to the TTF unit and formation of GSCC. This last process is directly related to the lifetime of the MSCC and is crucial for the working of the device. It was found that the foldamer segment blocks the conversion of the MSCC to the GSCC, and as a result the MSCC lifetime of rotaxanes increases; this fact is important in the design of nonvolatile molecular memories. 


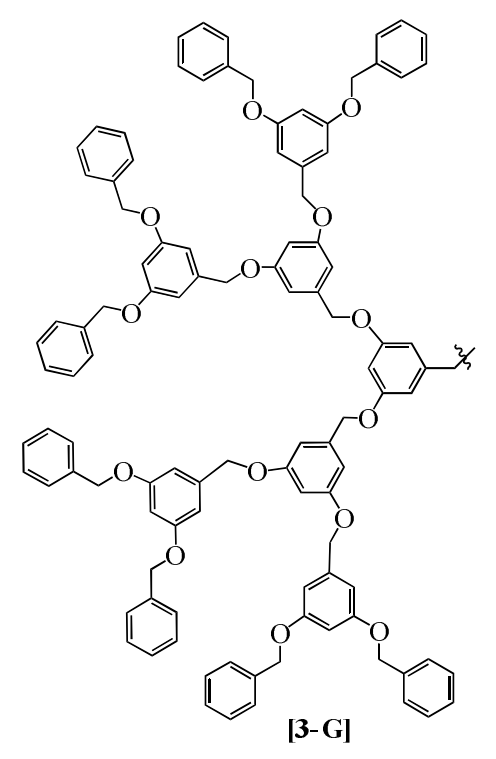

The Fréchet 3-G dendron
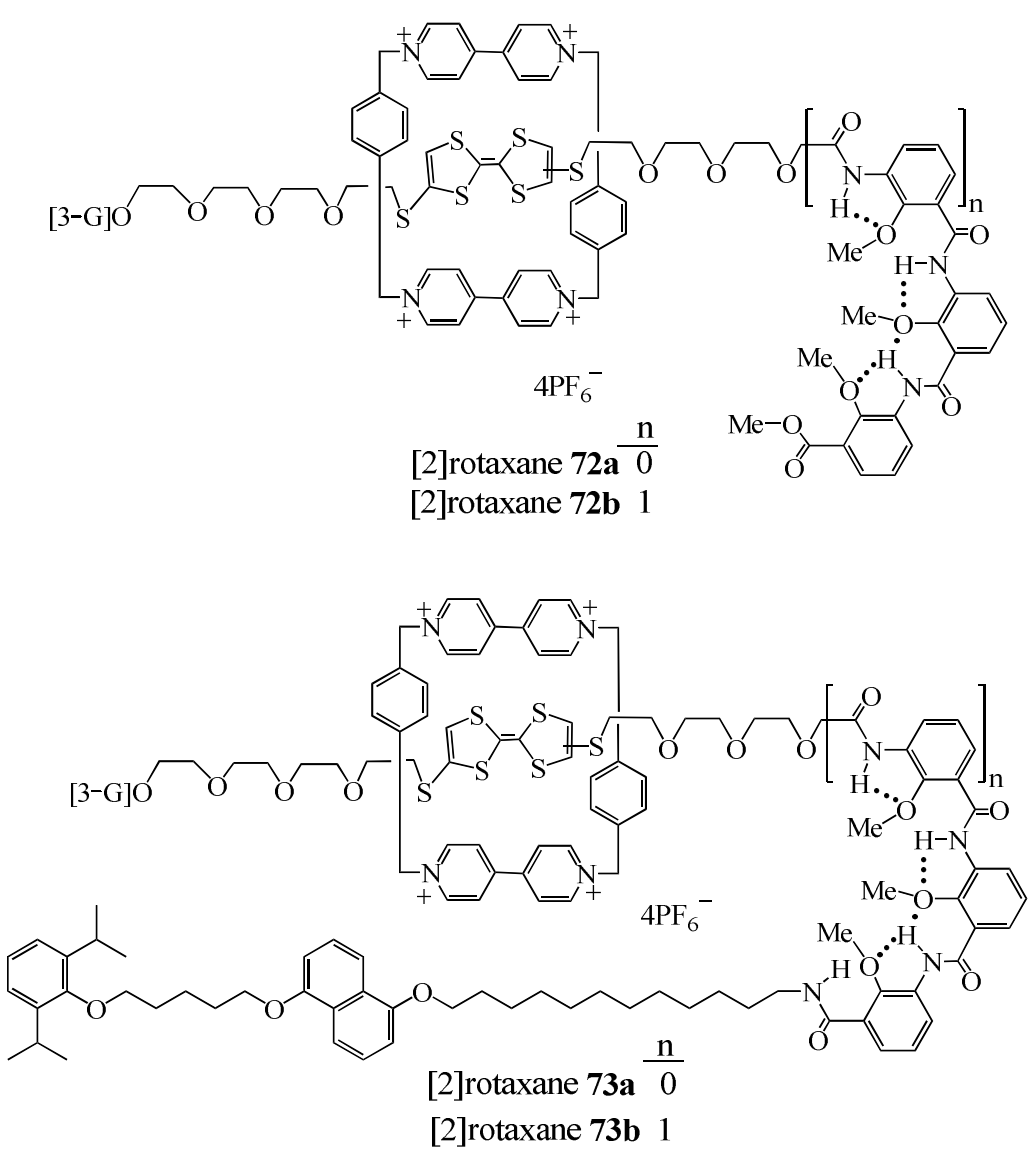

\section{Scheme 20}

Both rotaxanes 73a,b are soluble in organic solvents of low and of high polarity Therefore by changing the length of the foldamer segments and changing the polarity of medium it is possible to control the lifetime of the MSCC of rotaxanes.

The experimental results show that the above arylamide foldamers may serve as a new, deformable moiety in rotaxanes and pseudorotaxanes to modulate their switching kinetics and MSCC lifetime. The foldamers are flexible due to the noncovalent nature of the folding conformation, therefore they are able to modulate the mechanical movements of the ring $\mathbf{W}$ along the thread.

In bistable [2]rotaxanes in which foldamer segments were introduced to bridge the TTF and DNP units, the deformable sizes of foldamers serve as a steric barrier to the relaxation from MSCC to GSCC, therefore the lifetime of the of MSCC strongly increases from minutes to days. One should point out that the generation of the long-lived MSCC in [2]rotaxanes is of a great importance for their application in nonvolatile molecular memories. 


\section{The Secondary Structures of Rotaxanes}

It is known that noncovalent binding interactions play an important role in nature, namely in biopolymers such as proteins and nucleic acids, which may be considered as biomolecular machines. The control of these interactions in synthetic systems is important for the design of new, tailor-made polymers; here the better understanding of folding, i.e. secondary structure of biopolymers would be very useful. The knowledge of ordered structures of rotaxanes may help to understand the nature of primary, secondary and tertiary structures of proteins.

With this in view, the five donor-acceptor oligorotaxanes consisting of DNP units and the ring $\mathbf{W}$ have been synthesized in order to investigate their secondary structures and conformations. ${ }^{64}$ First the model rotaxane A (containing one DNP unit) has been obtained, and then rotaxanes $\mathrm{B}, \mathrm{C}, \mathrm{D}$ (each containing three DNP units) and $\mathrm{E}, \mathrm{F}$ (each containing five DNP units) were synthesized. All rotaxanes A-E are stoppered by 2,6-diisopropylphenoxy groups, linked with the thread by triazole rings.

\section{The synthesis of the model [2]rotaxane A}

The diol 74 was converted into ditosylate 75 which upon treatment with $\mathrm{NaN}_{3}$ yielded the diazide 76. The click reaction with the propargyl derivative 77, i.e. precursor of a stopper, performed in the presence of $\mathbf{W}$ afforded model [2] rotaxane A. (Scheme 21)
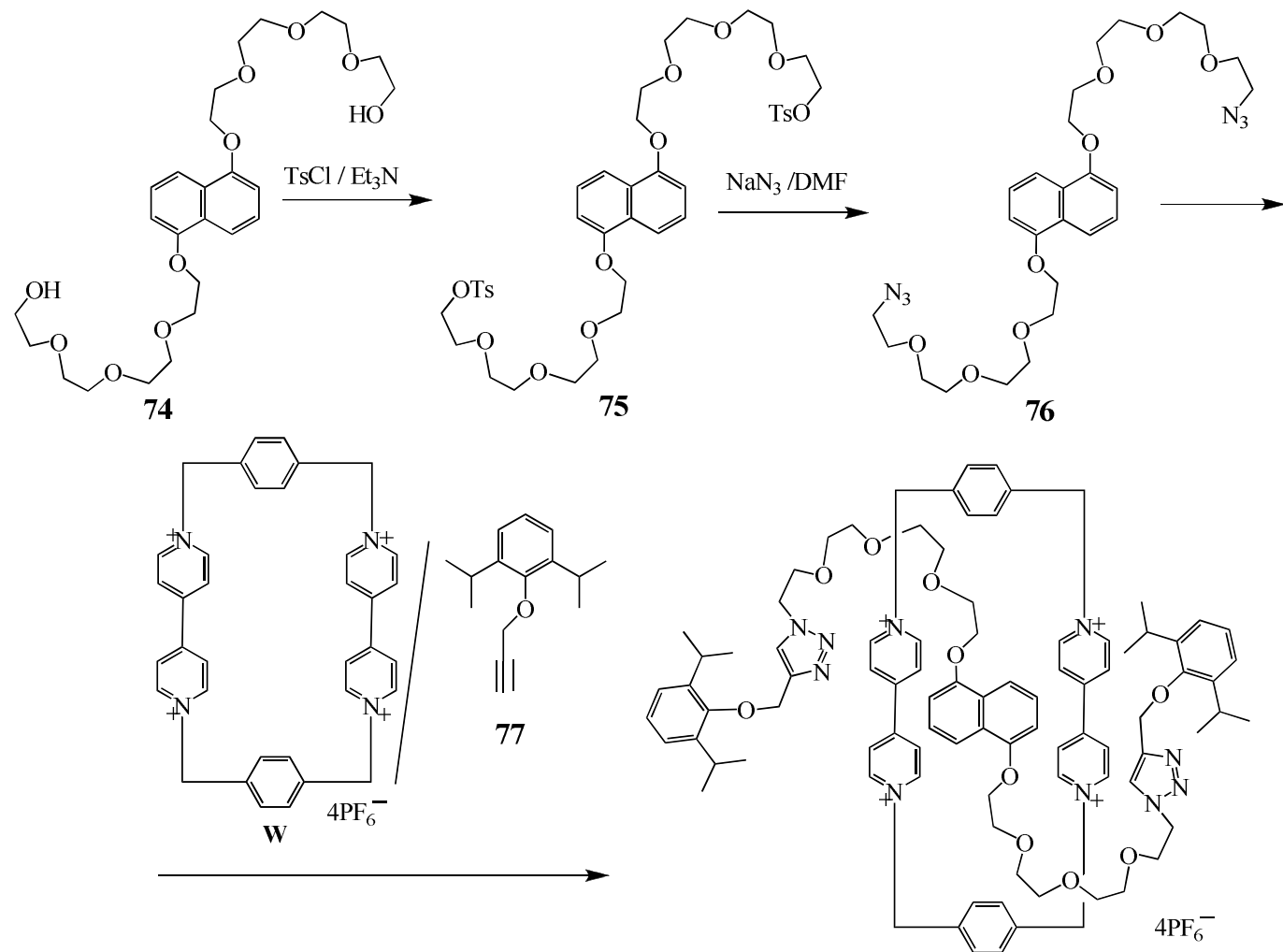

A

\section{Scheme 21}




\section{The synthesis of [2]rotaxane B, [3]rotaxane $C$ and [4]rotaxane D}

The diol $\mathbf{7 4}$ upon monotosylation afforded $\mathbf{7 8}$ which reacted with 1,5-dihydroxynaphthalene (DNP) yielding the diol 79. The subsequent tosylation of two hydroxyl groups of $\mathbf{7 9}$ leading to 80, and its reaction with $\mathrm{NaN}_{3}$ afforded the diazide 81 which upon treatment with the propargyl derivative $\mathbf{7 7}$ in the presence of $\mathbf{W}$ gave rotaxanes B, C and D. (Scheme 22)

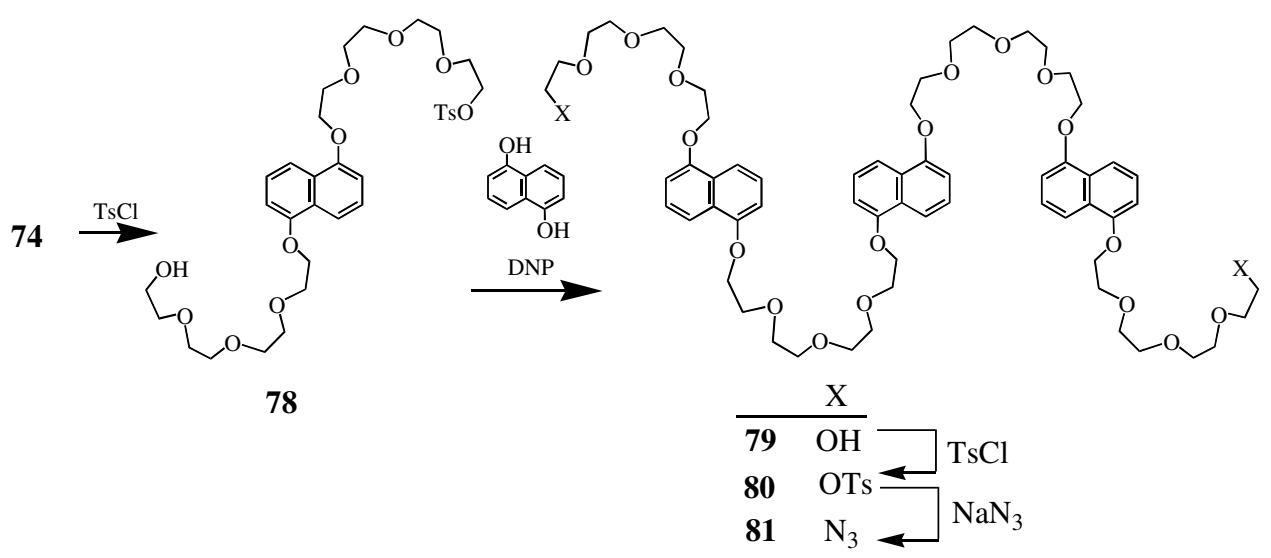




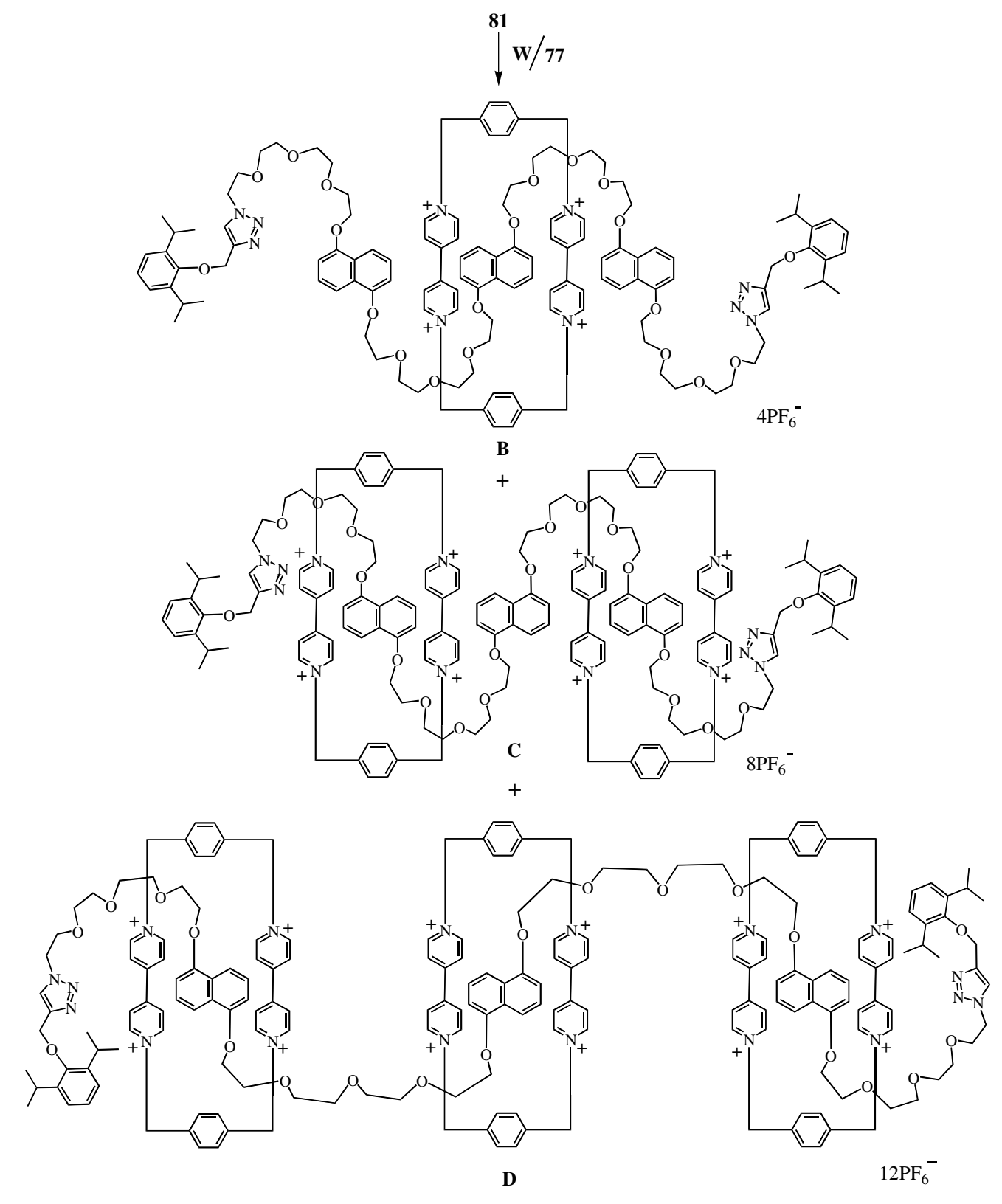

\section{Scheme 22}

The synthesis of [3] rotaxane $E$ and [4]rotaxane $F$

The reaction of ditosylate 80 with naphthol 82 yielded diol 83, which upon tosylation gave ditosylate 84, converted with $\mathrm{NaN}_{3}$ into diazide $\mathbf{8 5}$. The click reaction of $\mathbf{8 5}$ with the propargyl derivative $\mathbf{7 7}$ in the presence of $\mathbf{W}$ afforded [3] rotaxane $\mathrm{E}$ and [4]rotaxane F. (Scheme 23) 

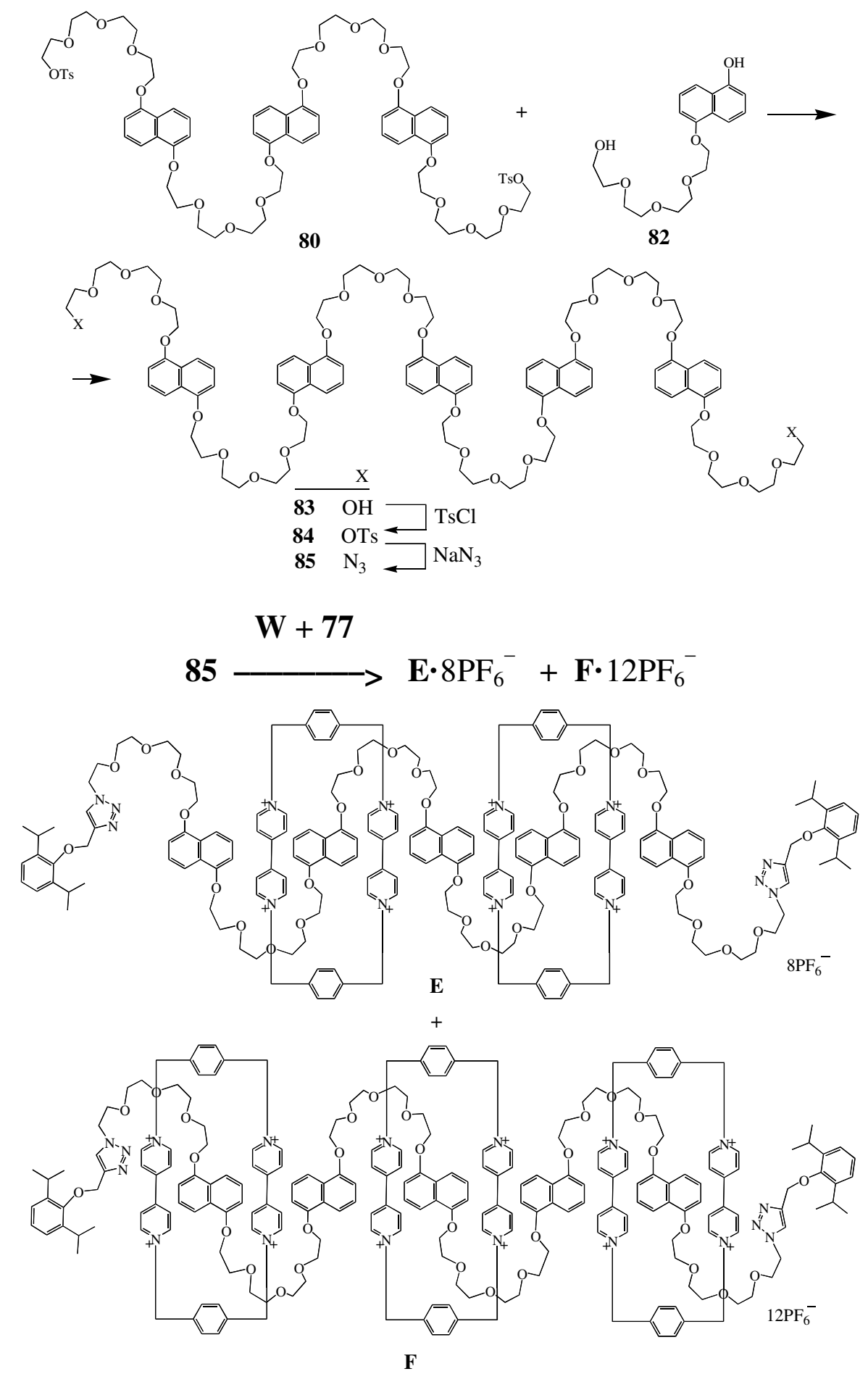

Scheme 23

It was established that rotaxanes B, C, E and F have a folded shape whereas the rotaxane D is not folded. This fact is due to the presence of 12 positive charges in $\mathrm{D}$; no $\pi$-donating systems 
are inserted between rings $\mathbf{W}$, therefore no shielding between these rings exists, and as a result the Coulombic repulsion occurs.

Quantification of the $\pi-\pi$ interactions governing tertiary structure of donor/acceptor [2]pseudorotaxanes was reported. The flexibility of pseudorotaxanes resulting from interactions between $\pi$-donor/acceptor units is responsible for formation of their folded structures, similar to tertiary structures of proteins. However the tertiary structure of pseudorotaxanes was not so efficiently studied as primary and secondary structures. The flexible poly(ethylene glycol), i.e. PEG linkers present in the majority of rotaxanes containing $\pi$-electron rich stations enable the existence of their folded tertiary structure.

In such rotaxanes the $\mathrm{C}-\mathrm{H}---\mathrm{O}$ hydrogen bonding between $\alpha$-protons of $\mathbf{W}$ and oxygen atoms of PEG linkers is present. However, in addition to these $\mathrm{C}-\mathrm{H}---\mathrm{O}$ hydrogen bonds there exist here also the CT interactions. Today for the understanding of the tertiary structures of pseudorotaxanes a quantitative account of these CT interactions is necessary. It is noteworthy that these CT interactions occur in the presence of $\pi$-donors and acceptors in nanotechnology, e.g. in molecular machines, molecular muscles or electrochromic materials.

Two foldable [2]pseudorotaxanes 86 and 87 consisting of half-dumbbells 86 and 87 and of the ring $\mathbf{W}^{4+}$ have been synthesized and investigated in order to quantify the CT interactions governing their tertiary alongside structure. ${ }^{68}$ The half-dumbbells 86 and $\mathbf{8 7}$ incorporate two different $\mathrm{TTF}$ units $\mathrm{TTF}(\mathrm{M})$ and $\mathrm{TTF}(\mathrm{B})$. In the primary structure, the left part of the halfdumbbells serves as a stopper, while the right part is the binding site.

In the secondary structure of the complex, the ring $\mathbf{W}^{4+}$ must encircle the TTF (B) unit since the combination of the central thioglycol linker with the SEt group creates a kinetic barrier, i.e. they form together a stopper. The central thioglycol linker serves to provide the flexibility necessary to allow the TTF (M) to fold back onto the $\mathbf{W}^{\mathbf{4 +}}$. In this way it can interact with $\mathbf{W}^{4+}$ in an alongside manner generating a tertiary structure.

The half-dumbbell 88, synthesized for comparison purposes, contains only TTF(B) unit, similar to the right part of $\mathbf{8 6}$ and $\mathbf{8 7}$.

When half-dumbbells 86-88 are mixed with $\mathbf{W}^{\mathbf{4 +}}$ in equimolar amounts, the corresponding pseudorotaxanes are formed; this fact is confirmed by the color change of the solution from yellow to green and the appearance of CT band in the absorption spectra. As a result, the ring $\mathbf{W}^{4+}$ encircles the thread $\mathbf{8 6}$ to give the secondary structure of pseudorotaxane $\mathbf{8 6} \cdot \mathbf{W}$; the TTF(M) unit folds back and interacts with one side of $\mathbf{W}$ to give the tertiary structure of pseudorotaxane $\mathbf{8 6} \cdot \mathbf{W}$ stabilized by $\mathrm{CT}$ interaction of $\mathrm{TTF}(\mathrm{M})$ with one side of $\mathbf{W}$ in an alongside manner.

It was established that the determined $K_{\mathrm{a}}$ values for $\mathbf{8 6} \cdot \mathbf{W}$ and $\mathbf{8 7} \cdot \mathbf{W}$ are nearly the same and are about twice as large as in the case of $\mathbf{8 8} \cdot \mathbf{W}$. This observation shows that the presence of TTF(M) which folds back affords a stabilizing effect of ca $0.5 \mathrm{kcal} \mathrm{mol}^{-1}$ in $\mathbf{8 6} \cdot \mathbf{W}$ and $\mathbf{8 7} \cdot \mathbf{W}$. This stabilization is valuable for the design of molecular machines. The molecular modeling of 86. W and $\mathbf{8 7} \cdot \mathbf{W}$ performed at the MO6-L/6-31G ${ }^{* *}$ level confirms their folded structures. 
The tertiary structure of pseudorotaxanes is stabilized by CT interaction between one side of $\mathbf{W}$ and $\operatorname{TTF}(\mathbf{M})$ which by folding of its flexible linker is situated alongside $\mathbf{W}$. It was found that at room temperature approximately $70 \%$ of pseudorotaxanes $\mathbf{8 6} \cdot \mathbf{W}$ and $\mathbf{8 7} \cdot \mathbf{W}$ exist in their folded state in acetonitrile. This qualitative estimation is of importance in the design of interlocked molecular machines and helps to understand the structures of biological molecules. (Schemes 24 and 25).
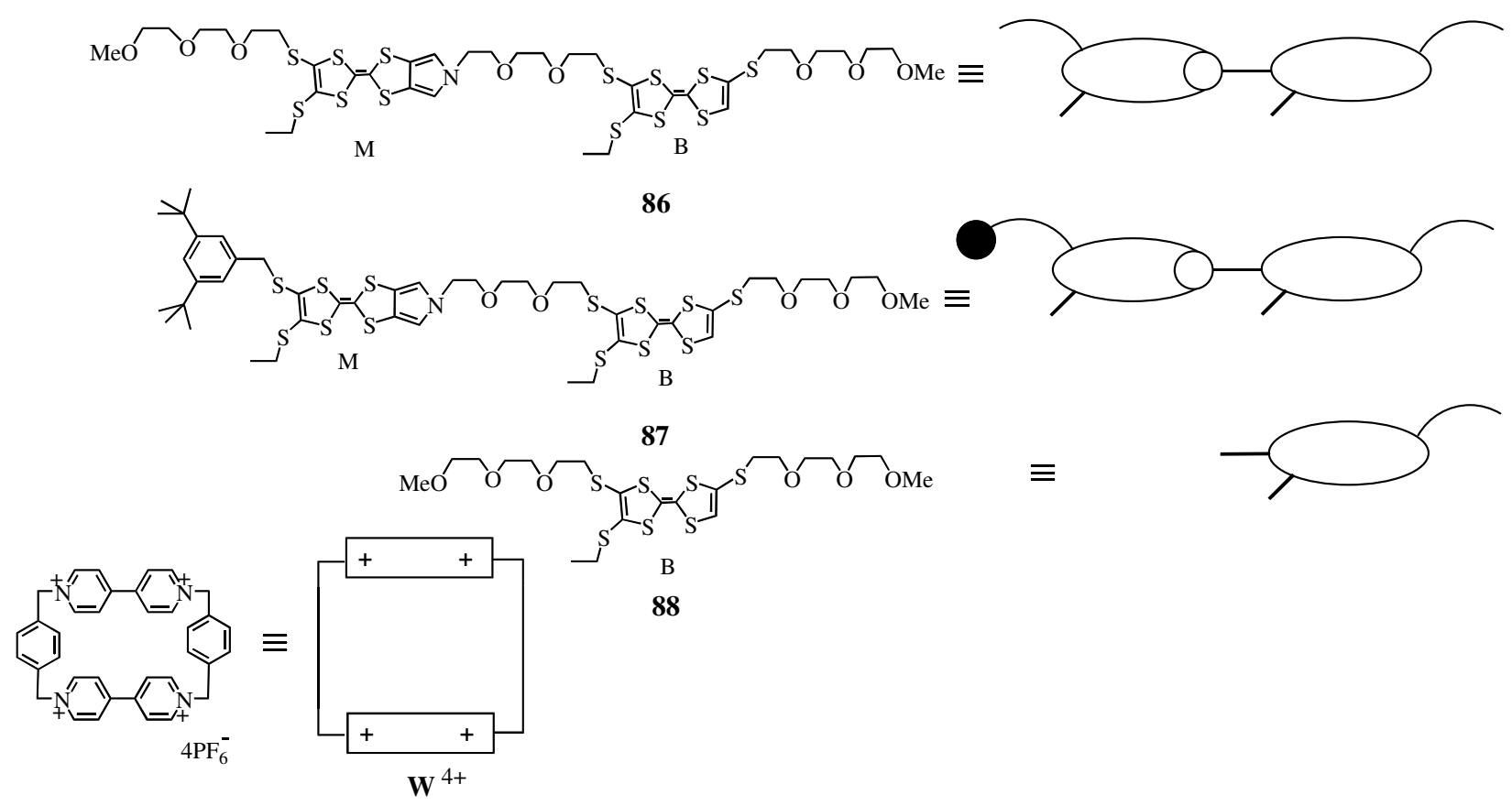

87
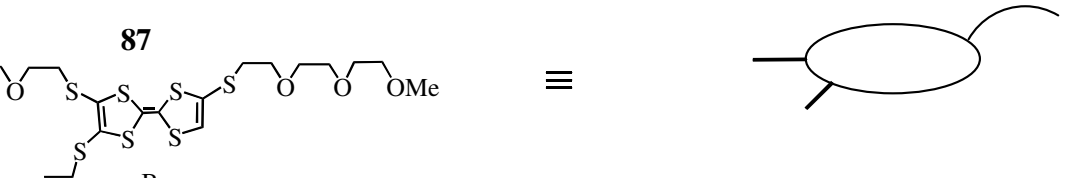

\section{Scheme 24}




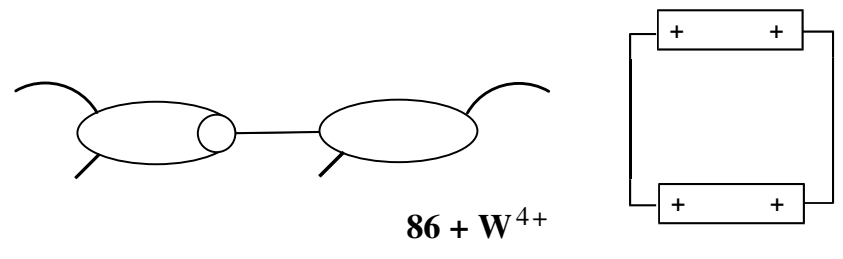

$86+\mathbf{W}^{4+}$

primary structure

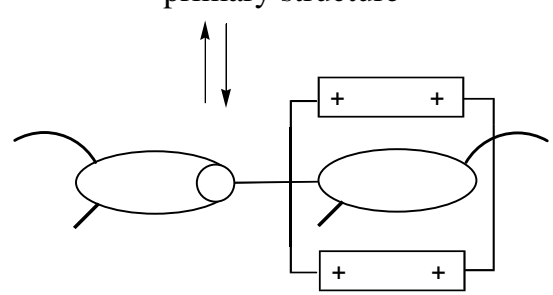

$86 \cdot \mathbf{W}^{4+}$

secondary structure

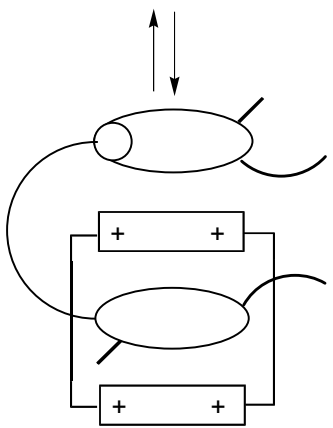

$86 \cdot \mathbf{W}^{4+}$

tertiary structure

\section{Scheme 25}

\section{Rotaxanes Containing a Modified Tetracationic Cyclophane Ring}

Below will be presented three examples of rotaxanes containing three differently modified tetracationic cyclophane rings.

\section{Example 1}

The [2] rotaxane $\mathbf{8 9}$ was investigated in view of its affinity for anions. ${ }^{69}$ This rotaxane consists of the indolocarbazole-containing dumbbell which is encircled by a tetracationic macrocycle 90 functionalized by isophthalamide group. ${ }^{70}$

Indolocarbazole is a $\pi$-electron-rich aromatic compound, requiring a ring with an electrondeficient cavity for an assembly, and as such the macrocycle 90 was used. Macrocycle 90 contains two positively charged bipyridinium units and an isophthalamide hydrogen-bond-donor group.

It is known that indole-containing receptors strongly bind anions. ${ }^{71,72}$ The indolo[2,3-a]carbazoles bind anions by their two hydrogen bond-donating pyrrole units. ${ }^{73}$ Due to their rodlike 
shape, indolo[2,3-a]carbazoles may serve as building blocks for the design of interlocked systems. $^{74}$

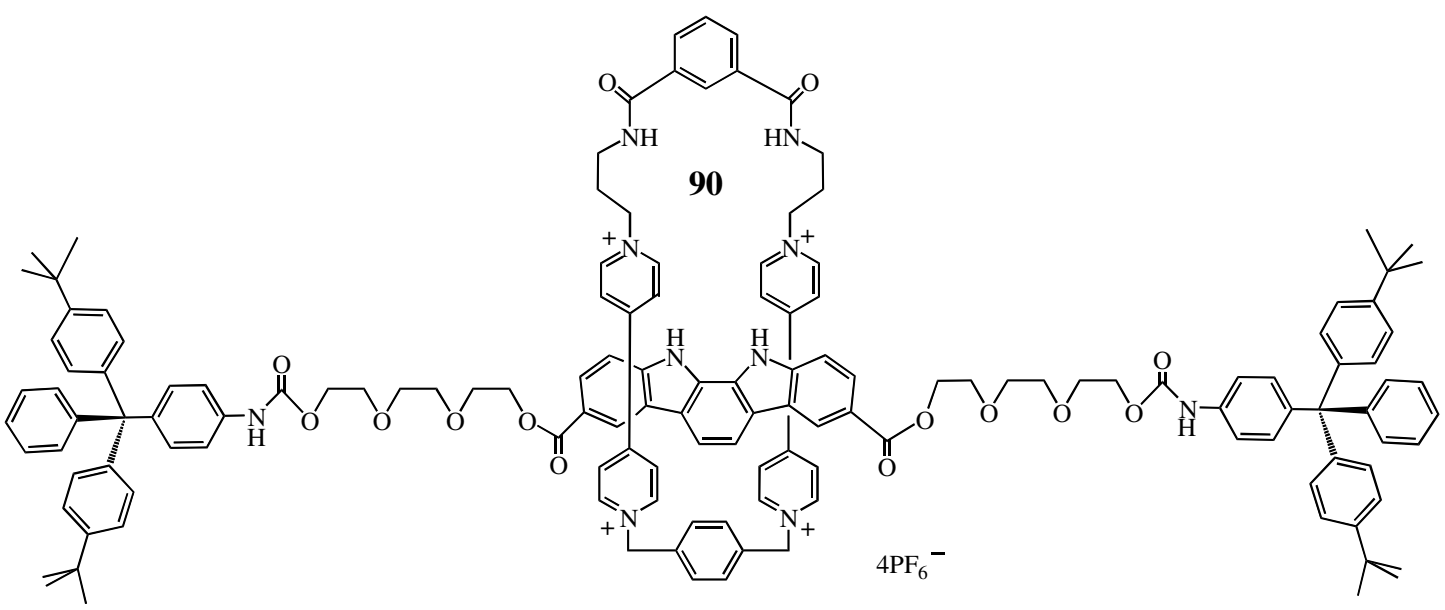

89

In the investigations, the anions $\mathrm{Cl}^{-}, \mathrm{Br}^{-}, \mathrm{I}^{-}$and $\mathrm{NO}_{3}{ }^{-}$were addeed as their TBA salts (TBA denotes tetrabutylammonium) to rotaxane 89 in DMSO- $d_{6}$. The ${ }^{1} \mathrm{H}$ NMR results showed that the stability constants of complexes of $\mathbf{8 9}$ with studied anions decreased in the order $\mathrm{Cl}^{-}>\mathrm{Br}^{-}>\mathrm{I}^{-}>$ $\mathrm{NO}_{3}{ }^{-}$, i.e. with larger anion radius and with lower hydrogen bond-acceptor ability of the anions. The molecular dynamics simulations and thermodynamic integration calculations showed that anion association is an enthalpy-driven process mediated by hydrogen bond donation from the indolocarbazole $\mathrm{N}-\mathrm{H}$ groups and the isophthalamide protons of the ring $\mathbf{9 0 .}$

It was found that rotaxane $\mathbf{8 9}$ binds chloride and bromide anions. The chloride and bromide anions have a suitable size for rotaxane 89, they are hydrogen bonded to the N-H binding sites of the isophthalamide cavity and the indolocarbazole dumbbell. The larger iodide and nitrate anions, however, cannot fully penetrate the binding cavity of $\mathbf{8 9}$, therefore they are more loosely associated with $\mathbf{8 9}$, and interact only with the indolocarbazole $\mathrm{N}-\mathrm{H}$ protons.

\section{Example 2}

The rotaxanes discussed here were investigated with a view to their use in molecular switches; for this purpose the thermodynamic prediction of their properties was carried out.

It is known that structural modifications of bistable rotaxanes strongly influence translation of the ring $\mathbf{W}$ which is responsible for their action as devices. Among structural modifications of rotaxanes, modifications of thread are more often used than those of the ring. In described experiments, the modification of the ring $\mathbf{W}$, involving substitution of a single position of the $p$-xylyl ring was investigated. Since the study of modified bistable [2]rotaxanes would be rather difficult, the study of pseudorotaxanes containing the same donor-acceptor recognition components was made, and the results were extrapolated. Structural modifications of $\mathbf{W}$ afford six substituted rings 91a-f, in the form of their $\mathrm{PF}_{6}^{-}$salts.

For study of thermodynamic parameters of pseudorotaxane formation, the noncovalent interactions for a series of monosubstituted cationic cyclophanes $\mathbf{W}$ with electron donor guests 
such as TTF, DNP, TTF-DEG and DNP-DEG were investigated using isothermal titration microcalorimetry (ITC). (DEG = diethylene glycol; TTF-DEG = TTF disubstituted by DEG; DNP-DEG $=$ DNP disubstituted by DEG). ${ }^{75}$

It was established that the changes in the free energy, i.e. $\Delta \Delta G^{0}$ values occurring during formation of pseudorotaxanes can be extrapolated to predict $\Delta G^{0}$ values for switching in analogous interlocked systems containing the same donor-acceptor recognition components. These results enabled the thermodynamic prediction for design and tuning of interlocked molecular switches. The structural modifications of molecular switches play an important role in the ground state equilibrium of their thermodynamics, and as a consequence, for the action of devices.

In bistable donor-acceptor pseudorotaxanes the ring $\mathbf{W}$ preferentially binds with TTF and not with DNP unit. It was observed that bistable pseudorotaxanes based on TTF-DEG • W and DNPDEG $\cdot \mathbf{W}$ are acting as very good molecular switches, their switching being achieved by chemical or electrochemical stimuli. The ground state co-conformation GSCC, in which the $\mathbf{W}$ ring encircles preferentially the TTF unit is in equilibrium with the metastable co-conformation MSCC, in which W encircles the DNP unit. The equilibrium between GSCC and MSCC corresponds to $\Delta G^{0}$ value.

The pseudorotaxanes are formed due to $[\pi---\pi]$, $[\mathrm{CH}---\pi]$ and $[\mathrm{CH}---\mathrm{O}]$ interactions between $\pi$-electron deficient host $\mathbf{W}$ and $\pi$-electron rich guests TTF-DEG or DNP-DEG. Therefore, the structural modifications of the host $\mathbf{W}$ or of threads containing donor units influences the $K_{\mathrm{a}}$ of complexation, in this way enabling to tune the thermodynamic equilibria of the resulting switches.

The synthesis of polymeric side-chain 91f starts with the methacrylate monomer containing azide group 92 which upon atom transfer radical polymerization (ATRP) using ethyl 2-bromoisobutyrate as the initiator afforded polymer $\mathbf{9 3}$. Polymer 93 reacted with alkyne derivative of $\mathbf{W}$, i.e. 91d via a click reaction to give $91 \mathrm{f}$.

The $\Delta G^{0}$ values for interlocked systems may be predicted by studying the difference in the binding energies $\left(\Delta \Delta G^{0}\right)$, i.e. $\left(\Delta G^{0} 1\right.$ (TTF-DEG $\left.\cdot \mathbf{W}\right)-\Delta G^{0} 2(\mathrm{DNP}-\mathrm{DEG} \cdot \mathbf{W})$. The thermodynamic parameters $\left(K_{\mathrm{a}}, \Delta G^{0}, \Delta H^{0}, \Delta S^{0}\right)$ were determined by ITC (isothermal titration calorimetry) and by X-ray crystallography for TTF-DEG binding with 91a-f and for DNP-DEG binding with 91a-f. It was observed that for the above rings, the binding strength values decrease in the order of guests: TTF-DEG>DNP-DEG>TTF; this order is the same as in the case of unsubstituted W. The above experiments concerning the thermodynamic approach to pseudorotaxanes which are precursors of switchable MIMs, allowed the experimenters to predict the activity of these switches. (Scheme 26) 


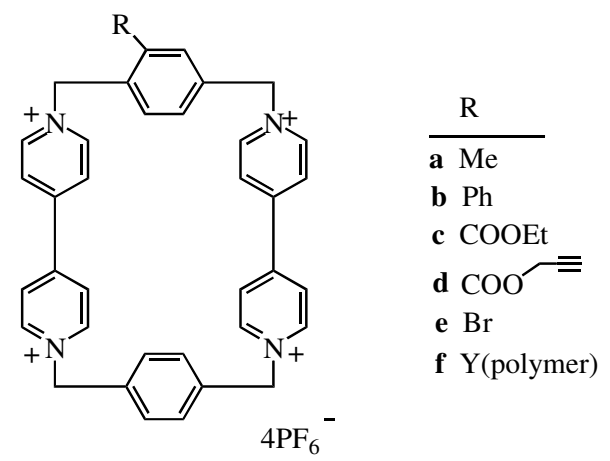

91

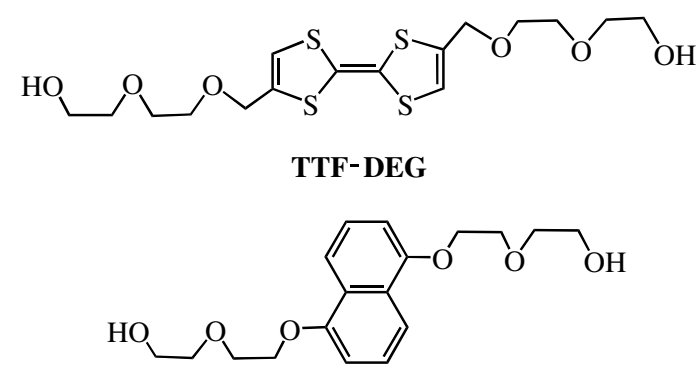

DNP-DEG

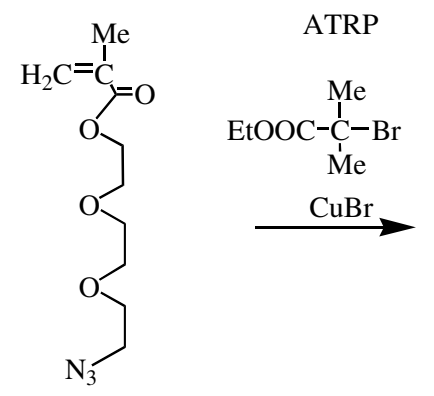

92

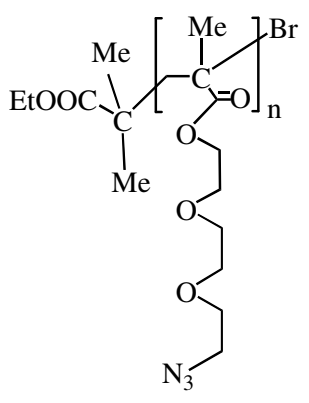

93

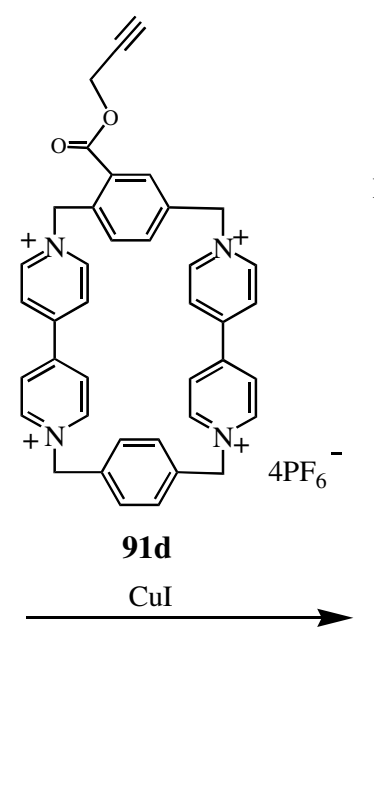

$\mathrm{n}=160$

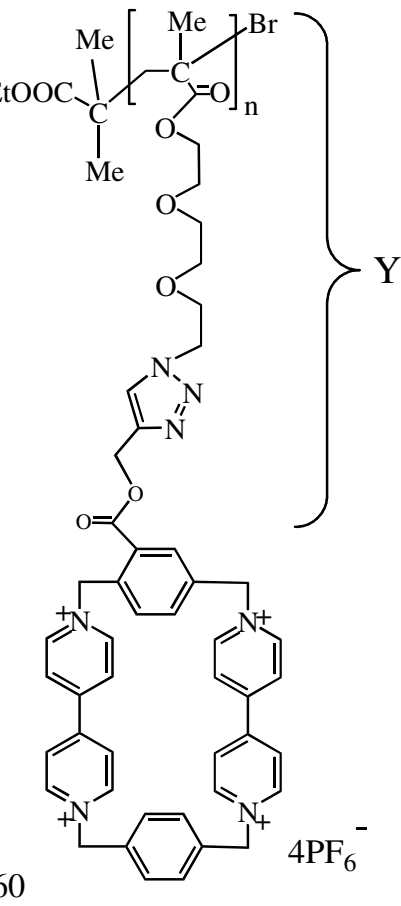

$91 f$

\section{Scheme 26}

\section{Example 3}

The synthesis of [3] rotacatenane $\mathbf{9 4} \cdot 4 \mathrm{PF}_{6}$, i.e. the compound consisting of rotaxane and catenane, has been performed in consideration of its possible use in molecular machines. Due to the simultaneous presence of a rotaxane and a catenane, it has the potential for both circumrotation of the ring (rotational motion) and shuttling in the dumbbell (translational motion). These two, rotational and translational, motions are combined in a synergistic manner in the same mechanically interlocked structure and can be induced by oxidation. ${ }^{76}$ 
The procedure begins with synthesis of [2] catenane $95 \cdot 4 \mathrm{PF}_{6}$ which is a precursor of [3] rotacatenane 94.4PF . The ring $\mathrm{MS}^{4+}$ is a large molecular square which can include two TTF guest molecules side by side, therefore it was possible to use the TTF derivative 96 to template the formation of catenane 95. It is noteworthy that the addition of 96 as a competitive binding agent increased the yield of the [2]catenane 95 by ca $30 \%$. The reaction of the cyclic polyether 97, compounds $98 \cdot 2 \mathrm{PF}_{6}, 99$ and 96 , performed in $\mathrm{MeCN}$ at room temperature (14 days) afforded compound 95. (Scheme 27) 


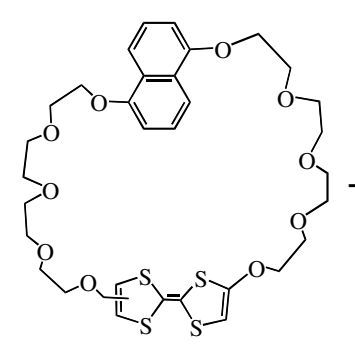

97

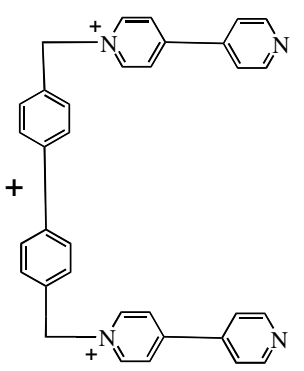

98<smiles>BrC/C=C/c1ccccc1</smiles>

99
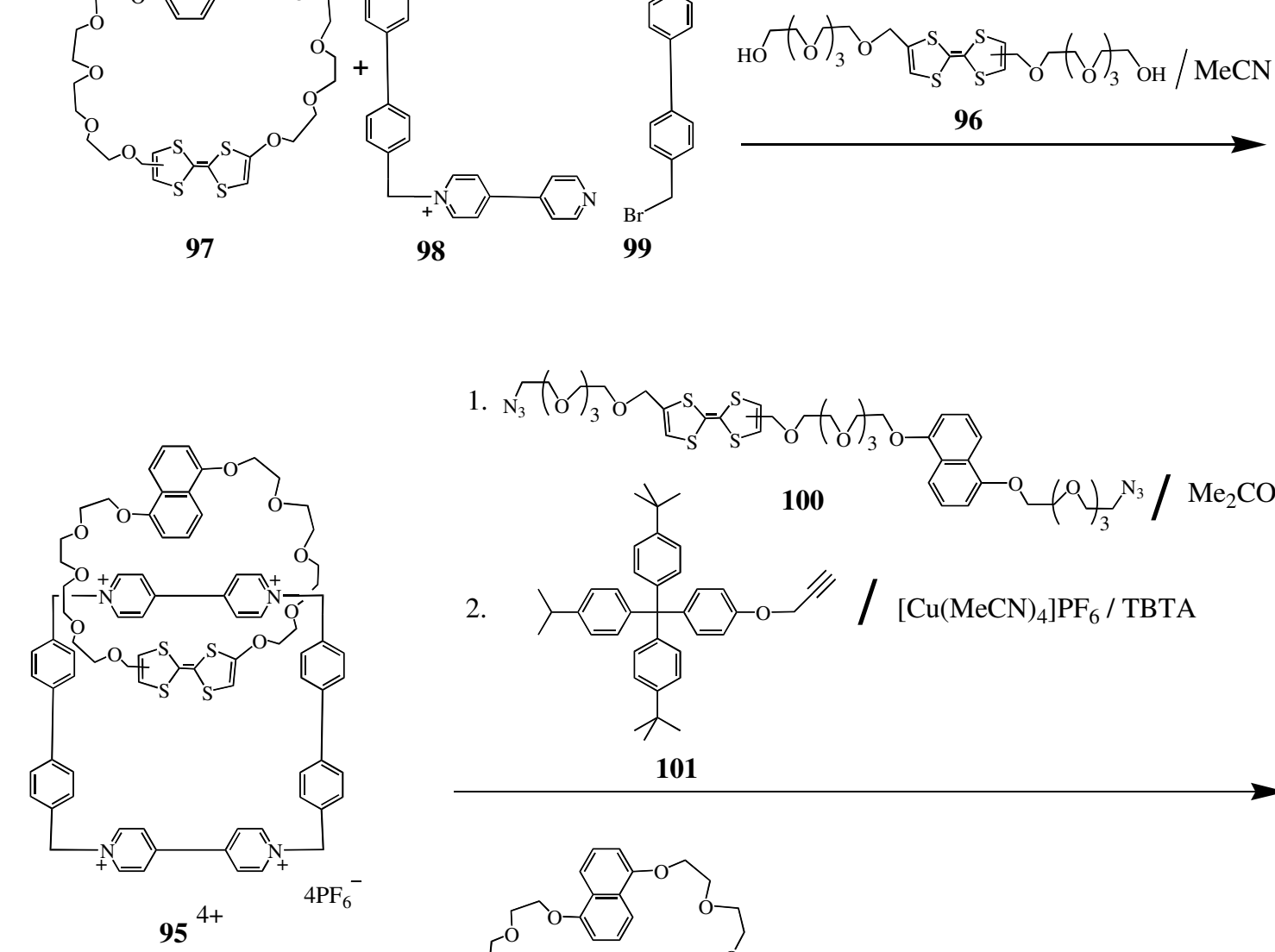

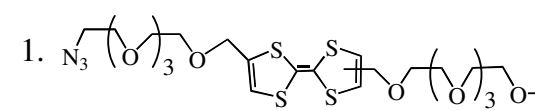

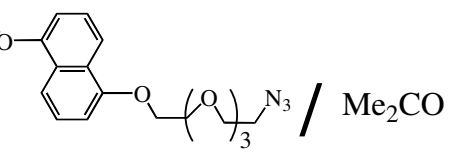

2.
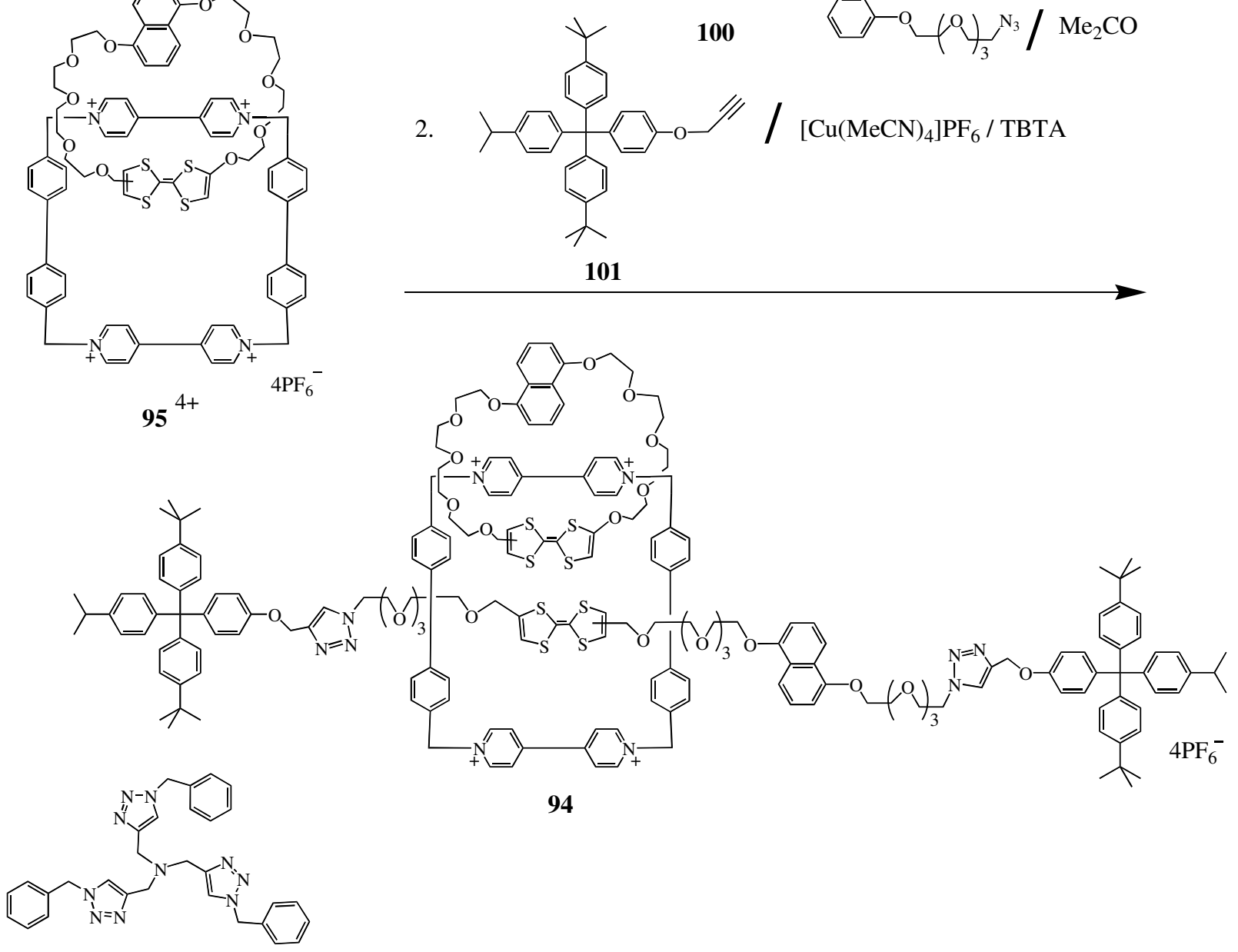

TBTA

Scheme 27 
The subsequent treatment of catenane 95 with diazide 100 and alkyne 101 in acetone, in the presence of catalytic amount of $\left[\mathrm{Cu}(\mathrm{MeCN})_{4}\right] \mathrm{PF}_{6}$ and TBTA carried out at room temperature (24h) yielded [3] rotacatenane $\mathbf{9 4} \cdot 4 \mathrm{PF}_{6}$ as a green solid. (Scheme 27 )

It was observed that the polyether ring of the [2]catenane 95 can move freely in the cavity of $\mathrm{MS}^{4+}$; due to this movement the two different ground state co-conformations GSCC, namely GSCC(1) and GSCC(2) appear. (Scheme 28) One should note that the GSCC(1) state is preferred for the formation of [3] rotacatenane 94. At room temperature only one co-conformation of 94 exists, namely that in which both TTF units, i.e. one from the polyether ring and other from the dumbbell, are situated inside the ring $\mathrm{MS}^{4+}$.
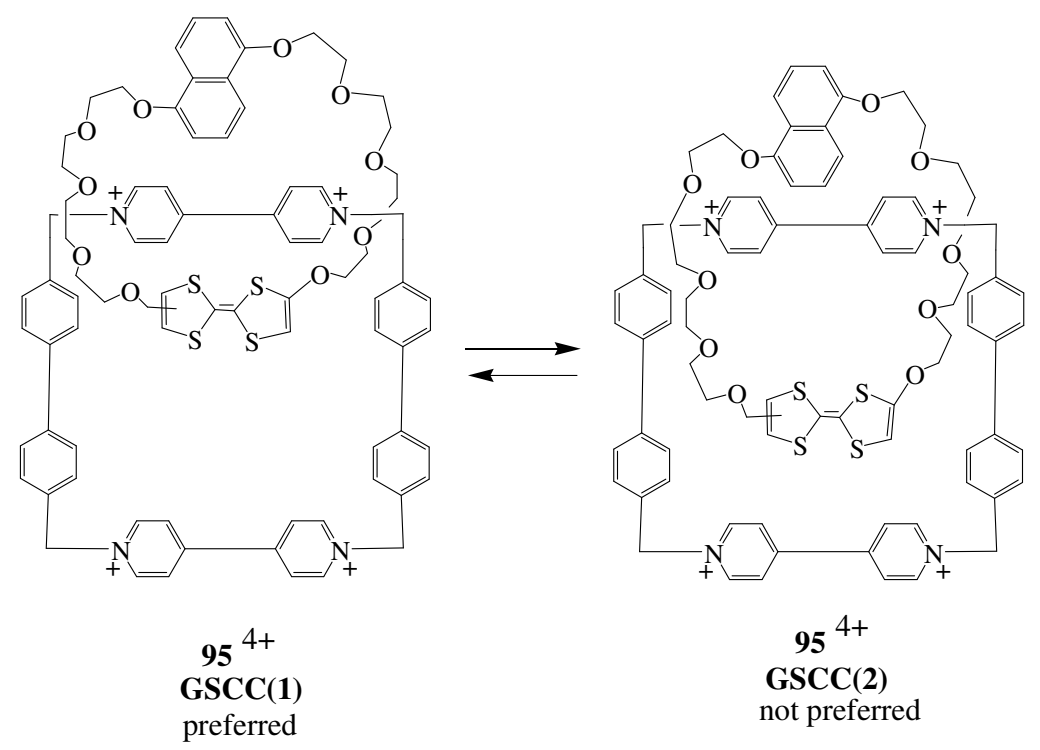

Scheme 28

The investigation of switching properties of $\mathbf{9 4}$ has shown the existence of five identifiable oxidation states. The oxidation of 94 begins with the one electron removal leading to mixed valence state $\left(\mathrm{TTF}_{2}\right)^{\bullet+}$, i.e. $\mathbf{9 4}{ }^{5+}$, and the subsequent one electron removal results in the formation of radical cation dimer $\left(\mathrm{TTF}^{\circ+}\right)_{2}$ state, i.e. $\mathbf{9 4}^{6+}$. (Scheme 29)

It was established that this state, i.e. $\mathbf{9 4}^{6+}$ in is at an equilibrium with the newly formed $\mathbf{9 4}^{\mathbf{6}+}$ out state in which both $\mathrm{TTF}^{\circ+}$ units are no more in the $\mathrm{MS}^{4+}$ cavity, since one $\mathrm{TTF}^{\circ+}$ incorporated into polyether ring leaves the $\mathrm{MS}^{4+}$ cavity due to the rotation of this polyether ring, and the second $\mathrm{TTF}^{\circ+}$ incorporated in the dumbbell leaves the $\mathrm{MS}^{4+}$ cavity due to the shuttling of the dumbbell. In the $94^{\mathbf{6}}{ }_{\text {out }}$ state the two DNP units are situated inside $\mathrm{MS}^{4+}$, therefore the separation of the radical cation dimer $\left(\mathrm{TTF}^{\circ+}\right)_{2}$ was possible. The final oxidations lead to $\mathbf{9 4}^{\mathbf{7 +}}$ and then to $\mathbf{9 4}^{\mathbf{8 +}}$ states. The process is fully reversible, the reduction recovers the starting state $94^{\mathbf{4 +}}$. One should mention that mixed valence state $\left(\mathrm{TTF}_{2}\right)^{\cdot+}$ and the radical cation dimer state $\left(\mathrm{TTF}^{\circ+}\right)_{2}$ have been also found during template directed synthesis of tripodal [4]rotaxane. ${ }^{77}$ The fact that rotational and translational motions of $\mathbf{9 4}$ may be induced by oxidation is promising for use of this rotacatenane in the design of complex molecular machines. 


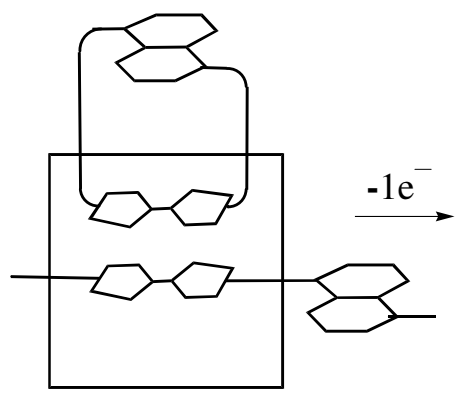

$94^{4+}$

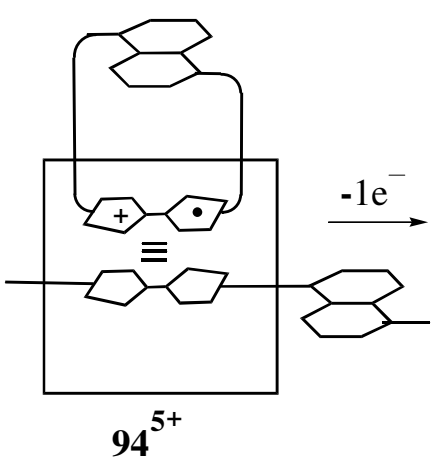

mixed valence state

$\left(\mathrm{TTF}_{2}\right)^{\bullet+}$

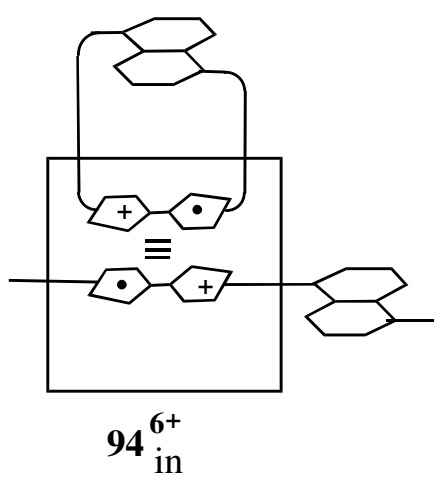

radical cation dimer

$\left(\mathrm{TTF}^{\bullet}\right)_{2}$
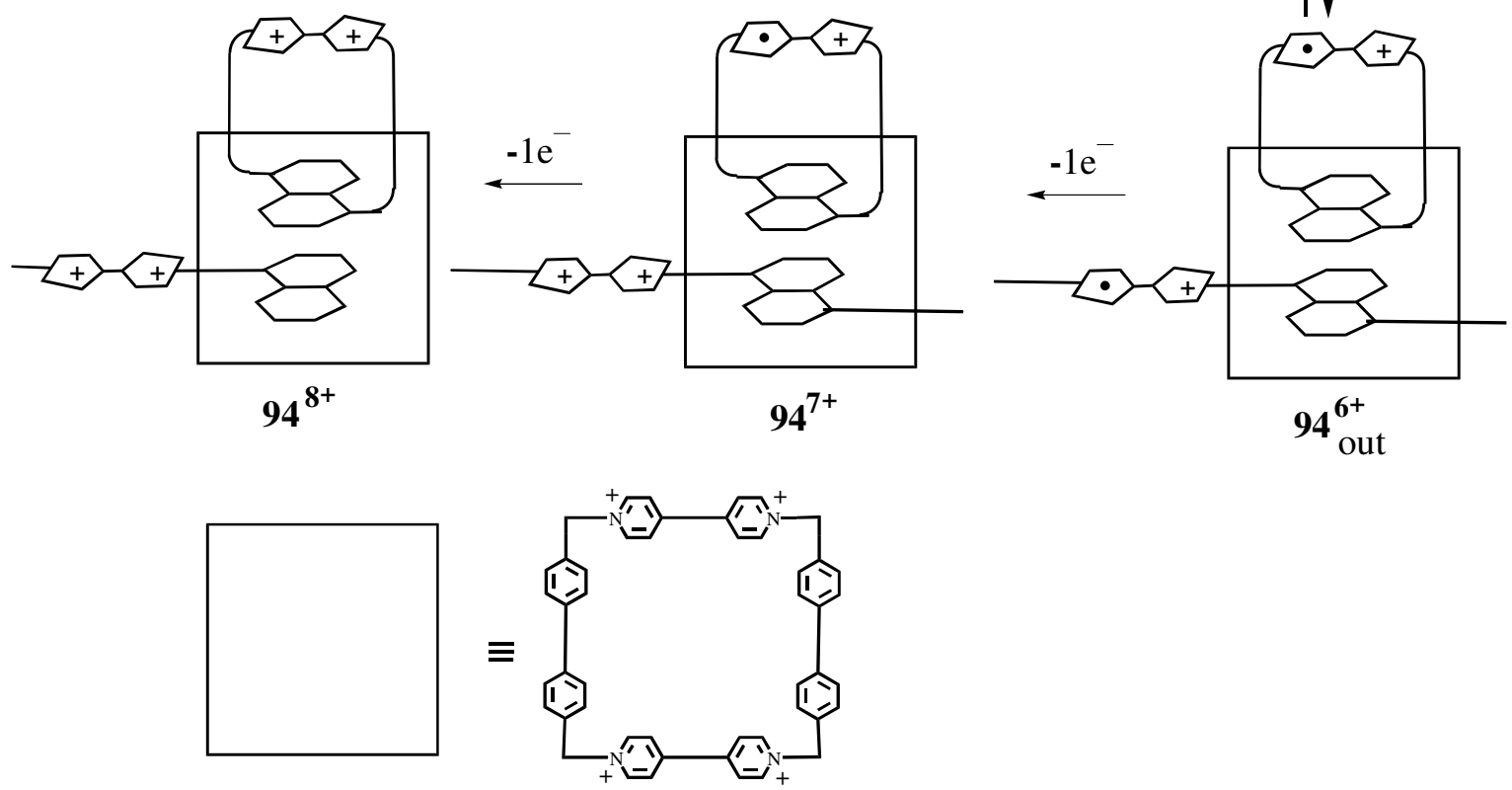

\section{Scheme 29}

\section{Conclusions}

Considerable progress has been observed in the study of MIMs, especially of rotaxanes ${ }^{78-82}$ and catenanes ${ }^{83,84}$ due to their promising properties for design of molecular devices and switches. Outside the coverage of the present review, one should also point out the research on rotaxanes containing cyclodextrins, ${ }^{85-87}$ both cyclodextrins and cucurbiturils, ${ }^{88}$ or cyclodextrins, cucurbiturils and calixarenes, ${ }^{89}$ as rings. 
In investigations of rotaxanes ${ }^{90-95}$ a growing attention is paid recently to radical-radical rotaxanes; ${ }^{13,14,16,24,96-100}$ one may hope that this area of radical-pairing interaction will become a topic of intense study.

Owing to the constantly increasing amount of work concerning rotaxane chemistry, it would be impossible to cover all published reports; the present review is only a fragment of a wide research. However, albeit not exhaustive, it may to some extent be useful for the dissemination of knowledge of this interesting scientific field.

\section{Acknowledgements}

This work is a part of the project no. NN209441539 financially supported by Ministry of Science and Higher Education.

\section{References}

1. Glen, P. E.; O'Neill, J. A. T.; Lee, A-L. Tetrahedron 2013, 69, 57. http://dx.doi.org/10.1016/j.tet.2012.10.069

2. Yu, G.; Suzaki, Y.; Abe, T. Osakada, K. Dalton Trans. 2013, 42, 1476. http://dx.doi.org/10.1039/c2dt31406a PMid:23135203

3. Coskun, A.; Wesson, P. J.; Klajn, R.; Trabolsi, A.; Fang, L.; Olson, M. A.; Dey, S. K.; Grzybowski, B. A.; Stoddart, J. F. J. Am. Chem. Soc. 2010, 132, 4310. http://dx.doi.org/10.1021/ja9102327 PMid:20218598

4. Li, Q.; Zhang, W.; Miljanic, O. S.; Knobler, C. B.; Stoddart J. F.; Yaghi, O. M. Chem. Commun. 2010, 46, 380.

http://dx.doi.org/10.1039/b919923c

PMid:20066298

5. Gaeta, C.; Talotta, C.; Mirra, S.; Margarucci, L.; Casapullo, A.; Neri P. Org. Lett. 2013, 15, 116.

http://dx.doi.org/10.1021/ol303142c

PMid:23286391

6. Loots, L.; Barbour, L. J. Chem. Commun. 2013, 49, 671. http://dx.doi.org/10.1039/c2cc37953h

PMid:23223403

7. Clark, P. G.; Day, M. W.; Grubbs, R. H. J. Am. Chem. Soc. 2009, 131, 13631. http://dx.doi.org/10.1021/ja905924u

PMid:19728719 
8. Sauvage, J. P.; Gaspard, P. From Non-Covalent Assemblies To Molecular Machines, Wiley-VCH: Weinheim 2011.

9. Davis, J. J.; Orlowski, G. A.; Rahman, H.; Beer, P. D. Chem. Commun. 2010, 46, 54. http://dx.doi.org/10.1039/b915122b

PMid:20024293

10. Coti, K. K.; Belowich, M. E.; Liong, M.; Ambrogio, M. W.; Lau, Y. A.; Khatib, H. A.; Zink, J. I.; Khashab, N. M.; Stoddart, J. F. Nanoscale 2009, 1, 16.

http://dx.doi.org/10.1039/b9nr00162j

PMid:20644858

11. Suhan, N. D.; Loeb, S. J.; Eichhorn, S. H. J. Am. Chem. Soc. 2013, 135, 400. http://dx.doi.org/10.1021/ja309558p

PMid:23215351

12. Allain, C.; Beer, P. D.; Faulkner, S.; Jones, M. W.; Kenwright, A. M.; Kilah, N. L.; Knighton, R. C.; Sørensen, T. J.; Tropiano, M. Chem. Sci. 2013, 4, 489. http://dx.doi.org/10.1039/c2sc21614k

13. Li, H.; Zhao, Y.-L.; Fahrenbach, A.C.; Kim, S.-Y.; Paxton, W. F.; Stoddart, J. F. Org. Biomol. Chem. 2011, 9, 2240. http://dx.doi.org/10.1039/c0ob00937g PMid:21344116

14. Fahrenbach, A. C.; Barnes, J. C.; Lanfranchi, D. A.; Li, H.; Coskun, A.; Gassensmith, J. J.; Liu, Z.; Benitez, D.; Trabolsi, A.; Goddard III, W. A.; Elhabiri, M.; Stoddart, J. F. J. Am. Chem. Soc. 2012, 134, 3061. http://dx.doi.org/10.1021/ja2089603 PMid:22148229

15. Stoddart, J. F. Chem. Soc. Rev. 2009, 38, 1802. http://dx.doi.org/10.1039/b819333a PMid:19587969

16.

16. Li, H.;

Fahrenbach, A. C.; Dey, S. K.; Basu, S.; Trabolsi, A.; Zhu, Z.; Botros, Y. Y.; Stoddart, J. F. Angew. Chem. Int. Ed. 2010, 49, 8260.

http://dx.doi.org/10.1002/anie.201004488

PMid:20865716

17. Deska, M.; Kozlowska, J.; Sliwa, W. Arkivoc 2013, (i) in press (paper 13-7774LR).

18. Deska, M.; Kozlowska, J.; Sliwa, W. Arkivoc 2013, (i) 66.

19. Sliwa, W.; Bachowska, B.; Girek, T. Curr. Org. Chem. 2012, 16, 1332. http://dx.doi.org/10.2174/138527212800564240

20. Sliwa, W.; Chrzastek, L. Curr. Org. Chem. 2009, 13, 339. http://dx.doi.org/10.2174/138527209787582295 
21. Ikeda, T.; Higuchi, M.; Sato, A.; Kurth, D. G. Org. Lett. 2008, 10, 2215. http://dx.doi.org/10.1021/o1800624c

PMid:18454536

22. Ikeda, T.; Higuchi, M.; Kurth, D. G. Chem. Eur. J. 2009, 15, 4906.

http://dx.doi.org/10.1002/chem.200802120

PMid:19308975

23. Ikeda, T.; Higuchi, M.; Kurth, D. G. J. Am. Chem. Soc. 2009, 131, 9158. http://dx.doi.org/10.1021/ja902992c

PMid:19522461

24. Trabolsi, A.; Khashab, N.; Fahrenbach, A. C.; Friedman, D. C.; Colvin, M. T.; Coti, K. K.; Benitez, D.; Tkatchouk, E.; Olsen, J.-C.; Belowich, M. E.; Carmielli, R.; Khatib, H. A.; Goddard III, W. A.; Wasielewski, M. R.; Stoddart, J. F. Nature Chem. 2010, 2, 42. http://dx.doi.org/10.1038/nchem.479 PMid:21124379

25. Ikeda, T.; Higuchi, M. Tetrahedron 2011, 67, 3046. http://dx.doi.org/10.1016/j.tet.2011.03.009

26. Abraham, W.; Wlosnewski, A.; Buck, K.; Jacob, S. Org. Biomol. Chem. 2009, 7, 142. http://dx.doi.org/10.1039/b815848g PMid:19081957

27. Vetter, A.; Abraham, W. Org. Biomol. Chem. 2010, 8, 4666. http://dx.doi.org/10.1039/c0ob00270d PMid:20730208

28. Yoon, I.; Miljanić, O. S.; Benítez, D.; Khan, S. I.; Stoddart, J. F. Chem. Commun. 2008, 4561.

http://dx.doi.org/10.1039/b808005d

PMid:18815683

29. Yoon, I.; Benítez, D.; Zhao, Y.-L.; Miljanić, O. S.; Kim, S.-Y.; Tkatchouk, E.; Leung, K. C.-F.; Khan, S. I.; Goddard, III, W. A.; Stoddart, J. F. Chem. Eur. J. 2009, 15, 1115. http://dx.doi.org/10.1002/chem.200802096

PMid:19105194

30. Zhao, Y.-L.; Aprahamian, I.; Trabolsi, A.; Erina, N.; Stoddart, J. F. J. Am. Chem. Soc. 2008, 130, 6348. http://dx.doi.org/10.1021/ja800731k PMid:18444642

31. Foster, M. E.; Sohlberg, K. J.Phys. Chem. A. 2011, 115, 7773. http://dx.doi.org/10.1021/jp202163j PMid:21595443

32. Rossi, M.; Sohlberg, K. J. Comput. Theor. Nanosci. 2011, 8, 1895. http://dx.doi.org/10.1166/jctn.2011.1867 
33. Foster, M. E.; Sohlberg, K. J. Chem. Theory Comput. 2010, 6, 2153. http://dx.doi.org/10.1021/ct100177u

34. Valiev, M.; Bylaska, E. J.; Govind, N.; Kowalski, K.; Straatsma, T. P.; Dam, H. J. J.v.; Wang, D.; Nieplocha, J.; Apra, E.; Windus, T. I.; Jong, W. A. d. Comput. Phys. Commun. 2010, 181, 1477. http://dx.doi.org/10.1016/j.cpc.2010.04.018

35. Smith, A. E.; Xu, X.; McCormick, C. L. Prog. Polym. Sci. 2010, 35, 45. http://dx.doi.org/10.1016/j.progpolymsci.2009.11.005

36. Schatz, C.; Louguet, S.; Le Meins, J.-F.; Lecommandoux, S. Angew. Chem., Int. Ed. 2009, $48,2572$.

http://dx.doi.org/10.1002/anie.200805895

PMid:19248065

37. McCormick, C. L.; Sumerlin, B. S.; Lokitz, B. S.; Stempka, J. E. Soft Matter 2008, 4, 1760. http://dx.doi.org/10.1039/b719577j

38. Sambe, L.; Stoffelbach, F.; Lyskawa, J.; Delattre, F.; Fournier, D.; Bouteiller, L.; Charleux, B.; Cooke, G.; Woisel, P. Macromolecules 2011, 44, 6532. http://dx.doi.org/10.1021/ma2009854

39. Bigot, J.; Charleux, B.; Cooke, G.; Delattre, F.; Fournier, D.; Lyskawa, J.; Sambe, L.; Stoffelbach, F.; Woisel, P. J. Am. Chem. Soc. 2010, 132, 10796. http://dx.doi.org/10.1021/ja1027452 PMid:20681712

40. Bigot, J.; Fournier, D.; Lyskawa, J.; Marmin, T.; Cazaux, F.; Cooke, G.; Woisel, P. Polym. Chem. 2010, 1, 1024. http://dx.doi.org/10.1039/c0py00085j

41. Klajn, R.; Fang, L.; Coskun, A.; Olson, M. A.; Wesson, P. J.; Stoddart, J. F.; Grzybowski, B. A. J. Am. Chem. Soc. 2009, 131, 4233. http://dx.doi.org/10.1021/ja9001585 PMid:19265400

42. Aprahamian, I.; Yasuda, T.; Ikeda, T.; Saha, S.; Dichtel, W. R.; Isoda, K.; Kato, T.; Stoddart, J. F. Angew. Chem. Int. Ed. 2007, 46, 4675.

http://dx.doi.org/10.1002/anie.200700305 PMid:17492810

43. Spruell, J. M.; Dichtel, W. R.; Heath, J. R.; Stoddart, J. F. Chem. Eur. J. 2008, 14, 4168. http://dx.doi.org/10.1002/chem.200800067 PMid:18384025

44. Stoddart, J. F. Nat. Chem. 2009, 1, 14. http://dx.doi.org/10.1038/nchem.142 PMid:21378786 
45. Deng, H.; Olson, M. A.; Stoddart, J. F.; Yaghi, O. M. Nat. Chem. 2010, 2, 439. http://dx.doi.org/10.1038/nchem.654 PMid:20489710

46. Heath, J. R. Annu. Rev. Mater. Res. 2009, 39, 1. http://dx.doi.org/10.1146/annurev-matsci-082908-145401

47. Zheng, H.; Zhou, W.; Lv, J.; Yin. X.; Li, Y.; Liu, H.; Li, Y. Chem. Eur. J. 2009, 15, 13253. http://dx.doi.org/10.1002/chem.200901841

PMid:19876975

48. Canevet, D.; Salle, M.; Zhang, G.; Zhang, D.; Zhu, D. Chem. Commun. 2009, 2245. http://dx.doi.org/10.1039/b818607n

PMid:19377656

49. Sue, C.-H.; Basu, S.; Fahrenbach, A. C.; Shveyd, A. K.; Dey, S. K.; Botros, Y. Y.; Stoddart, J. F. Chem. Sci.2010, 1, 119. http://dx.doi.org/10.1039/c0sc00176g

50. Trabolsi, A.; Fahrenbach, A. C.; Dey, S. K.; Share, A. I.; Friedman, D. C.; Basu, S.; Gasa, T. B.; Khashab, N. M., Saha, S.; Aprahamian, I.; Khatib, H. A.; Flood, A.H.; Stoddart, J. F. Chem. Commun. 2010, 46, 871. http://dx.doi.org/10.1039/b918321c

PMid:20107634

51. Coskun, A.; Friedman, D. C.; Li, H.; Patel, K.; Khatib, H. A.; Stoddart, J. F. J. Am. Chem. Soc. 2009, 131, 2493.

http://dx.doi.org/10.1021/ja809225e

PMid:19193031

52. Hmadeh, M.; Fahrenbach, A. C.; Basu, S.; Trabolsi, A.; Benitez, D.; Li, H.; Albrecht-

Gary,A.-M.; Elhabiri, M.; Stoddart, J. F. Chem. Eur. J. 2011, 17, 6076.

http://dx.doi.org/10.1002/chem.201002933

PMid:21500290

53. Zhao, X.; Li, Z.-T. Chem. Commun. 2010, 46, 1601. http://dx.doi.org/10.1039/b924552a

PMid:20177592

54. Gong, B.; Acc. Chem. Res. 2008, 41, 1376.

http://dx.doi.org/10.1021/ar700266f

PMid:18459803

55. Hecht, S.; Huc, I. Eds.: Foldamers: Structure, Properties and Applications, Wiley-VCH: Weinheim, 2007.

56. Guichard, G.; Huc, I. Chem. Commun. 2011, 5933.

http://dx.doi.org/10.1039/c1cc11137j

PMid:21483969 
57. Yu, Z.; Hecht, S. Angew. Chem., Int. Ed. 2011, 50, 1640. http://dx.doi.org/10.1002/anie.201006084

58. Saraogi, I.; Hamilton, A. D. Chem. Soc. Rev. 2009, 38, 1726. http://dx.doi.org/10.1039/b819597h

PMid:19587965

59. Qin, B.; Sun, C.; Liu, Y.; Shen, J.; Ye, R. J.; Zhu, J.; Duan, X.-F.; Zeng, H.-Q. Org. Lett. 2011, 13, 2270. http://dx.doi.org/10.1021/ol200538d PMid:21469659

60. Qin, B.; Ong.; W. Q.; Ye, R. J.; Du, Z. Y.; Chen, X. Y.; Yan, Y.; Zhang, K.; Su, H. B.; Zeng, H. Q. Chem. Commun. 2011, 5419. http://dx.doi.org/10.1039/c0cc05791f PMid:21298191

61. Yan, Y.; Qin, B.; Ren, C. L.; Chen, X. Y.; Yip, Y. K., Ye. R. J.; Zhang, D. W.; Su, H. B.; Zeng, H. Q. J. Am. Chem. Soc. 2010, 132, 5869.

http://dx.doi.org/10.1021/ja100579z PMid:20364840

62. Zhang, K.-D.; Zhao, X.; Wang, G.-T.; Liu, Y.; Zhang, Y.; Lu, H.-J.; Jiang, X.-K.; Li, Z.-T. Tetrahedron 2012, 68, 4517. http://dx.doi.org/10.1016/j.tet.2011.10.116

63. Zhang, K.-D.; Zhao, X.; Wang, G.-T.; Liu, Y.; Zhang, Y.; Lu, H.-J.; Jiang, X.-K.; Li, Z.-T. Angew. Chem. Int. Ed. 2011, 50, 9866.

http://dx.doi.org/10.1002/anie.201104099

PMid:21887826

64. Basu, S.; Coskun, A.; Friedman, D. C.; Olson, M. A.; Benitez, D.; Tkatchouk, E.; Barin, G.; Yang, J.; Fahrenbach, A. C.; Goddard, III, W. A.; Stoddart, J. F. Chem. Eur. J. 2011, 17, 2107. http://dx.doi.org/10.1002/chem.201001822

PMid:21274953

65. Guo, L.; Almeida, A. M.; Zhang, W.; Reidenbach, A. G.; Choi, S. H.; Guzei, I. A.; Gellman, S. H. J. Am. Chem. Soc. 2010, 132, 7868.

http://dx.doi.org/10.1021/ja103233a

PMid:20491510 PMCid:2904518

66. Zhu, Z.; Cardin, C. J.; Gan, Y.; Colquhoun, H. M. Nat. Chem. 2010, 2, 653. http://dx.doi.org/10.1038/nchem.699

PMid:20651728

67. Korth, M.; Grimme, S. J. Chem. Theory Comput. 2009, 5, 993. http://dx.doi.org/10.1021/ct800511q

68. Hansen, S. W.; Stein, P. C.; Sorensen, A.; Share, A. I.; Witlicki, E. H.; Kongsted, J.; Flood, A. H.; Jeppesen, J. O. J. Am. Chem. Soc. 2012, 134, 3857. 
http://dx.doi.org/10.1021/ja210861v

PMid:22280483

69. Brown, A.; Mullen, M.; Ryu, J.; Chmielewski, M. J.; Santos, S. M.; Felix, V.; Thompson, A. L.; Warren, J. E.; Pascu, S. I.; Beer, P. D. J. Am. Chem. Soc. 2009, 131, 4937.

http://dx.doi.org/10.1021/ja809905x

PMid:19296631

70. Ng, K. Y.; Felix, V.; Santos, S. M.; Rees, N. H.; Beer, P. D. Chem. Commun. 2008, 1281. http://dx.doi.org/10.1039/b719304a

PMid:18389107

71. Gale, P. A. Chem. Commun. 2008, 4525.

http://dx.doi.org/10.1039/b809508f

PMid:18815678

72. Suk, J.-m.; Jeong, K.-S. J. Am. Chem. Soc. 2008, 130, 11868.

http://dx.doi.org/10.1021/ja804845m

PMid:18700772

73. Ju, J.; Park, M.; Suk, J.-M.; Lah, M. S.; Jeong, K.-S. Chem. Commun. 2008, 3546.

http://dx.doi.org/10.1039/b804284e

PMid: 18654708

74. Chmielewski, M. J.; Zhao, L.; Brown, A.; Curiel, D.; Sambrook, M. R.; Thompson, A. L.;

Santos, S. M.; Felix, V.; Davis, J. J.; Beer, P. D. Chem. Commun. 2008, 3154.

http://dx.doi.org/10.1039/b804941f

PMid:18594726

75. Olson, M. A.; Braunschweig, A. B.; Ikeda, T.; Fang, L.; Trabolsi, A.; Slawin, A. M. Z.;

Khan, S. I.; Stoddart, J. F. Org. Biomol. Chem. 2009, 7, 4391.

http://dx.doi.org/10.1039/b911874h

PMid:19830288

76. Barin, G.; Coskun, A.; Friedman, D. C.; Olson, M. A.; Colvin, M. T.; Carmielli, R.; Dey, S. K.; Bozdemir, O. A.; Wasielewski, M. R.; Stoddart, J. F. Chem. Eur. J. 2011, 17, 213. http://dx.doi.org/10.1002/chem.201002152

PMid:21207618

77. Aprahamian, I.; Olsen, J.-C.; Trabolsi, A.; Stoddart, J. F. Chem. Eur. J. 2008, 14, 3889.

http://dx.doi.org/10.1002/chem.200800191

PMid:18351705

78. Mateo-Alonso, A.; Ehli, C.; Guldi, D. M.; Prato, M. Org. Lett. 2013, 15, 84.

http://dx.doi.org/10.1021/o1303108q

PMid:23256512

79. Bi, S.; Cui, Y.; Li, L. Analyst 2013, 138, 197.

http://dx.doi.org/10.1039/c2an36118c

PMid:23148205 
80. Gong, H-Y.; Rambo, B. M.; Lynch, V. M.; Keller, K. M.; Sessler, J. L. Chem. Eur. J. 2012, 18,7803 .

http://dx.doi.org/10.1002/chem.201200304

PMid:22615161

81. Lewandowski, B.; De Bo, G.; Ward, J. W.; Papmeyer, M.; Kuschel, S.; Aldegunde, M. J.;

Gramlich, P. M. E.; Hackmann, D.; Goldup, S. M.; D'Souza, D. M.; Fernandes, A. E.;

Leigh, D. A. Science 2013, 339, 189.

http://dx.doi.org/10.1126/science.1229753

PMid:23307739

82. Tejerina, B.; Gothard, C. M.; Grzybowski, B. A. Chem. Eur. J. 2012, 18, 5606.

http://dx.doi.org/10.1002/chem.201103388

PMid:22454368

83. Chambron, J.-C.; Sauvage, J.-P. New J. Chem. 2013, 37, 49.

http://dx.doi.org/10.1039/c2nj40555e

84. Aleman Garcia, M. A.; Bampos, N. Org. Biomol. Chem. 2013, 11, 27.

http://dx.doi.org/10.1039/c2ob26587g

PMid:23051853

85. Kim, D. H.; Zo, H. J.; Park, J. S. J. Appl. Polym. Sci. 2013, 127, 3864.

http://dx.doi.org/10.1002/app.37682

86. Teuchert, C.; Michel, C.; Hausen, F.; Park, D-Y.; Beckham, H. W.; Wenz, G.

Macromolecules 2013, 46, 2.

http://dx.doi.org/10.1021/ma302204a

87. Girek, T. J. Incl. Phenom. Macrocycl. Chem. 2012, 74, 1.

http://dx.doi.org/10.1007/s10847-012-0112-1

88. Ke, C.; Smaldone, R. A.; Kikuchi, T.; Li, H.; Davis, A. P.; Stoddart, J. F. Angew. Chem.

Int. Ed. 2013, 52, 381.

http://dx.doi.org/10.1002/anie.201205087

PMid:22976927

89. Sun, R.; Ma X.; Tetrahedron 2013, 69, 1069.

http://dx.doi.org/10.1016/j.tet.2012.11.066

90. Mercer D. J.; Yacoub, J.; Zhu, K.; Loeb, S. K.; Loeb, S. J. Org. Biomol. Chem. 2012, 10, 6094.

http://dx.doi.org/10.1039/c2ob25200g

PMid:22581393

91. Friscic, T., Chem. Soc. Rev. 2012, 41, 3493.

http://dx.doi.org/10.1039/c2cs15332g

PMid:22371100

92. Rambo, B. M.; Gong, H-Y.; Oh M.; Sessler, J. L. Acc. Chem. Res. 2012, 45, 1390.

http://dx.doi.org/10.1021/ar300076b

PMid:22676474 
93. Fahrenbach, A. C.; Bruns, C. J.; Cao, D.; Stoddart, J. F. Acc. Chem. Res. 2012, 45, 1581. http://dx.doi.org/10.1021/ar3000629 PMid:22741809

94. Mercer, D. J; Vella, S. J.; Guertin, L.; Suhan, N. D.; Tiburcio, J.; Vukotic, V. N.; Wisner, J. A.; Loeb, S. J. Eur. J. Org. Chem. 2011, 1763. http://dx.doi.org/10.1002/ejoc.201001616

95. Yasuda, T.; Tanabe, K.; Tsuji, T.; Coti, K. K.; Aprahamian, L.; Stoddart, J. F.; Kato, T. Chem. Commun. 2010, 46, 1224.

http://dx.doi.org/10.1039/b922088g PMid:20449257

96. Li, H.; Zhu, Z.; Fahrenbach, A. C.; Savoie, B. M.; Ke, C.; Barnes, J. C.; Lei, J.; Zhao, Y.L.; Lilley, L. M.; Marks, T. J.; Ratner, M. A.; Stoddart, J. F. J. Am. Chem. Soc. 2013, 135, 456.

http://dx.doi.org/10.1021/ja310060n

PMid:23163704

97. Fahrenbach, A. C.; Zhu, Z.; Cao, D.; Liu, W.-G.; Li, H.; Dey, S. K.; Basu, S.; Trabolsi, A.; Botros, Y. Y.; Goddard III, W. A.; Stoddart, J. F. J. Am. Chem. Soc. 2012, 134, 16275. http://dx.doi.org/10.1021/ja306044r PMid:23002805

98. Barnes, J. C.; Fahrenbach, A. C.; Dyar, S. M.; Frasconi, M.; Giesener, M. A.; Zhu, Z.; Liu, Z.; Hartlieb, K. J.; Carmieli, R.; Wasielewski, M. R.; Stoddart, J. F. PNAS 2012, 109, 11546.

http://dx.doi.org/10.1073/pnas.1201561109

PMid:22685213 PMCid:3406866

99. Qu, D.-H.; Tian, H. Chem. Sci 2011, 2, 1011. http://dx.doi.org/10.1039/c0sc00653j

100. Li, H.; Fahrenbach, A. C.; Coskun, A.; Zhu, Z.; Barin, G.; Zhao, Y.-L.; Botros, Y. Y.; Sauvage, J.-P.; Stoddart, J. F. Angew. Chem.Int. Ed. 2011, 50, 6782. 


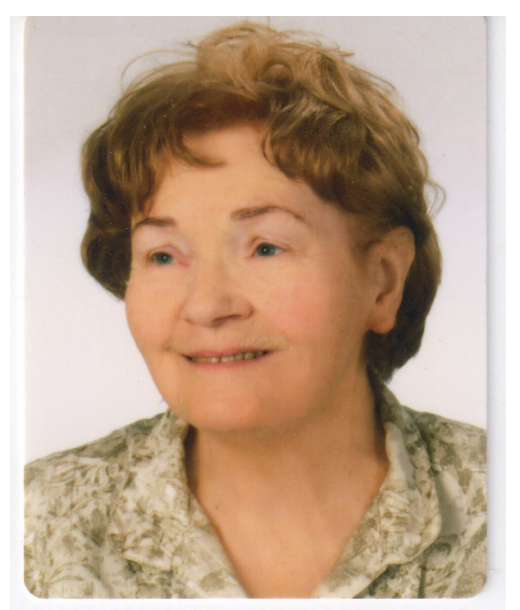

Wanda Sliwa graduated from Wrocław University of Technology, Poland, where she became an associate professor. After a year of research at the Université Paul Sabatier in Toulouse, France, she moved to Jan Dlugosz University, Czestochowa, Poland, where she has been Professor of Chemistry since 1990, as well as being a vice-rector, head of the Organic Chemistry Department and director of the Institute of Chemistry. She is author or coauthor of four books and 16 monographs, around 350 papers and ten patents, and has received several awards for scientific and pedagogical achievements. Her research concerns azaaromatic compounds and supramolecular chemistry.

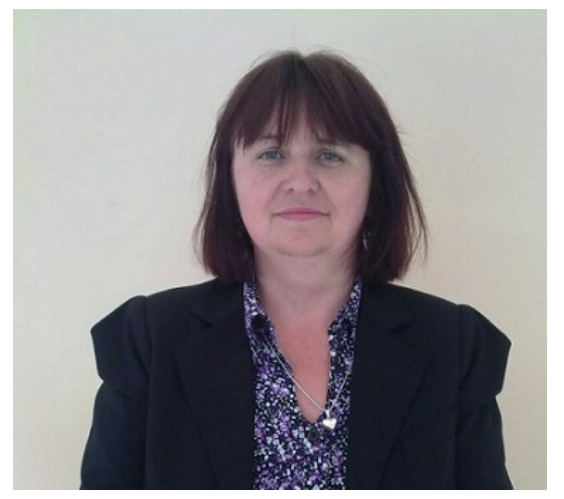

Malgorzata Deska graduated from the Pedagogical University of Częstochowa, Poland; she received there the M.Sc. degree in 1990. Since that time she has worked at the Jan Długosz University (formerly Pedagogical University) of Częstochowa in the Organic Chemistry and Biochemistry Departments. In 2004 she obtained her PhD at Technical University of Cracow; Her doctoral thesis concerned the physicochemical properties of diazaphenanthrenes. She has published fifteen papers in refereed journals, five communications to scientific meetings, and is a 
coauthor of a book. The research interests of Dr Malgorzata Deska are connected with the chemistry of heterocyclic compounds, cyclodextrins and calixarenes.

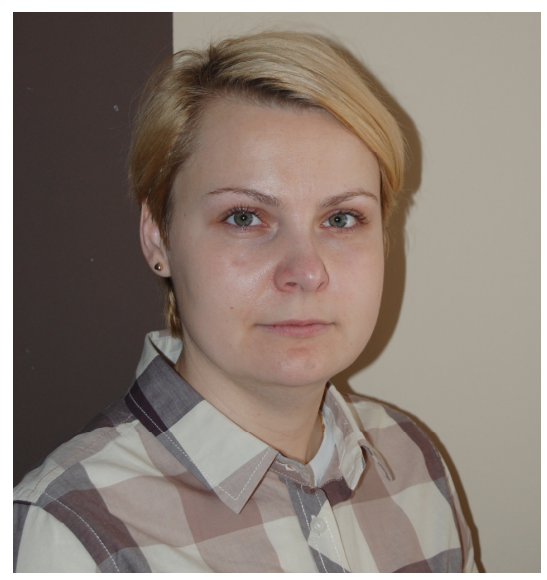

Anna Nowik-Zajac graduated from Nicolaus Copernicus University of Torun, Poland and received there the Biotechnology M.Sc degree in 2007. Since that time she has worked at the Jan Dlugosz University of Czestochowa, in the Institute of Chemistry, Environmental Protection and Biotechnology. She is coauthor of six papers in refereed journals, and of five conference communications. Her research is connected with the application of membrane techniques in the separation of metal ions. 